A dynamically-coupled groundwater, land surface and regional climate model to predict seasonal watershed flow and groundwater response, FINAL LDRD REPORT.

R.M. Maxwell, S.J. Kollet, F.K. Chow, P. Granvold, Q. Duan

February 26, 2007 
This document was prepared as an account of work sponsored by an agency of the United States Government. Neither the United States Government nor the University of California nor any of their employees, makes any warranty, express or implied, or assumes any legal liability or responsibility for the accuracy, completeness, or usefulness of any information, apparatus, product, or process disclosed, or represents that its use would not infringe privately owned rights. Reference herein to any specific commercial product, process, or service by trade name, trademark, manufacturer, or otherwise, does not necessarily constitute or imply its endorsement, recommendation, or favoring by the United States Government or the University of California. The views and opinions of authors expressed herein do not necessarily state or reflect those of the United States Government or the University of California, and shall not be used for advertising or product endorsement purposes.

This work was performed under the auspices of the U.S. Department of Energy by University of California, Lawrence Livermore National Laboratory under Contract W-7405-Eng-48. 
A dynamically-coupled groundwater, land surface and regional climate model to predict seasonal watershed flow and groundwater response, FINAL LDRD REPORT.

Reed Maxwell ${ }^{1}$, Stefan Kollet ${ }^{1}$, Fotini Katapodes Chow $^{2}$, Patrick Granvold ${ }^{2}$ and Qingyun Duan $^{1}$

${ }^{1}$ Atmospheric, Earth, and Energy Department, Lawrence Livermore National Laboratory, Livermore, California

${ }^{2}$ Department of Civil and Environmental Engineering, University of California, Berkeley, California

Final LDRD Report: Tracking Number 05-ERD-043 


\section{Organization of the Final Report}

This final report is organized in four sections. Section 1 is the project summary (below), Section 2 is a submitted manuscript that describes the offline, or spinup simulations in detail, Section 3 is also a submitted manuscript that describes the online, or fully-coupled simulations in detail and Section 3, which is report that describes work done via a subcontract with UC Berkeley.

\section{Project Summary}

The goal of this project was to develop and apply a coupled regional climate, land-surface, groundwater flow model as a means to further understand important mass and energy couplings between regional climate, the land surface, and groundwater. The project involved coupling three distinct submodels that are traditionally used independently with abstracted and potentially oversimplified (inter-model) boundary conditions. This coupled model lead to (1) an improved understanding of the sensitivity and importance of coupled physical processes from the subsurface to the atmosphere; (2) a new tool for predicting hydrologic conditions (rainfall, temperature, snowfall, snowmelt, runoff, infiltration and groundwater flow) at the watershed scale over a range of timeframes; (3) a simulation of hydrologic response of a characteristic watershed that will provide insight into the certainty of hydrologic forecasting, dominance and sensitivity of groundwater dynamics on land-surface fluxes; and (4) a more realistic model representation of weather predictions, precipitation and temperature, at the regional scale.

Regional climate models are typically used for the simulation of weather, precipitation and temperature behavior over 10-1000 km domains for weather or climate prediction purposes, and are typically driven by boundary conditions derived from global climate models (GCMs), observations or both. The land or ocean surface typically represents a bottom boundary condition of these models, where important mass (water) and energy fluxes are approximated. The viability and influence of these approximations on the predictions is not well understood because of the detail and complexity in landand subsurface processes and the need for computational efficiency. However, theoretical and experimental data suggest that these interactions may have a profound impact upon hydrologic and climatic budgets and weather predictions.

Conversely, land-surface and groundwater models are typically applied on smaller domains ( $<10 \mathrm{~km}$ in scale) to analyze runoff, streamflow, infiltration, evapotranspiration behavior, but are still influenced in many ways by couplings with the atmosphere (as in precipitation and temperature). Atmospheric inputs to these classes of models are typically represented as simplified "upper" boundary conditions, derived, in part, from coarse observations, uncoupled simulations, or other idealized simplifications.

In this project, we developed a framework to couple these models by developing a new land-surface /subsurface model and coupling it to a regional climate model at the same temporal and spatial scales. We focused the coupling to examine the role of important mass and energy couplings between these models as a means to understand the difference between traditional and detailed approaches to this interconnection. From this understanding of these interconnections, we were able to determine to what extent these connections need to be abstracted or preserved in modeling atmospheric, land-surface and groundwater interactions. We have found a strong connection between groundwater 
dynamics (i.e. aquifer storage) and energy fluxes at the land surface and in the Atmospheric Bounday Layer (ABL). The following papers outline this connection theoretically, demonstrate it with coupled modeling and propose strategies for better observing it in real settings. 


\title{
Capturing the influence of groundwater dynamics on land surface processes using an integrated, distributed watershed model.
}

\author{
Stefan J. Kollet and Reed M. Maxwell \\ Atmospheric, Earth, and Energy Department, Lawrence Livermore National Laboratory, \\ Livermore, California
}

To be submitted to Water Resources Research

February 23, 2007

\section{Abstract}

The influences of groundwater dynamics on the energy balance at the land surface are studied using an integrated, distributed watershed modeling platform. This model includes the mass and energy balance at the land surface; variably-saturated subsurface flow; explicit representation of the water table; and overland flow. The platform is suitable for large scale, high resolution simulations, because it is parallel and designed for high performance computing. The model is applied to the Little Washita watershed in Central Oklahoma, USA and compared to runoff, soil moisture and energy flux observations. The connection between groundwater dynamics and the land surface energy balance is studied using a variety of conventional and spatial statistical measures. For a number of energy variables a strong interconnection is demonstrated with water table depth. This connection varies seasonally and spatially depending on the spatial composition of shallow soil moisture and water table depth. For this particular watershed a critical water table depth range is established between 1 and $5 \mathrm{~m}$ in which the land surface energy budget is most sensitive to groundwater storage. Finally, concrete recommendations are put forth to characterize this interconnection in the field. 


\section{Introduction and Motivation}

Land surface processes are important as they control the transfer of water and energy between the lower atmosphere and subsurface. Characterization of these control mechanisms (e.g. evapotranspiration, ET, and recharge) are critical in the understanding and quantification of feedbacks between the atmospheric boundary layer (ABL), the land surface and the subsurface. This has been the subject of research for some time, both in the atmospheric community [Betts, et al., 1996] and the groundwater community [NRC, 2004; Sophocleous and Perkins, 2000; Sophocleous, et al., 1999]. The extent to which atmospheric and land surface processes are influenced by groundwater dynamics has been discussed previously [Liang, et al., 2003; Maxwell and Miller, 2005; Quinn, et al., 1995; Yeh and Eltahir, 2005; York, et al., 2002] though many aspects are still unresolved.

Groundwater dynamics and storage influences surface soil moisture and surface water flow. As there has been recent evidence that shallow soil moisture has a pronounced affect on atmospheric processes and weather prediction [Chow, et al., 2006; Holt, et al., 2006; Patton, et al., 2005] groundwater may be an important part of this feedback. In this paper, we present a methodology to characterize and evaluate the effect of groundwater on land surface processes (such as surface soil temperature and ET) and shallow soil moisture. We postulate that there is more influence of the groundwater on land surface processes than previously thought and that zones of varying influence may be delineated within a watershed. In addition to this general methodology, numerical simulations in conjunction with traditional statistical analysis will be presented to quantify these effects.

Originally developed as a lower boundary condition for global climate models [Manabe, et al., 1970], land surface models (LSMs) have steadily evolved and become more sophisticated 
(see e.g. the review by [Betts, et al., 1996]). A large number of LSMs have been developed, with differing parameterizations [Chen, et al., 1997; Dai, et al., 2003; Henderson-Sellers and Henderson-Sellers, 1995; Lohmann, et al., 1998; Pitman, et al., 1999; Qu, et al., 1998;

Schlosser, et al., 2000; Shao and HendersonSellers, 1996]. Until recently, LSMs have ignored the saturated zone (i.e. groundwater); though there has been recent work incorporating a groundwater component into LSMs [Liang, et al., 2003; Maxwell and Miller, 2005; Yeh and Eltahir, 2005]. Studies by [Liang, et al., 2003] and [Yeh and Eltahir, 2005] incorporated groundwater processes into a land surface model and demonstrated feedbacks. [Maxwell and Miller, 2005] explicitly coupled a saturated-unsaturated groundwater model to a land surface model and show feedbacks from the water table dynamics, particularly in shallow soil moisture. While these studies are promising they have not accounted for lateral subsurface and overland flow, nor has a study clearly demonstrated correlation between water table dynamics and surface processes.

In this paper, a coupled numerical approach that realizes a fully-three dimensional, coupled land-surface, overland flow and subsurface model is presented. Using a simulation for a watershed in Central Oklahoma, USA, statistical tools are employed to establish the connection between groundwater and land surface processes and to delineate zones of spatial correlation.

\section{Conceptual Approach}

The underlying hypothesis in this work is that there exists a linkage between groundwater dynamics and the mass and energy balance at the land surface. This linkage occurs via the shallow soil moisture ( $<2 \mathrm{~m}$ below ground surface), which is directly impacted by processes at the land surface, such as ET, and the location of the water table. The question arises when does 
the groundwater table exert control on the distribution of shallow soil moisture? Three different cases can be identified that are illustrated in Figure 1: (1) the depth to the water table, $D$, is small (D $\left.<10^{0} \mathrm{~m}\right)$; (2) the water table is at intermediate depth $\left(\mathrm{D} \sim 10^{0} \mathrm{~m}\right)$; and (3) the water table is far from the land surface $\left(\mathrm{D}>10^{0} \mathrm{~m}\right)$.

In Case 1, processes at the land surface are not water limited and do not depend on small variations in the water table depth, i.e. the linkage between the groundwater dynamics and land surface processes can be weak. In Case 3, processes at the land surface are strongly water limited and again do not depend on small variations in the water table depth. Water transport is directed downward in case of recharge and there is no significant upward redistribution of soil moisture. Case 1 and Case 3 constitute two different end members in the functional relationship between groundwater dynamics and the energy balance.

In Case 2, the water table is at, what we define as, the critical depth from the ground surface. Small changes in $D$ cause significant vertical redistribution of soil moisture near the land surface resulting in changes of the mass and energy balance at the land surface. Since the energy and mass balance is expected to be continuous for finite $D$ values, Case 2 characterizes the transition between Case 1 and Case 3.

The above conceptual model is based primarily on vertical moisture distribution in a single soil column. Figure 2 expands on this concept, depicting an idealized hillslope transect with a stream on the left. This transect has been divided into region A) with shallow depth to groundwater; B) with an intermediate depth to groundwater; and C) with a large depth to groundwater. These three regions can be associated conceptually with the three soil columns in Figure 1 and are hydraulically connected via topographically driven groundwater flow. 
In the case of topographically driven groundwater flow, the water table closely follows the topography, i.e. topographic lows coincide with groundwater discharge areas, whereas topographic highs coincide with recharge areas. Thus, the water table depth increases from the valleys to the hill tops. We then expect to find case 1 and case 2 in the valleys and at the hilltops, respectively, and case 3 in a transition zone along the hillslope extending from the valleys toward the hilltops. This conceptual approach is a simplification of real-world systems. For example, subsurface heterogeneity in the hydraulic properties, on a number of spatial scales, may result in a non-uniform moisture distribution and perched water lenses, which may influence the water and energy balance at the land surface. However, we believe that on intermediate to large spatial scales, our model provides insight into fundamental processes related to the linkage of the mass and energy balance at the land surface. This is similar to Toth's classical analysis of watershed hydrodynamics using a simple analytical solution [Toth, 1963]. In this study we look at a real system, using numerical simulations, relaxing many of the simplifying assumptions in Toth's approach.

The conceptual model put forth above linking groundwater dynamics and the energy balance at the land surface is only one and two dimensional (i.e. a single-column representation of the linked surface-subsurface domain). Groundwater dynamics may have transient, threedimensional components, i.e. perturbations of the hydraulic potential in one location propagate through the system at a certain speed, which is mainly determined by the hydraulic diffusivity of the aquifer. Thus, an increase in the water table at one location due to e.g. recharge from a rain storm will cause a response throughout the entire system. These are well known principles of groundwater dynamics that have been reviewed recently by [Alley, et al., 2002]. In this study, we go a step further and argue that changes in groundwater levels in recharge areas along ridges and 
hilltops will influence groundwater behavior in discharge areas along streams and seeps directly affecting the energy balance at these locations. This type of linkage is determined by the interrelationship of our 1D groundwater-energy linkage with 3D hydrodynamic effects on the watershed scale.

\section{Shallow groundwater}

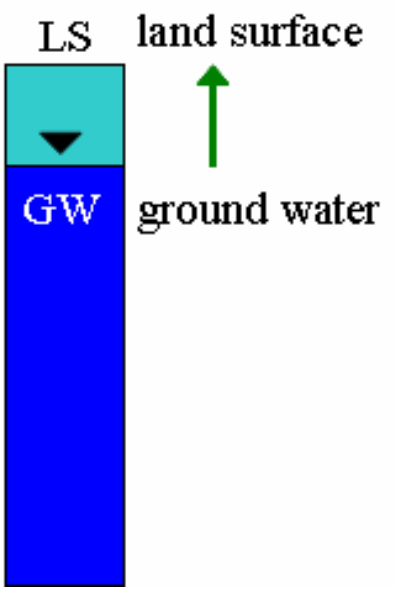

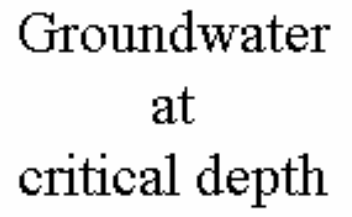

LS land surface

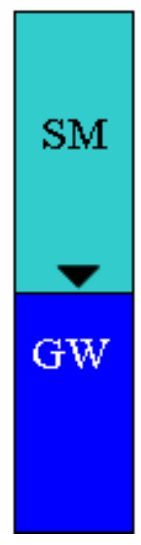

Deep groundwater

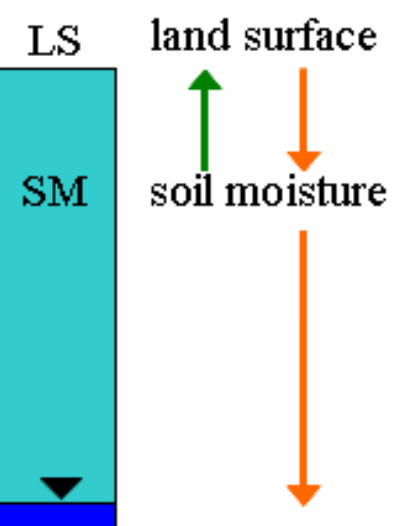

GW ground water

Figure 1. Schematic of the interconnection between groundwater (GW), shallow soil moisture (SM) and land surface (LS) processes: shallow groundwater (Case 1); groundwater at intermediate aquifer depth (Case 2); and deep groundwater (Case 3). 


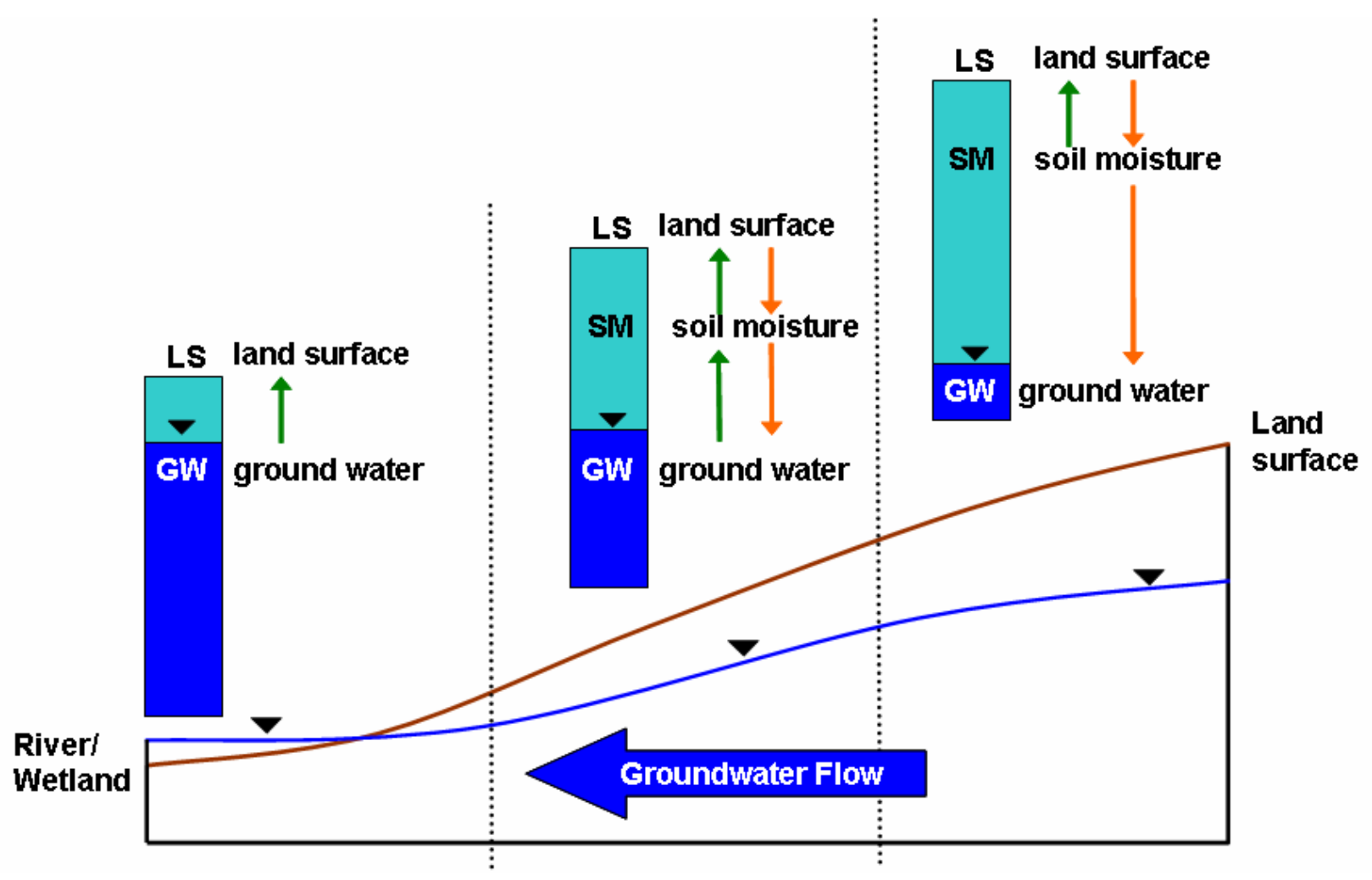

Figure 2. Schematic cross-section of land surface and water table showing theoretical delineation of three zones of influence of groundwater on land surface processes as a function of groundwater depth.

\section{Coupled model approach}

ParFlow is variably saturated groundwater flow model with an integrated overland flow simulation capability. It solves the three-dimensional Richards equation using cell-centered finite differences in space and an implicit backward Euler scheme in time. ParFlow was designed for high performance computing applications and is, thus, parallel. It lends itself to large scale high resolution simulations that require the efficient use of large computational resources. To simulate fully-coupled surface-subsurface flow, a free-surface overland flow boundary condition is applied at the land surface and consists of the kinematic wave equation (Kollet and Maxwell, 
2006). This equation is discretized using a finite control volume approach in space and also an implicit backward Euler scheme in time. The coupled equations are solved simultaneously using a Newton-Krylov method with multigrid preconditioning. An additional advantage of ParFlow is the use of an advanced octree data structure for the rendering of overlapping objects in 3D space, which facilitates geologic modeling of the subsurface, representation of the topography using information from digital elevation models and watershed boundaries. For details the reader is refereed to [Ashby and Falgout, 1996], [Jones and Woodward, 2001], and [Kollet and Maxwell, 2006].

For this work, ParFlow has been extended to incorporate physical processes that are related to the energy and mass balance at the land surface. This was accomplished by integrating a land surface model, the Common Land Model (CLM), into ParFlow building on the approach by [Maxwell and Miller, 2005]. In their approach, ParFlow replaced the soil moisture module of CLM by replacing the soil column/root zone formulation and providing CLM with the moisture distribution at each time step. In turn CLM, provided ParFlow with the fluxes at the land surface, such as evpotranspiration and infiltration from precipitation. The passing of information between both models was performed via input and output files of each model. Additionally the coupled model was run in single column mode in undistributed fashion.

In the study presented here, ParFlow still replaces the soil column/root-zone formulation in CLM [Maxwell and Miller, 2005] and CLM calculates the mass and energy balance at the land surface. Furthermore, CLM was incorporated into ParFlow in distributed manner as a module, i.e at each $x, y$ location in the computational domain, an individual CLM tile coincides with the upper face of an individual cell at the top of the subsurface model in ParFlow. An additional difference from [Maxwell and Miller, 2005] is the replacement of the TOPMODEL based runoff 
scheme in CLM with the integrated overland flow simulator in ParFlow. In this coupled model, CLM is also parallel including a parallel input and output file strucutre. Atmospheric data, such as temperature, precipitation, solar radiation, humidity, and barometric pressure, are used to force the model and can be applied in a distributed fashion as well.

As aforementioned, ParFlow calculates the mass balance in the subsurface, while CLM calculates the mass and energy balance at the land surface [Dai, et al., 2003 Maxwell, 2005 \#107; Maxwell and Miller, 2005]. The latter include evaporation from canopy and the ground surface; transpiration from plants; ground heat flux; freeze-thaw processes and sensible heat fluxes. Since the governing equations have been discussed in the great detail in the literature, we will only briefly reiterate some fundamental equations to illustrate the intrinsic coupling of the mass and energy balance.

At the land surface, the mass and energy balance can be written as

$$
R_{n}(\theta)=H(\theta)+L E(\theta)+G(\theta)
$$

where $R_{n}$ is net radiation, $H$ is the sensible heat, $L E$ is latent heat, $\mathrm{G}$ is ground heat flux, and $\theta$ is the soil moisture at the land surface. Hence, all energy variables depend on the water content at or close to the ground surface.

The mass balance of the subsurface can be written as follows

$$
S_{s} \theta \frac{\partial \psi}{\partial t}+\frac{\partial \theta(\psi)}{\partial t}=\nabla \cdot q(T)+q_{s}(\theta)
$$

where, $S_{S}$ is the specific storage, $\psi$ is the soil pressure head, $q$ is the water flux, $T$ is temperature, $t$ is time, and $q_{s}$ is a general source/sink term. At or near the land surface, $q_{s}$ can be expressed as $q_{s}=L E(\theta)+q_{g}(\theta)$ 
where $q_{g}$ is the flux of water infiltrating at the land surface due to precipitation and canopy throughfall and/or surface runoff.

Equations (1) through (3) illustrate the coupling a of the subsurface-land surface system that occurs mainly through the nonlinear source $q_{s}$ and the dependence of the energy variables on $\theta$. The strength of coupling and the resulting non-linearity depends on the parameterization of the relationships $R_{n}(\theta), H(\theta), q_{s}(\theta), G(\theta), \theta(\psi)$, and $q(T)$ and the inherent assumptions and simplifications. Some simplifications applied in the coupled modeling approach include the independence of $q$ on $T$ (the hydraulic conductivity of the subsurface materials are independent of $T$ ); neglecting the convective component in $G$; and neglecting explicit vapor transport in the subsurface in the calculation of ground evaporation.

A detailed discussion of parameterization schemes of components of the energy balance at the land surface will be given below. This will provide insight into the causes of the influence of ground water dynamics on the mass and energy balance at the land surface as calculated by CLM.

\section{Little Washita Watershed: Description and Model Setup}

In the current work, the coupled ParFlow-CLM (PF.CLM) watershed model was applied to the Little Washita watershed, an approximately 600 square kilometer watershed located in the Southern Great Planes (SGP) region of the United States in Southwestern Oklahoma (Figure 3). The Little Washita watershed lies within the DOE Atmospheric Radiation Monitoring (ARM) facility. This case study illustrates the major aspects of the coupled model. The model inputs include atmospheric forcing, land and soil cover information, topography, and surface and subsurface geologic models. 
The PF.CLM watershed model was constructed wiht a lateral spatial discretization $(\mathrm{d} x=\mathrm{d} y)$ of $1 \mathrm{~km}$ and a vertical discretization $(\mathrm{dz})$ of $0.5 \mathrm{~m}$ using $32 \mathrm{x} 45 \mathrm{x} 390$ cells in the $x, y$ and $z$ dimension, respectively, resulting in a total of 561,600 rectilinear elements. The lower zcoordinate originates at about 260m above mean sea level and the lower-left cell center latitude and longitude are 34.74 and -98.30, respectively. A preprocessed digital elevation model (DEM) was used to define the land surface boundary and thus the depth of the subsurface (defined as the topographic elevation to the bottom of the model) ranged from a minimum of $63 \mathrm{~m}$ to a maximum of 191m. The model used no-flow boundary conditions for the subsurface on all sides and allowed overland flow out of the domain along all sides based upon the surface slopes. Note, the model domain extends beyond the watershed boundaries; therefore the location of the water divide of the Little Washita watershed develops naturally in the model.

The model used RAWLS soil parameters for of the surface soil types shown in Figure 5 and International Geosphere-Biosphere Program (IGBP) parameters for each land cover type, also shown in Figure 5. In the model, the first layer at the land surface contains the USGS soil cover information (Figure 5). The vanGenuchten parameters required for the soil moisture pressure head relationships were obtained from the RAWLS data base [Schaap and Leij, 1998]. The deeper subsurface was based on an effective representation using effective parameters values based on the analysis of public records of some 200 boreholes in the region. The properties of the effective subsurface are as follows: saturated hydraulic conductivity, $K_{\text {sat }}=4.8$ $\mathrm{m} / \mathrm{d}$, porosity, $\phi=0.4$, vanGenuchten parameters $\alpha=3.5(1 / \mathrm{m})$ and $n=2$, and the residual saturation $S_{\text {res }}=0.2$. 
Vegetation cover information was obtained from the USGS (Figure 5). Corresponding vegetation parameters were obtained following the standard of the International GeosphereBiosphere Program (IGBP).

In order to obtain a realistic initialization of all state variables the model was run repeatedly over one year using the same forcing until a dynamic equilibrium was reached (commonly referred to as model spinup). Starting at the beginning of the spinup the water table was initialized $2 \mathrm{~m}$ below ground surface everywhere and the model was run over successive years until equilibrium was reached, which was seven years.

Figure 4 below shows an example soil moisture distribution in the Little Washita watershed in July after the spinup is completed. The non-uniform moisture distribution is a result of the topography and the non-uniform soil and land cover distributions, shown in Figure 5. Note, groundwater naturally converges and discharges in the valley, forming the Little Washita River. 


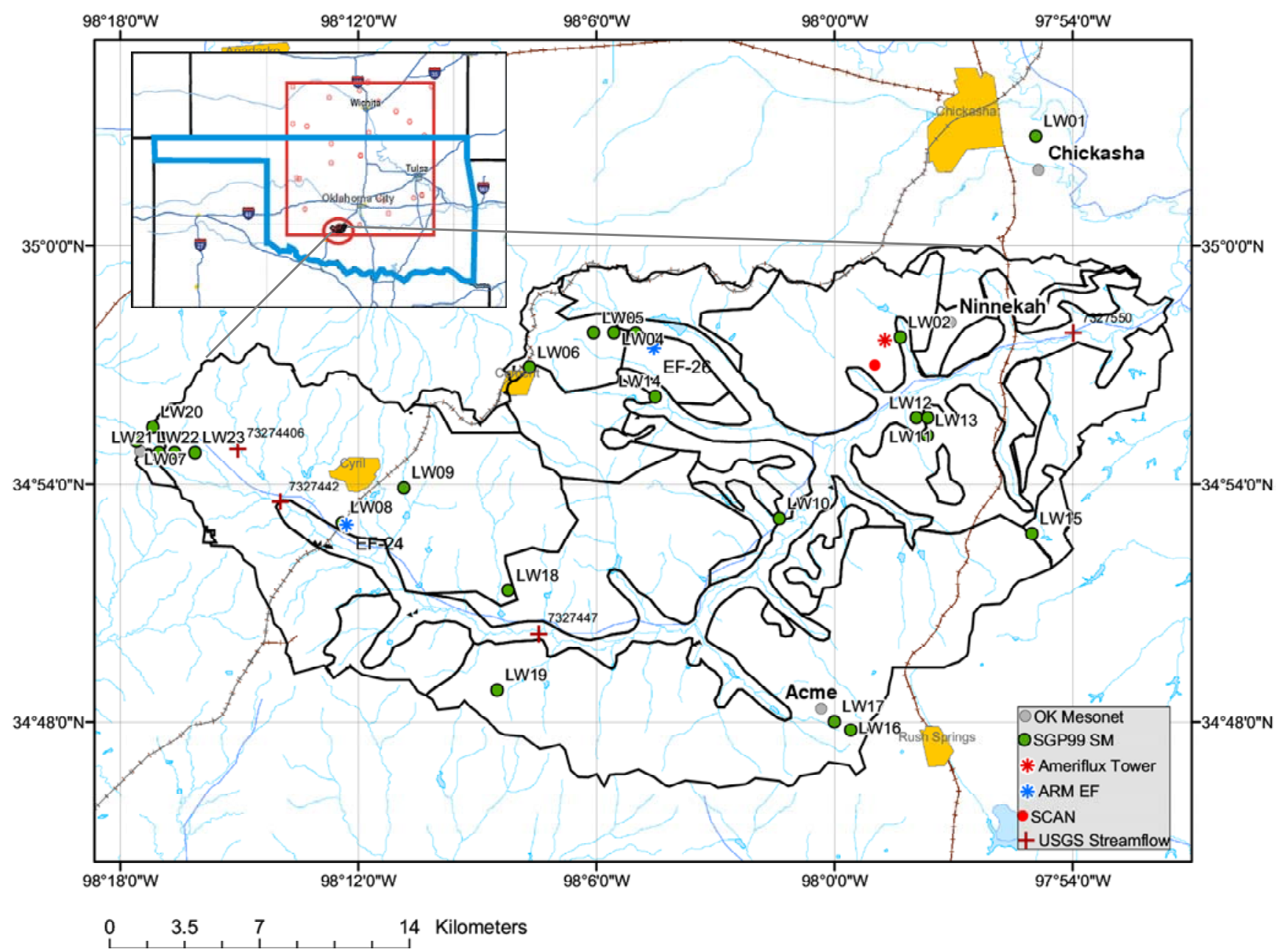

Figure 3. Location of the Little Washita watershed. The inset shows the location of the watershed in the state of Oklahoma. The footprint of the DOE ARM site is shown in the inset. 

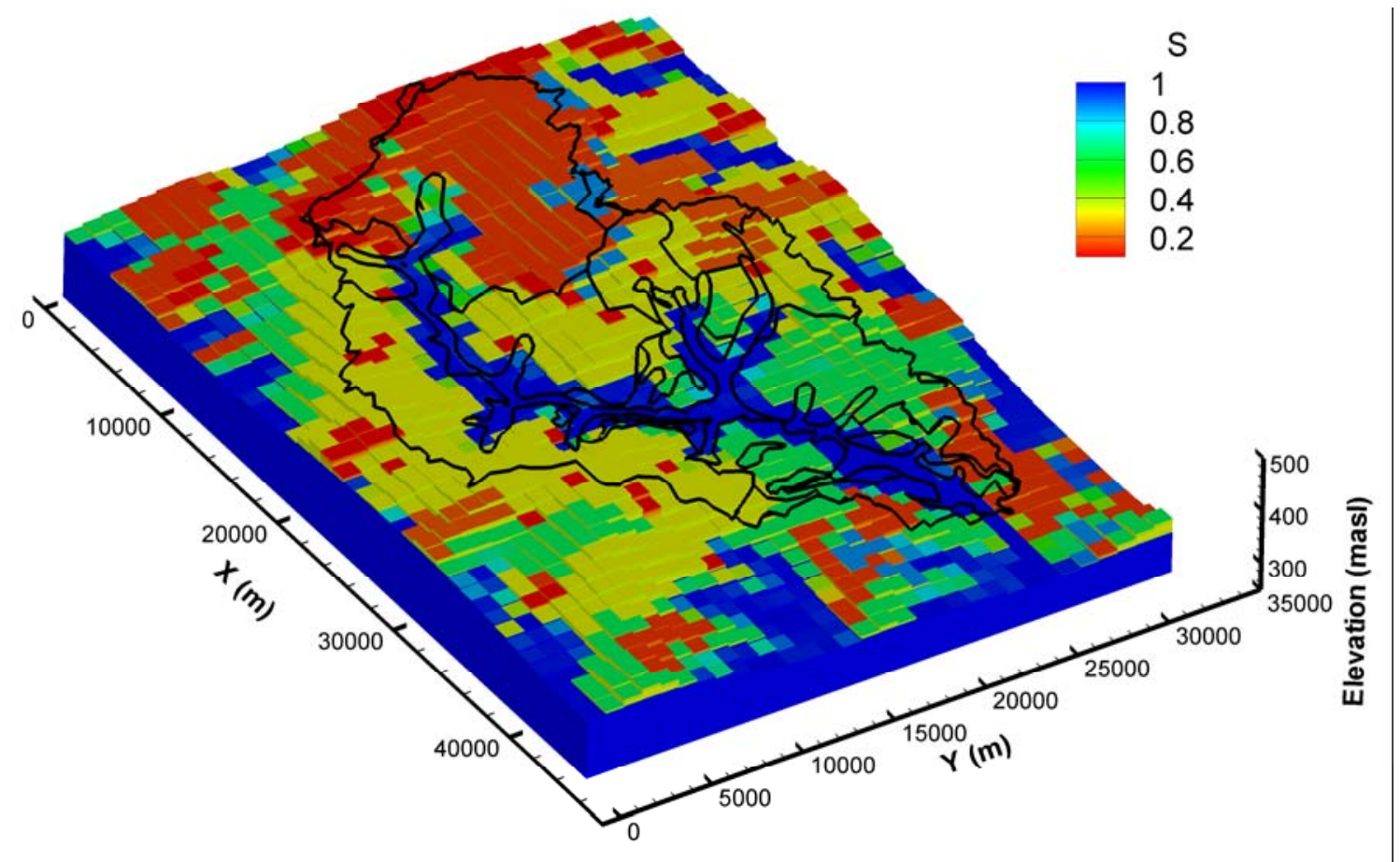

Figure 4. Plot of relative soil saturation for the entire Little Washita watershed model for mid June, 1999. Note the watershed outline from Figure 3 is overlain on the land surface.
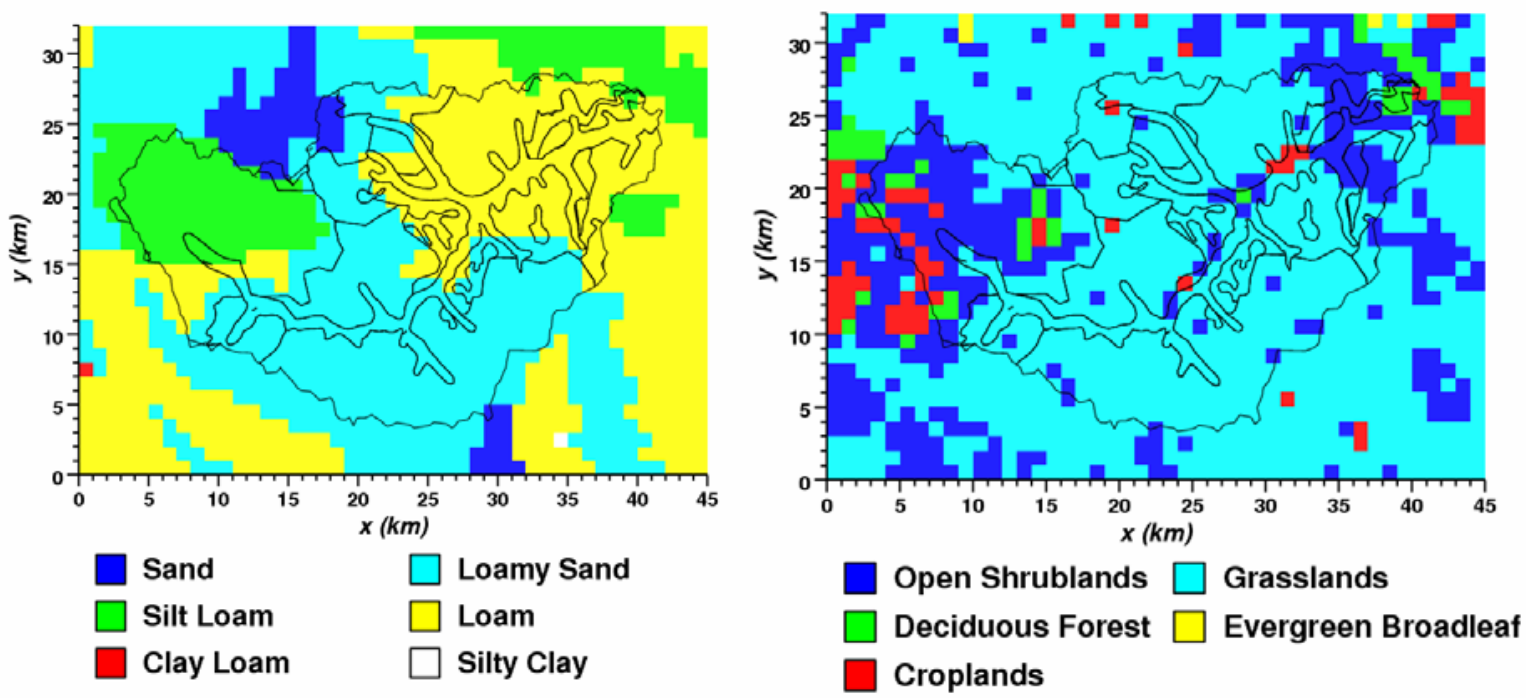

Figure 4. Spatially distributed soil (left) and vegetation cover (right) information used in the simulations. 


\section{Comparison to field data}

The Little Washita watershed has been subject of many field campaigns in the ARM and SGP framework [Jackson, et al., 1999].. These field campaigns focused on measurements of shallow soil moisture, soil temperature, and variables of the atmospheric boundary layer and have produced a number of datasets the locations of which are shown in Figure 3. Remote sensing data (both from satellites and aircraft over-flights) are also available, because many of the field campaigns were directed at the application of remote sensing for measuring of land surface variables. Additionally, there are data available from the following sources: 1) USGS steam gauging stations; 2) the Oklahoma Mesonet; 3) Ameriflux tower; 4)Soil Climate Analysis Network (SCAN); and 5) the ARS Micronet. Thus, there are data from the shallow subsurface upward. Although there are a number of groundwater wells in the watershed, almost all are private and have only a single water-level measurement taken at the time of installation. Unfortunately, there is virtually no groundwater data available during the study period from September, 1998 until August, 1999 or any other time period that is also covered by the aforementioned data sources.

Nevertheless, the available data can be used to demonstrate the fitness of the model to simulate the mass and energy balance in an integrated and distributed fashion on the watershed scale. Here we show a brief comparison of the simulated soil moisture with data from the SCAN station, simulated energy fluxes with the data from the Ameriflux tower, and simulated stream discharge with data from a USGS stream gauging station. Note that the model was not comprehensively calibrated to measured data as mentioned earlier. During the spinup process, the saturated hydraulic conductivity was adjusted slightly using limits established by effective theory to better match the measured hydrograph. 
Comparison with the measured hydrograph from the USGS station 7327550 shows good agreement during baseflow conditions from September 1998 until the end of February 1998 (Figure 6). After February 1999, the model dries out too quickly. Additionally the model generally matches the peak discharge rates during and after rainfall events, capturing the timing very well but overestimating the peak flow. From July until September, the model is not able to capture the low flow conditions, but soil moisture values are maintained at or close to saturation in the river valley during that time period.

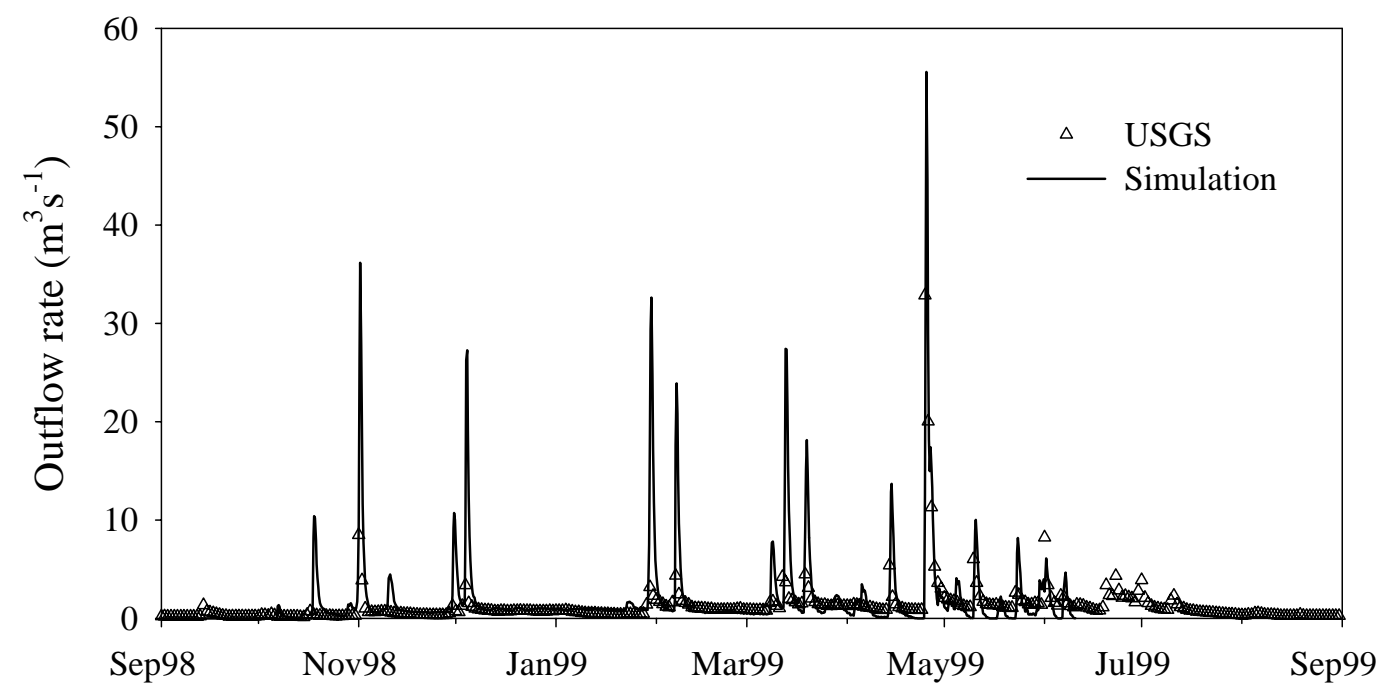

Figure 6. Comparison of the simulated and measured hydrograph from the USGS gauging station 7327550.

Figure 7 shows the comparison with the soil moisture data from the SCAN site at about 20 and $50 \mathrm{~cm}$ depths with averaged simulated values of the top model layer. The averaged simulated values were derived from equally weighted values of the four modeling cells closest to the SCAN site. Despite the fact that the comparison is based on a point measurement and simulation 
results that use $1 \mathrm{~km}$ lateral resolution, the results agree well. The model is able to capture the major wetting and drying cycles. The peaks are generally underestimated from December 1998 until June 1999, whereas the model does not dry out quickly enough from June until August 1999. Reasons for these discrepancies might include spatial grid resolution, application of uniform atmospheric forcing, and the choice of effective subsurface and land surface parameters.

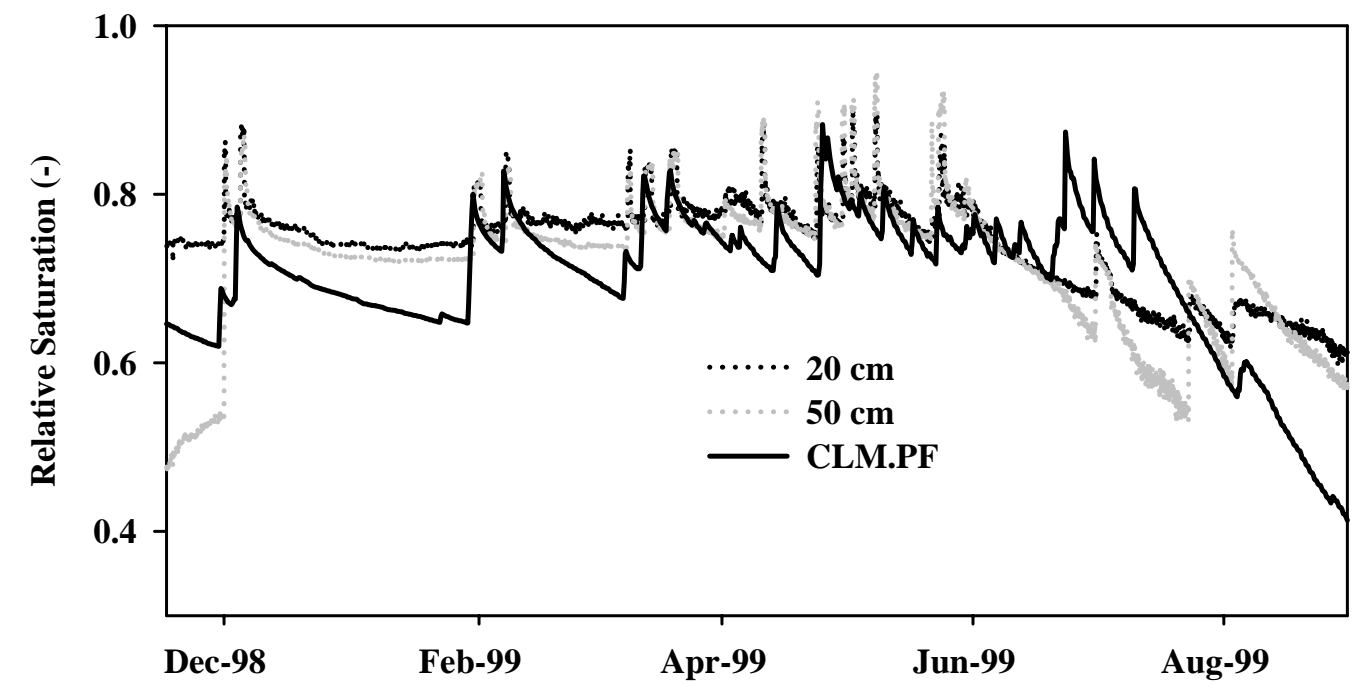

Figure x. Comparison of simulated and measured soil moisture from the SCAN site.

To evaluate the energy simulations we compared daily averaged estimates of latent heat ( $L E)$ from the model output to results from the Ameriflux tower in the domain (Figure 8). The model overestimates $L E$ especially from September until December 1998, however the overall trend in $L E$ is captured reasonably well. Other studies have shown the complexities and difficulties of comparisons with Ameriflux tower data that are related with, for example, fetch uncertainty [Twine, et al., 2000]. The large discrepancies especially in September 1998 may also stem from the spinup that assures that the energy balance at the end of August 1999 is the same as the 
energy balance at the beginning of September 1998. Yet, the energy balance at the end of August 1999 is not at all similar to the actual energy balance at the end of August 1998 that was recorded by the Ameriflux tower.

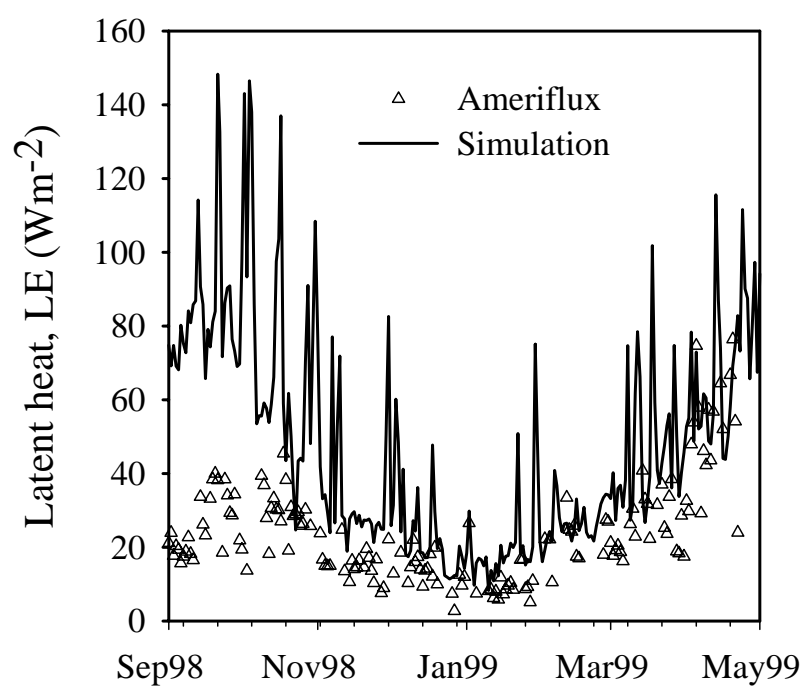

Figure 8. Comparison of simulated daily averaged latent heat with the data from the Ameriflux tower.

Although the comparison shows discrepancies between simulated and measured data, the model reproduces major trends and large parts of measured time series reasonably well. Significant improvement of model performance could possibly be accomplished through a calibration exercise and parameter uncertainty study, which is outside the scope of the current work. Since the model is not used for prediction purposes, but for process identification and examination, we feel that the fitness of the model to capture major physical processes and behavior of the real system is adequate. 


\section{Model Results}

\section{6.a Yearly averaged, spatially distributed data}

In this section, we present some yearly-averaged, summary results from the coupled model spinup mentioned in the previous section. Figure 9 shows plots of yearly averages of the energy balance, depth to groundwater level and ground surface temperature. These components are discussed below.

The depth to the water table (Figure 9b) correlates strongly with topography (Figure 9a), i.e. the water table is shallow in the valley and deep along the hilltops. Inspection of the different components of the energy balance shows the impact of vegetation cover and the shallow water table (Figure 9e-f). The influence of the water table is especially pronounced for the ground heat flux (Figure 9h). While soil cover has surprisingly little influence on the average fluxes, vegetation cover is clearly a primary factor. Soil cover only plays a significant role in the distribution of the relative saturation (Figure 9c)

What cannot be deduced from this Figure, however, is the contribution that different vegetation types impart on the water and energy flux variables to assess the impact of groundwater dynamics, i.e. water table depth. A more detailed analysis is performed in the following sections; first using scatter plots and then univariate and bivariate geostatistics. 
a)
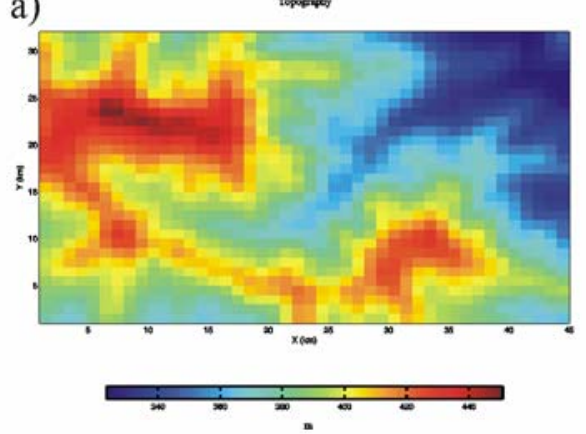

c)
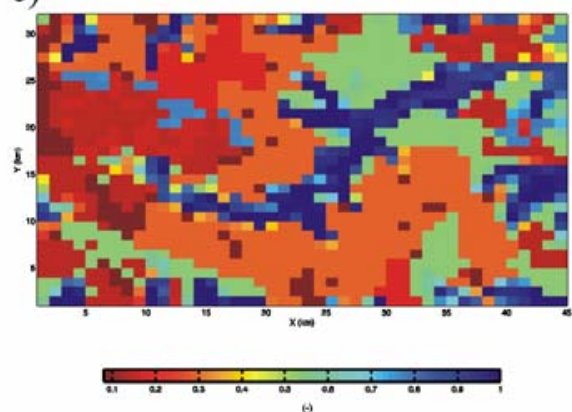

e)
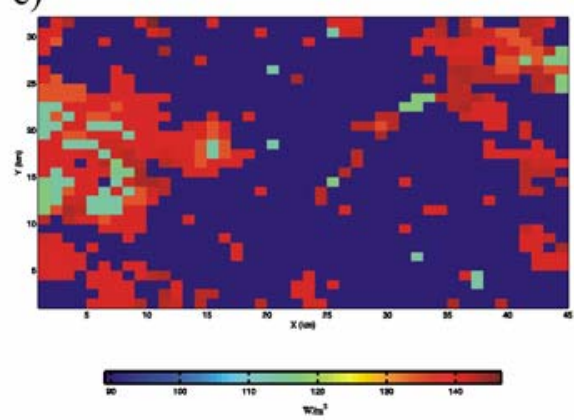

g)
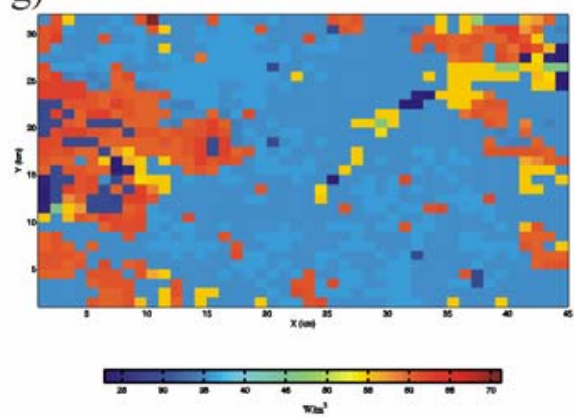

b)
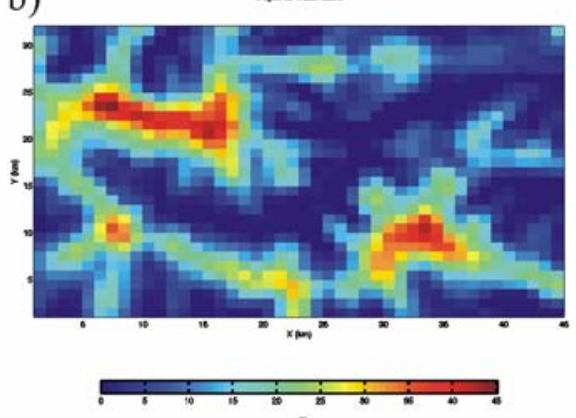

d)

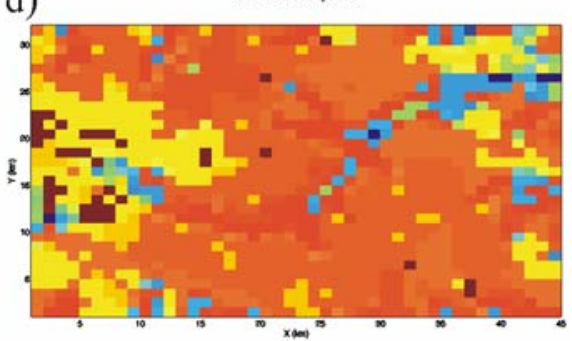

f)
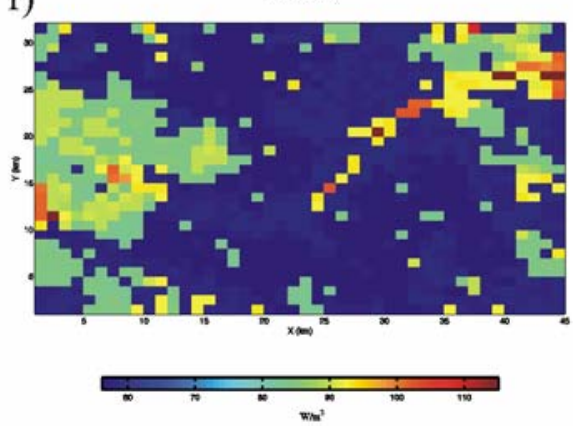

h)

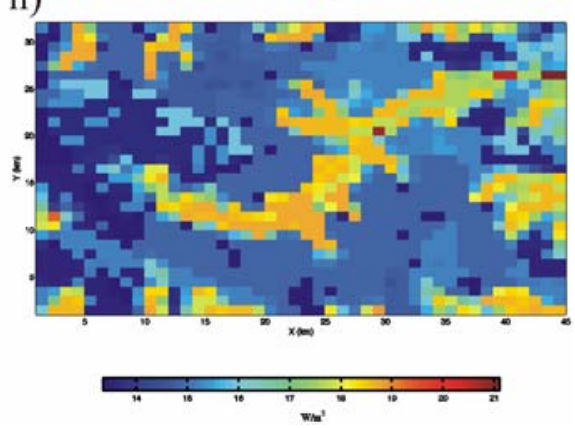

Figure 9. Plots of yearly-averaged a) topography; b) depth to water table c) relative soil

saturation; d) ground surface temperature; e) net radiation; f) latent heat flux; g) sensible heat flux; and h) ground heat flux. 


\section{6.b Scatter plots}

In this section, we use scatter plots to study the interdependence between different components of the land surface mass and energy balance and water table depth (and thus groundwater dynamics). Figure 10 shows scatter plots of yearly averaged values of a) net radiation, $R_{n}$; b) latent heat, $L E$; c) sensible heat, $H$; and d) ground heat flux, $G$ as a function of yearly averaged water table depth, $D$. In these plots, each symbol represents an individual $x$-, $y$ location in the computational domain with a corresponding yearly averaged energy and water table depth value. Because of the spatially varying vegetation, different symbols were used for grasslands, open shrublands, croplands, and deciduous forest to identify the vegetation cover at individual $x$-,y-locations.

Preliminary inspection of the Figure 10 shows wide scatter that can be primarily attributed to the spatially varying vegetation types and secondarily to soil type. Well-defined relationships between $D$ and the different components of the energy budget emerge for open shrublands, croplands, and deciduous forest, if the data is analyzed for each vegetation type individually.

These relationships are characterized by a segmented behavior including two flat segments separated by a steep segment of positive or negative slope in the range $1<D<5 \mathrm{~m}$. The flat segments indicate no sensitivity of the energy variables to $D$ and are formed by value pairs at locations with either relatively small or large $D$ values, i.e. very shallow or deep water tables. The steep segments, which are particularly pronounced in the case of $G$ (Figure 10d), form the range in which the energy variables are most sensitive to $D$. In case of $R_{n}, L E$, and $G$ the correlations with $D$ are negative. Thus the energy fluxes decrease with increasing water table 
depth. In case of $H$, the correlation is positive. For grasslands, energy variables show generally very little dependence on $D$, except in the case of $G$. In the range $1<D<5 \mathrm{~m}$, energy fluxes can vary by up to a factor of two in the case of $H$ and the vegetation type deciduous forest.

$$
\text { 政 }
$$

a)
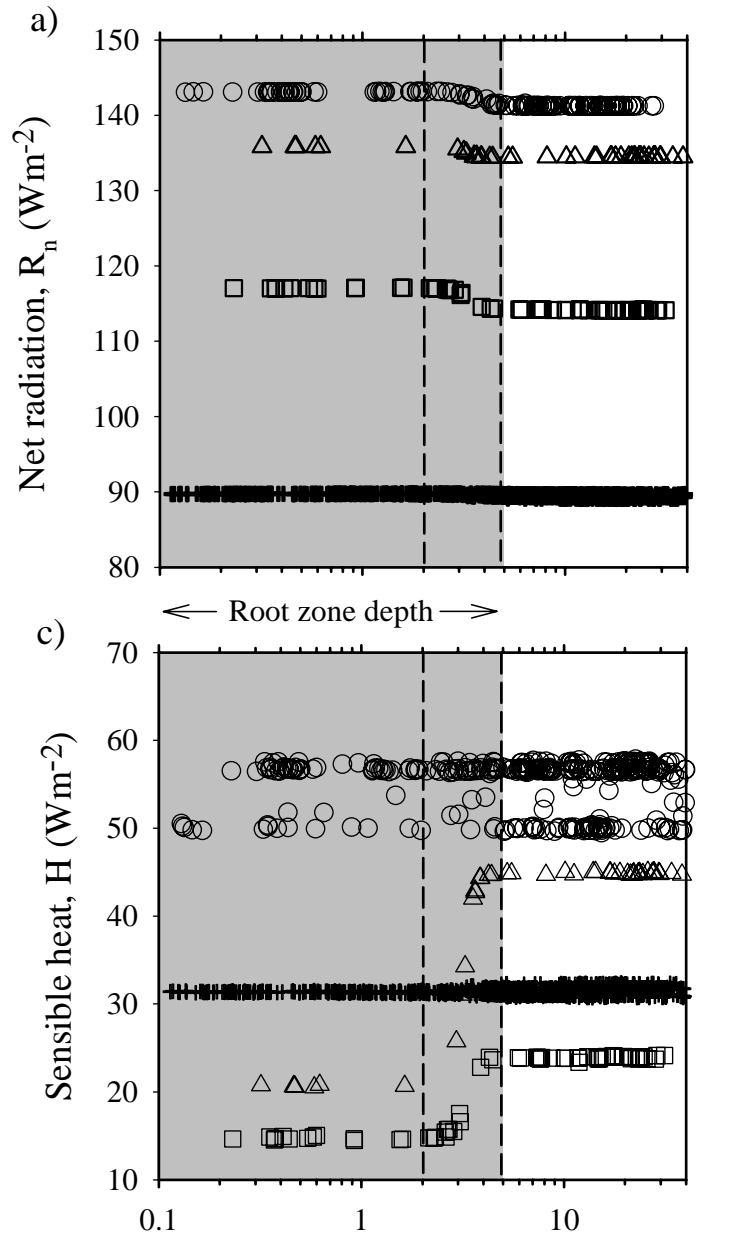

Water table depth (m)

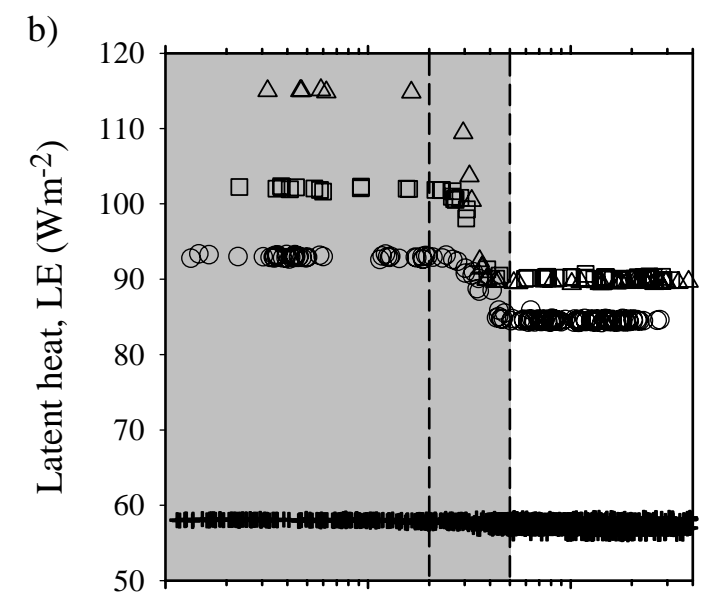

+ Grasslands $\quad \bigcirc$ Open shrublands

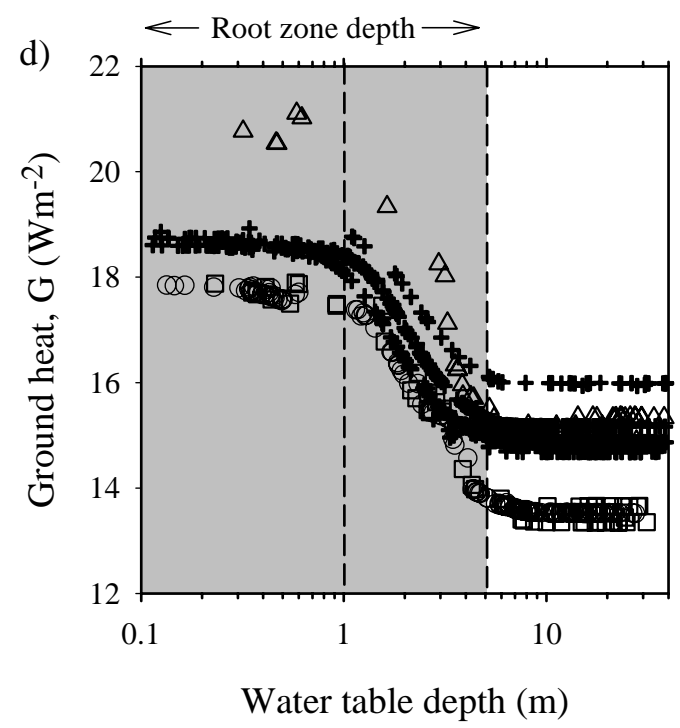

$\square \quad$ Croplands

$\triangle$ Deciduous forest

Figure 10. Semi-logarithmic scatter plots of yearly averaged a) net radiation; b) latent heat; c) sensible heat; and d) ground heat flux as a function of water table depth. The gray areas indicate the root zone depth. The dashed lines separate three segments that characterize the curves for 
different vegetation types indicated that are plotted using different symbols. Note the different scales for the y-axes in this figure.

\section{6.c Spatial bivariat statistics}

In order to test whether the model captures the spatial structure of the shallow soil temperature appropriately, we developed omni-directional unit semivariograms using data from the Micronet network for June, July and August 1999 and compared those with the predicted semivariograms from the simulations. The comparison is shown in Figure 11 and reveals good agreement of the measured and predicted spatial structure in the shallow soil temperature. In both cases, the semivariances stabilize after about $6 \mathrm{~km}$ lag size. However, for small lag sizes there is only a limited amount and, naturally, more noise in the unit semivariograms of the measured data.

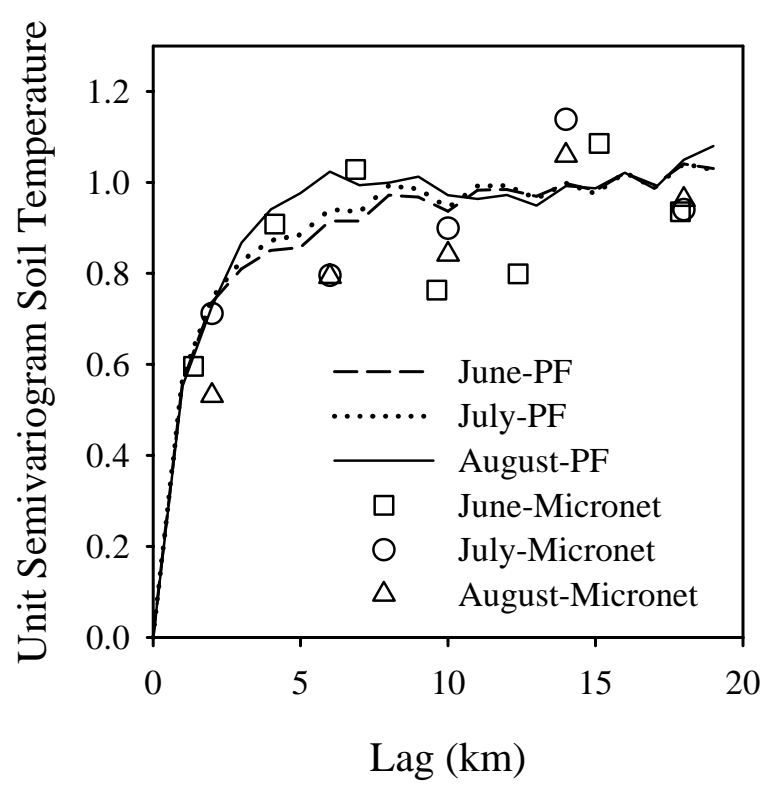

Figure 11. Unit variograms for shallow soil temperature from the simulation and Micronet monitoring network in the Little Washita watershed. 
In the model, the water table closely follows the topography. The water table exhibits a spatial structure that is influenced by the topography and characterized by relatively shallow water levels in the topographic depressions and relatively deeper water levels along the hilltops (Figures 4 and 9). Because the water table follows the topography, variograms of simulated water table depths, $D$, can be used to identify the scale of the spatial structure in $D$ that arises from topographically-driven processes. Figure 12 shows the directional, unit semivariograms in the $x$ - and $y$-directions for the yearly averaged $D$ values. These semivariograms show differences in structure in the two directions. In the $x$-direction, which is aligned with the principal flow direction of the Little Washita, the sill is reached for a lag size of about $11 \mathrm{~km}$. In the $y$-direction which is mainly transverse to the Little Washita, the spatial correlation in water table depth appears to deteriorate at a smaller lag size of about $7 \mathrm{~km}$.

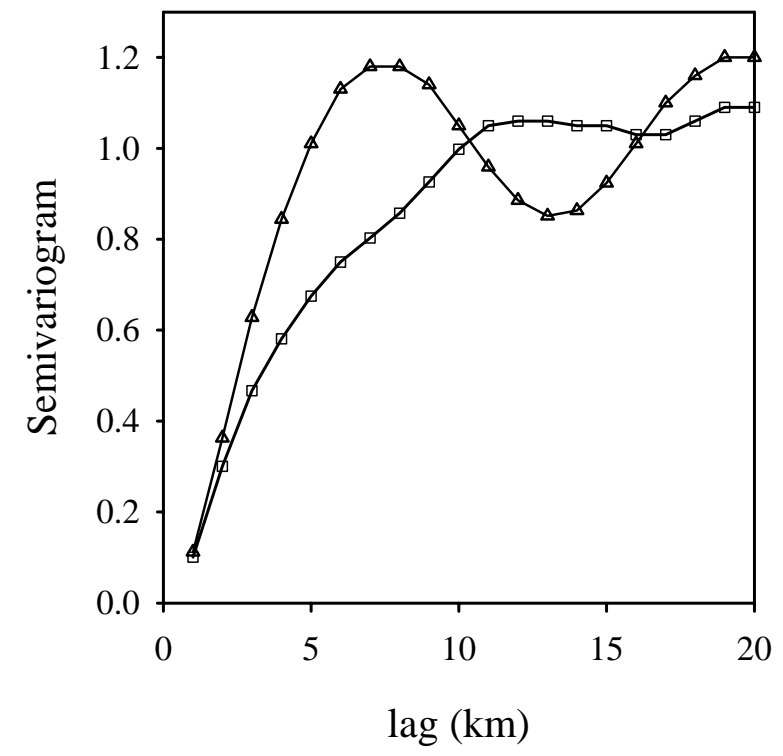

Figure 12. Semivariograms in the $\mathrm{x}$ and $\mathrm{y}$ direction for yearly averaged water table depths values. 
In order to study the cross-dependence of the components of the energy balance and ground surface temperature $T_{s}$ with water table depth, monthly cross correlograms were generated (Figure 13). The components of the energy balance are net radiation, $R_{n}$; latent heat, $L E$; sensible heat, $H$; and the ground heat flux, $G$. Ground surface temperature was included in the analysis, because it contributes to the energy balance and is a commonly monitored variable in the field.

In Figure 13, the net radiation, $R_{n}$, does not show cross dependence with $D$ over the entire year on all spatial scales. Latent heat, $L E$, shows weak negative cross dependence in December, January, and February. Sensible heat, $H$, shows weak positive cross dependence in July, August, and September. The largest cross dependence was observed for the ground heat flux, $G$, with maximum values of about 0.7 and -0.7 in January and July respectively. The cross correlation values are positive in the cool months of the year (November until March) and become negative in the warmer months from April until September. The transition from positive to negative values occurs quite abruptly from March to April. This is in contrast to the reverse case, when the cross dependence changes more gradually from negative to positive values from September to October.

Cross correlations were also calculated for the ground surface temperature, $T_{s}$, which shows positive cross correlation from July until September and negative values for December and January. For lag sizes larger than 7km, the cross correlations for all variables are close to zero over the entire year. In cases of significant cross correlation, the scale of the cross correlation structure appears to be 6 to $7 \mathrm{~km}$. Thus, the scale of the cross correlation structure is comparable to the hillslope scale depicted in Figure 12. 

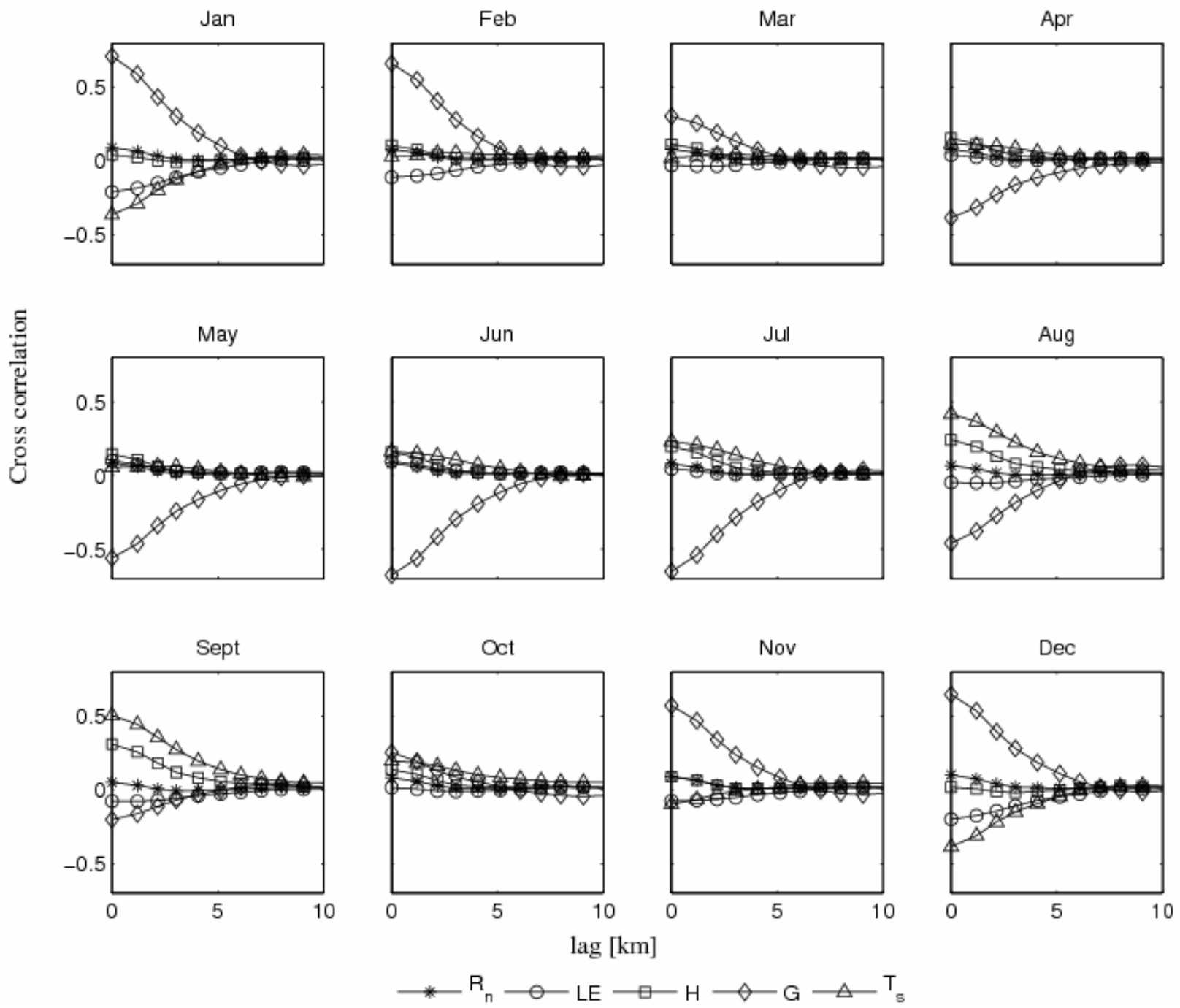

Figure 13. Cross correlations of the components of the energy balance and ground surface temperature with water table depth $\left(\mathrm{R}_{\mathrm{n}}\right.$, net radiation; $\mathrm{LE}$, latent heat; $H$, sensible heat; $\mathrm{G}$, ground heat flux; $\mathrm{T}_{\mathrm{s}}$, ground surface temperature).

Because strong cross dependence was observed for ground heat flux and water table depth, unit directional semivariograms in the $x$ - and $y$-directions were calculated for each month of the year (Figure 14) The directional semivariograms for monthly-averaged water table depths show directional variation (Figure 14), which was also true for the semivariograms of the yearly 
averages in case of $D$ (Figure 12). There is also very little variation in semivariograms from month to month.

In most months, the semivariograms of $G$ also show a directional dependence. This dependence is very similar to the directional dependence of the semivariograms of $D$ with smaller correlation lengths in the $x$ - than in the $y$-direction. The overall shape of the semivariograms of $G$ and $D$ are very similar as well over most of the year. However, there is a shift in the semivariograms of $G$ toward slightly smaller correlation lengths that is especially apparent in January.

In March and April, and from August until October, the directional dependence weakens in the $G$ semivariograms. In these months the semivariograms in the $y$-direction approach the semivariograms in the $x$-direction and it appears that the spatial structure in $G$ becomes selfgoverning, i.e. independent of $D$. The correlation length decreases to approximately $5 \mathrm{~km}$ in the $x$ - and $y$ - direction. The disappearance of the directional dependence and apparent decoupling of the structure of $G$ from $D$ coincides with transition in the cross correlation from positive to negative in March and April, and from negative to positive from August until September (Figure 13). 

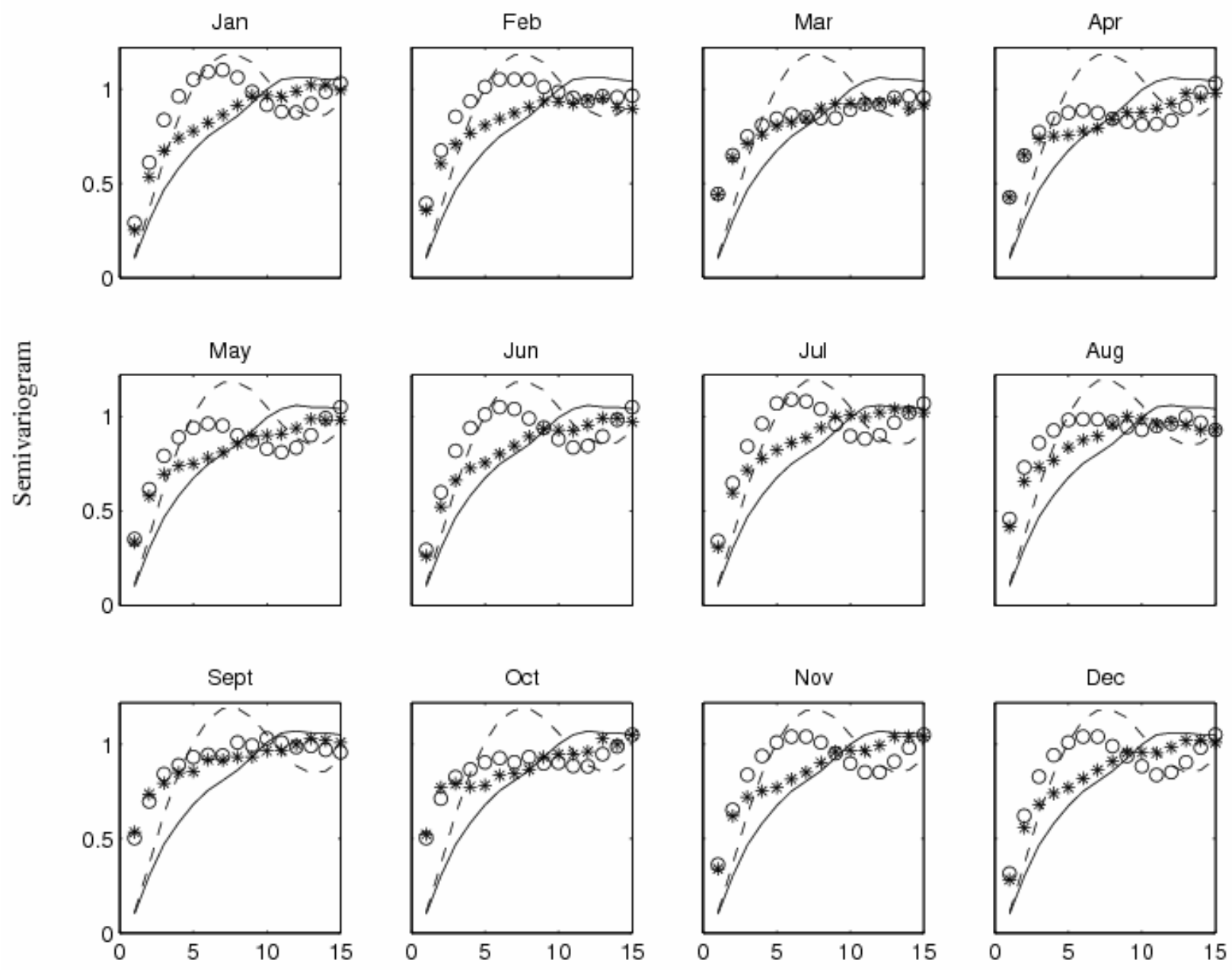

lag $[\mathrm{km}]$

* Gx-direction $O$ G y-direction — D x-direction - - - D y-direction

Figure 13. Directional semivariograms for ground heat flux, $G$, and water table depth, $D$, for each month of the year.

\section{Discussion of Results}

\section{7.a Scatter Plots}

The scatter plots (Figure 10) illustrate the correlations of the components of the energy balance of the land surface with water table depth and, thus, groundwater dynamics. The three segments of the curves in Figure 10 are characterized by two flat segments for the ranges $0.001<D<1 \mathrm{~m}$ and $D>5 \mathrm{~m}$ that are separated by a steep segment with positive or negative slope for the range 
$1<D<5 \mathrm{~m}$. We explain this behavior as follows: in the range $0.001<D<1 \mathrm{~m}$, the water table is very close to land surface and the system is never water limited. This is true even during the very dry months of the year, because moisture is easily redistributed vertically upward from the shallow water table. The shallow water table is maintained in the valleys by topographically driven flow. Thus the first segment corresponds to Case 1 in Figure 1 and Zone A in Figure 2 as discussed in Section 3.

In the range $D>5 \mathrm{~m}$, the water table is far enough below the root zone that the system is water limited. This is true in general, except during and shortly after precipitation events. In areas where $D>5 \mathrm{~m}$ (primarily on the hill tops), soil moisture is not distributed vertically upward from the water table toward the land surface; transport of moisture is solely downward. This range is equivalent to Case 3 in Figure 1 and Zone C in Figure 2 of Section 3.

In the range $1<D<5 \mathrm{~m}$, both negative and positive correlations exist between the different energy variables and $D$. This range is equivalent to Case 2 as defined in Figure 1 and designates a critical water table depth for this system (as defined in Section 3) between 1 and $5 \mathrm{~m}$ below the ground surface. The distinct correlations for different vegetation types and energy variables stem from the parameterizations of the different processes in the land surface model and from variably saturated groundwater flow above the water table. This will be discussed in detail by inspecting the physical components of latent heat, $L E$ : ground evaporation and transpiration.

In CLM [Dai, et al., 2003], ground evaporation, $E_{g}$ is defined as a conductance or a resistance in the form

$$
E_{g}=\rho_{a} \frac{\left(q_{g}-q_{a}\right)}{r_{d}}
$$

where $\rho_{a}$ is the intrinsic density of air; $q_{g}$ is the air specific humidity at the ground surface; $q_{a}$ is the air specific humidity at reference height $z_{q}$ obtained from atmospheric forcing; and $r_{d}$ is the 
aerodynamic resistance of evaporation between the atmosphere at $z_{q}$. In CLM, the specific humidity of the ground surface, $q_{g}$, is parameterized as

$$
q_{g}=q_{s a t} e^{\left(\frac{\psi g M}{R T}\right)}
$$

where $\psi$ is the soil total potential [L], $\mathrm{g}$ is the gravity constant $\left[\mathrm{LT}^{-2}\right], M$ is the molar weight of water [M]; $R$ is the gas constant $\left[\mathrm{JM}^{-1} \mathrm{~K}^{-1}\right]$; and $T$ is the temperature at the ground surface $[\mathrm{K}]$. The aerodynamic resistance, $r_{d}$, is based on the Monin-Obukhov similarity principle and is also a function of $q_{g}$. In general, evaporation from the ground decreases with decreasing $q_{g}$, which explains much of the negative correlation of $L E$ and $D$ in the range $1<D<5 \mathrm{~m}$. Yet, $L E$ includes transpiration, $E_{t r}$, which competes with $E_{g}$ for the amount of available moisture (and thus energy) in the shallow subsurface. In CLM, $E_{t r}$ is parameterized as follows

$$
E_{t r}=\sigma_{f} L_{S A I} \delta\left(E_{f}^{p o t}\right) L_{d} \frac{r_{b}}{r_{b}+r_{s}}
$$

where $\sigma_{f}$ is the vegetation fraction; $L_{S A I}$ is the stem plus leaf area index; $\delta$ is the step function; $E_{f}^{\text {pot }}$ is the potential evaporation from wet foliage; $L_{d}$ is the dry fraction of foliage surface; $r_{b}$ is the conductance of heat and vapor flux from leaves; and $r_{s}$ is the stomatal resistance.

In Equation $6, r_{s}$ dependends on $\psi(\theta)$ and increases with decreasing water content. This dependency is weak as transpiration may still occur even under very dry conditions. The result is small contribution of $E_{t r}$ to the correlation between $L E$ and $D$ in the range $1<D<5 \mathrm{~m}$. Other LSMs use different stomatal resistance parameterzations ([Qu, et al., 1998], Table 1) and the correlation between $L E$ and $D$ is, of course, very sensitive to this parameterizaton..

For $L E$, the critical depth is between about 1 and $5 \mathrm{~m}$. Modifications in the parameterization schemes (e.g. a stronger dependence of $E_{t r}$ on $\psi(\theta)$ ) would change the range of the critical depths at which water table effects are significant. However, the overall behavior, i.e. 
the segmentation of the curves for the different vegetation types, would not be affected. Thus, the underlying hypothesis that there exist some critical depths at which the water table cannot be neglected appears to be valid in general terms.

It is also expected that the critical depth depends on the soil type, because the parameters of the pressure-saturation relationship vary with soil type. In the PF.CLM model as applied to the Little Washita watershed, the upper layer contains the distributed pedology from STATSGO, while the rest of the subsurface is approximated as a uniform, effective continuum (as described in Section 4). The scatter plot analysis (Figure 10) exposes that variation in soil type had little influence on the energy balance at the land surface. This is reflected by the small scatter of the data for each individual vegetation type. While the insensitivity of critical depth to soil type might seem counterintuitive, a more in-depth analysis using LE shows the consistency of this result. Although, in the model, the parameterization of $L E$ depends on $\psi(\theta)$, it is most sensitive to $\psi(\theta)$ when the soil is very dry, i.e. when $E_{g}$ is reduced. For these $\psi(\theta)$ values $\theta$ is at or near the residual water content. This is true regardless of soil type and results in a homogenization of $\psi(\theta)$ and thus the energy fluxes. A more pronounced effect of the soil type would be expected at intermediate water contents, when the sensitivity of $\theta$ to $\psi$ is largest. But in that $\psi(\theta)$ range, the sensitivity of the energy variables to soil moisture is relatively small. The ground evaporationpressure, $E_{g}(\psi)$, functional relationship described by Equation 5 is shown in Figure 15. This Figure indicates that ground evaporation is most sensitive to $\psi$ in the range $-10^{2}<\psi<-10^{5} \mathrm{~m}$. The upper limit of this range $\left(\psi \approx-10^{2} \mathrm{~m}\right)$ coincides with the wilting point threshold used in the calculation of $E_{t r}$ in CLM [Dai, et al., 2001]. For $|\psi|>10^{2}-10^{3}$, the sensitivity of $\theta$ to changes in $\psi$ is small also for structured soils, such as clay, and $\theta$ is rapidly approaching the residual 
water content. Thus the overlap of the sensitivity ranges of the energy variables and $\theta$ on $\psi(\theta)$ is relatively small.

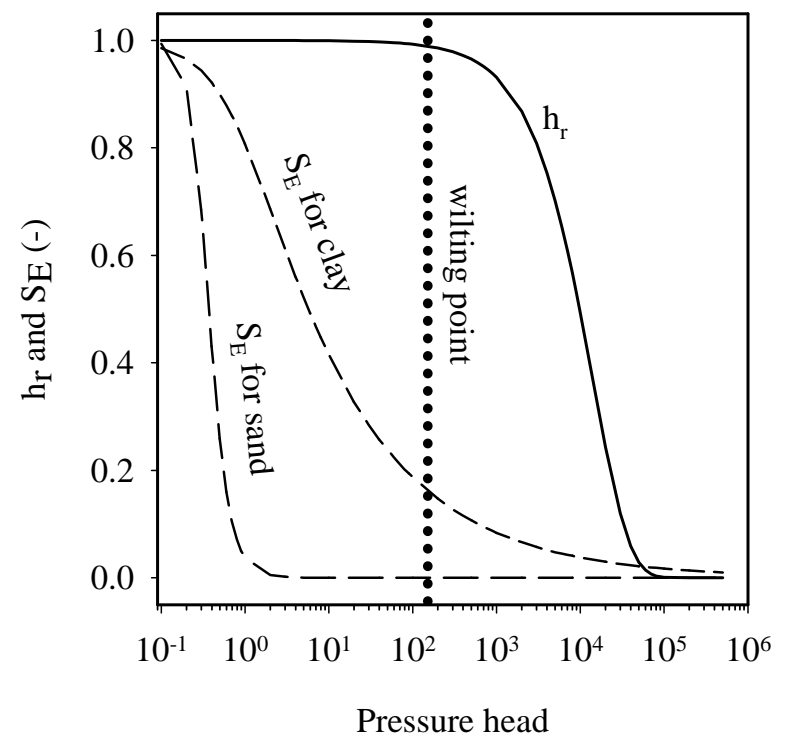

Figure 15. Semi logarithmic plot of relative humidity, $\mathrm{h}_{\mathrm{r}}$, and relative saturation, $\mathrm{S}_{\mathrm{E}}$, versus soil pressure head as predicted by Gibbs' and vanGenuchten formulae. A wilting point value of 150m is indicated with the dotted line.

Although the analysis thus far has been based on yearly averaged relationships of energy variables and $D$, the scatter plots suggest a transient effect of $D$ over the critical depth range. A transient effect would be marked by temporal variations in the energy balances that are prompted by temporal variations of $D$. The time scale of the transient effect will depend on how quickly the pressure head profile adjusts to perturbations in $D$ and is thus, influenced by the soil type, subsurface heterogeneity, vegetation cover, ambient moisture conditions, and the magnitude and duration of the perturbation. Whilst the analysis of transient effects requires additional work in future, it is obvious that large scale trends in $D$ might cause significant changes in the energy 
balance at the land surface. This might be important in regions such as the Great Plains, where large scale groundwater mining has resulted in a decline of previously shallow groundwater levels.

\section{7.b Spatial bivariat statistics}

The semivariograms of the yearly averaged water table depths $(D)$ (Figure 12) show a strong directional dependence. The $x$-directional semivariogram is closely aligned with the principal flow direction of the Little Washita from west to east and therefore captures the larger scale of processes that are associated with the longitudinal river architecture. Because the $y$ direction is aligned normal to the principal flow direction of the Little Washita River, the scale of the $D$ structure in the $y$-direction semivariogram is smaller than in the $x$-direction,. This means the semivariogram in the y direction mainly captures hillslope processes from the center of the valley to the hilltops. Thus, the main process captured here is groundwater flow from recharge areas along the hillslope and hilltops toward discharge areas along the river corridor and the associated spatial variation in $D$.

In the analysis of cross correlations shown in Figure 13, it is important to keep in mind that nonlinearities in the dependence between water table depths and the energy variables are not captured. Thus, small cross correlations do not necessarily entail the absence of cross dependence. Additionally, cross correlations were calculated over the entire domain without distinguishing between vegetation and soil type. This was done to obtain an integrated measure of cross dependence at the watershed scale. On the other hand, large cross correlations do not necessarily suggest a mechanistic dependence. However, because a process-based model was used, this study is able to address this ambiguity inherent in statistical analysis. 
The cross correlograms of variables with significant cross dependence exhibit distinct seasonality both in the values and in structure. This will be discussed using the ground heat flux, $G$, which exhibits the strongest linear cross correlation with water table depth, $D$.

During the summer months, $G$ is directed from the atmosphere into the subsurface. This is shown in Figure 13 by negative cross correlations. $G$ decreases with increasing water table depth, because drier conditions reduce the thermal conductivity of the soil, which in turn reduces $G$. The cross correlation reverses in September and October and remains positive during the winter months. This reversal is caused by a switch in the direction of $G$ which is from the subsurface into the atmosphere during the winter. The positive cross correlation only indicates a reversal in the direction of $G$, the magnitude of $G$ is still negatively correlated with $D$.

Juxtaposition of the $G$ cross correlograms and semivariograms (Figures 13 and 14) shows that the spatial structure of $G$ is very similar to the water table structure during most of the year. The scale of the $G$ structure is 6 to $7 \mathrm{~km}$, which can be inferred from the cross correlograms and semivariograms, and is similar to the hill slope scale in the $y$-direction. Changes in the structure of $G$ (Figure 14) occur when the cross correlograms are in transition from positive to negative values (Mach and April) or vice versa (September and October). Therefore, the change in the structure of $G$ coincides with a change in its direction from the subsurface toward the atmosphere or vice versa. In the transition months the correlation scale decreases to about $5 \mathrm{~km}$ and does not show directional dependence. That has implications for the design of field studies, which will be discussed below, because it demonstrates during which time periods process interactions are expected to be detectable.

The good agreement of the structure in $G$ and $D$ stems from their interdependence. This is reflected in the scatter plots and cross correlograms (Figure 10 and 13) and is most pronounced 
when the subsurface equilibrates to the prevalent seasonal atmospheric conditions at the land surface. The scale of the $G$ structure is shifted to slightly smaller values, mainly because of the influence of vegetation and soil cover. Additionally, hydraulic pressure perturbations from, for example, precipitation and recharge events propagating through the system on relatively small time scales also affect the spatial structure. This effect could be more pronounced for nonuniform atmospheric forcing, which is not taken into account in this study.

\section{Recommendations for Future Field Studies}

The simulation results suggest that PF.CLM is a useful tool in the design of field campaigns, because it affords the selection of important parameters, measurement locations and time periods. Based on the findings of this study, we recommend collecting co-located measurements of at least groundwater level, soil temperature and pressure head profiles, as well as the basic atmospheric variables. These co-located measurements should be collected at locations where the water table is in the range of the critical depth, 1-5m in this work. In cases of larger or very shallow $(D<0.5 \mathrm{~m})$ water table depths, water level measurements appear to be secondary. Figure 16 shows the scatter plot of average ground surface temperature versus water table depths at each $x-, y$ - location in the domain for the month of June 1999. For deciduous forest, croplands and open shrublands, water table depth affects ground surface temperature in the range of $2 \mathrm{~K}$ and should be detectable from simple field measurements. For these vegetation types water table effects are on the order of land cover effects, i.e. neglecting water table effects may have the same impact as simulating open shrublands instead of croplands. 


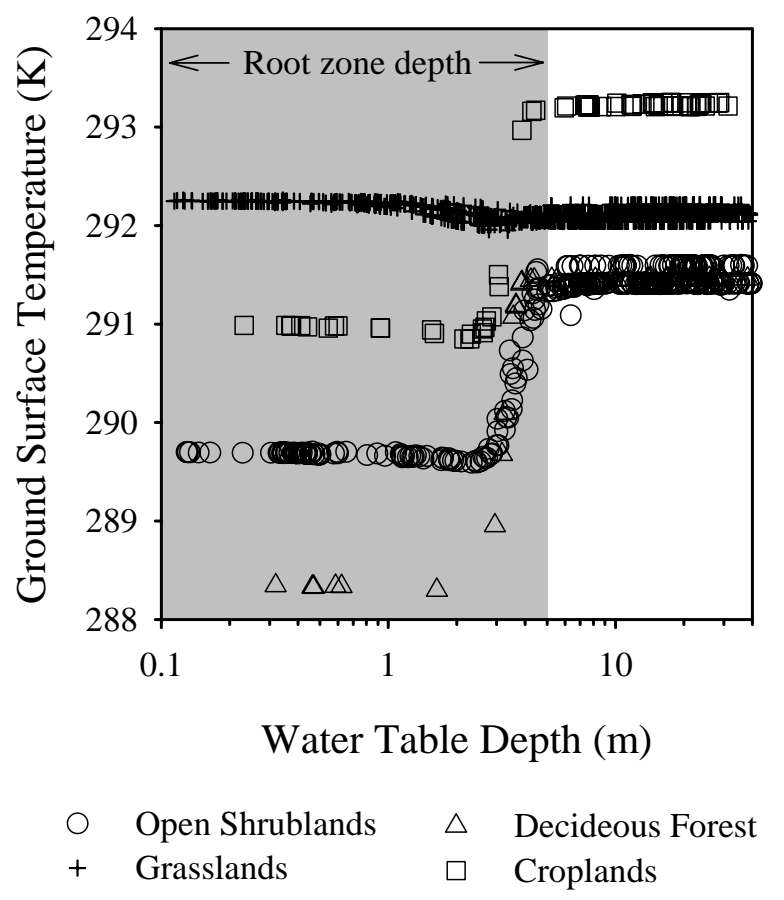

Figure 16. Scatter plot of average ground surface temperature versus water table depth for the month of June 1999. The depth of the root zone is indicated with the gray area.

Figure 13 and 14 also suggest that cross dependence of groundwater dynamics and energy variables might only be detectable in the field for the ground heat flux, $G$, and ground surface temperature. Since the cross correlations and the similarity of the spatial structure of $G$ and $D$ are strongest in the months when the seasonal direction of $G$ is well established, measurement campaigns should avoid the transition months from winter to summer and vice versa. In our case, this transition occurred during March and April and September and October, respectively, though regional and yearly variations must also be taken into account

We also believe that shallow soil moisture data from the first few centimeters below the ground surface, often inferred from remote sensing data, might be inherently difficult to interpret and might not reflect the intrinsic spatial composition of the system especially under dry 
conditions. Soil moisture directly at the land surface does not necessarily represent the moisture availability of the underlying system. At the surface, the moisture availability and, thus, mass fluxes, are governed by the structure of the soil and the vertical gradient of the soil water pressure head throughout the soil column. Therefore the soil moisture value at the land surface does not suffice to characterize the system and is not a measure of the "true dryness" or moisture state of the system.

This point is illustrated using a simple analytical solution for steady evaporation at the ground surface for a structured soil for two different evaporation rates. Figure 17 shows depth to the water table versus relative saturation for two water table - evaporation rate $(E)$ configurations. At the land surface and right below it, saturations for both configurations are very similar and close to the residual water content. Thus, application of Gibbs equation in conjunction with boundary layer theory to calculate $E$ will result in identical values.

However, Figure 17 shows that in case of water table A, the system is able to maintain an evaporation rate that is two times larger than in case of water table B, because of increased moisture transport toward the land surface. From this analysis, it is obvious that the saturation value at the land surface does not allow inference of $E$ or the "true drynesss" of the subsurface if no information of $\theta(z)$ and the depth to the water table is available in the case of a homogeneous soil profile. The analysis is further complicated in the case of a heterogeneous subsurface, because knowledge of $\theta(z)$ does not suffice to infer fluxes and thus $E$. Knowledge of $\theta(z, \psi)$ of the material of the soil profile or direct measurements of $\psi$ are required.

The latter also has implications for parameterizations of $E$ in commonly applied land surface models (e.g. NP etc) that incorporate empirical resistance terms based on the shallow soil moisture profile. Knowledge of vertical soil heterogeneity and $\theta(\psi)$ relationships would be 
required to make the application of these parameterization schemes warranted, though this type of data is rarely available on the watershed scale.

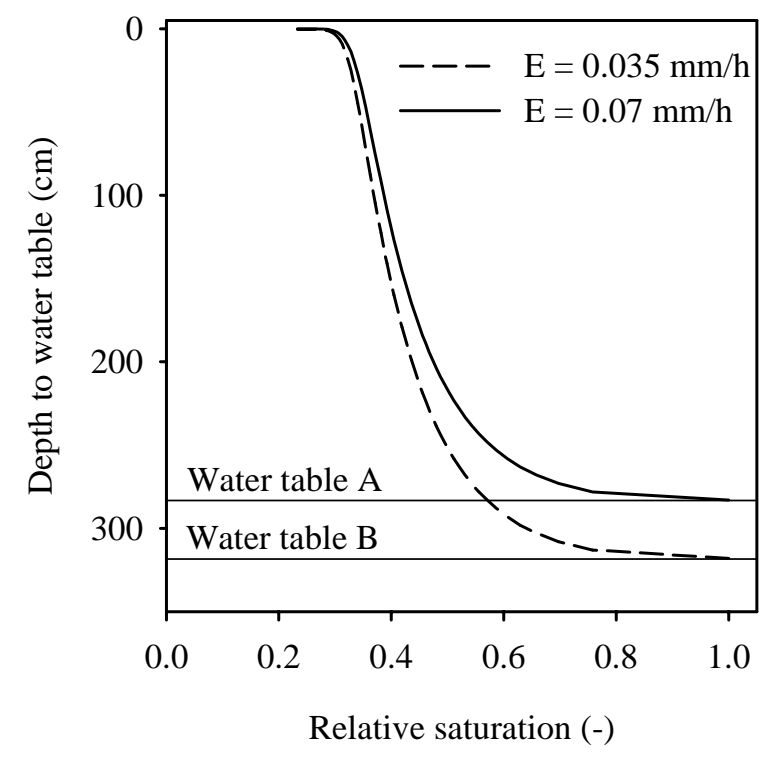

Figure 17. Depth below ground surface for two evaporation rate - water table configurations. Water table A corresponds to evaporation rate $\mathrm{E}=0.035 \mathrm{~mm} / \mathrm{h}$ and water table $\mathrm{B}$ corresponds two $\mathrm{E}=0.07 \mathrm{~mm} / \mathrm{h}$.

The above analysis might also explain the spatially random soil moisture patterns from remote sensing after long drying periods that tend to exhibit no spatial structure, because $\theta$ at the land surface is homogenized close to the residual value. This does not mean, however, that the moisture fluxes do not show spatial patterns under dry conditions, $\theta$ simply might not be the correct indicator. We suggest humidity close to the ground surface as a better indicator for the moisture state of the system, because this parameter is directly determined by the moisture fluxes at the land surface interface. 


\section{Summary and Conclusions}

In this study, simulations were performed to examine the influence of groundwater dynamics on the energy and mass balance at the land surface. ParFlow, a 3D variably saturated groundwater flow model was coupled to the Common Land Model (CLM) to simulate water and energy fluxes in the subsurface and at the land surface including saturated flow in the deeper aquifer. The coupled model, PF.CLM, was applied to the Little Washita watershed, Oklahoma, USA. Continuous atmospheric time series from the North American Regional Reanalysis data set were used to force the model uniformly in space over one entire year from September 1998 to August 1999. A dynamic equilibrium, commonly referred to as spinup, was established in which the average mass and energy balance does not change over the simulation period. The simulation results were compared to measured data from a USGS stream gauging Station, an Ameriflux tower and the Soil Climate Analysis Network. The comparison showed reasonable agreement for stream discharge, latent heat and soil moisture without calibration.

The results of this study show that components of the energy balance are sensitive to groundwater dynamics, if the groundwater level is in the range of, what we define as, the critical depth that extents 1 to $5 \mathrm{~m}$ below the ground surface. This critical depth coincides with the root zone defined in the model. Therefore, the sensitivity of the energy variables on groundwater dynamics also depends on the land cover. Although, the connection of groundwater dynamics and surface processes clearly is a function of the parameterizations in the coupled model, we believe that the connection generally exists but can be of varying strength depending on the applied model or physical conditions.

In a second step, the spatial structure and cross dependence of the energy variables and water level was analyzed. Unit semivariograms from measured soil temperature data from 
Micronet stations in the Little Washita watershed agreed well with simulated semivariograms (Figure 11), which suggest that (1) there exists spatial structure in the energy variables and (2) the model is able to realistically capture this structure.

The underlying mechanism that generates the structure is lateral subsurface flow from recharge areas along hilltops to discharge zones along the Little Washita river corridor. Directional dependence of the structure stems from the geometry of the watershed and flow direction of the Little Washita which is predominantly from west to east. Semivariograms of depth to the water level and ground heat flux suggest two spatial scales of correlation, 7 and $11 \mathrm{~km}$, which are the result of the aforementioned watershed geometry and the hillslope scale. Structure in the ground heat flux is predominantly determined by the underlying water table structure, but deteriorates during the transition from warm to cold months and vice versa. Spatial cross dependence derived from cross correlograms is significant only in the case of ground heat flux, ground surface temperature and possibly latent heat. Cross dependence exists on a scale similar to the hillslope scale, which suggests lateral subsurface flow toward the Little Washita river as the underlying mechanism.

This study calls attention to the need for co-located measurements of groundwater level, soil pressure head, soil temperature and standard atmospheric variables, which are virtually nonexistent. These co-located measurements are needed in spatially distributed fashion to identify the interconnection of groundwater dynamics and the mass and energy balance at the land surface as well as any spatial structure and cross dependence that potentially exists. This study also points to the usefulness of the applied coupled model in process identification, measurement network design and data analysis. 
A deeper analysis of shallow soil moisture using a simple analytical solution for steady evaporation reveals the limited information content of this variable about the moisture state of the system in the case of shallow groundwater. This should be taken into consideration in studies related to the interactions of the land surface and the lower atmospheric boundary layer. Additionally, the model is useful in providing realistic soil moisture initial conditions for atmospheric models that do not account for groundwater dynamics [Maxwell, et al., 2007].

\section{References}

Alley, W. M., et al. (2002), Hydrology - Flow and storage in groundwater systems, Science, 296, 1985-1990.

Ashby, S. F., and R. D. Falgout (1996), A parallel multigrid preconditioned conjugate gradient algorithm for groundwater flow simulations, Nucl Sci Eng, 124, 145-159.

Betts, A. K., et al. (1996), The land surface-atmosphere interaction: A review based on observational and global modeling perspectives, J Geophys Res-Atmos, 101, 7209-7225.

Chen, T. H., et al. (1997), Cabauw experimental results from the project for intercomparison of land-surface parameterization schemes, J Climate, 10, 1194-1215.

Chow, F. K., et al. (2006), High-resolution large-eddy simulations of flow in a steep Alpine valley. Part I: Methodology, verification, and sensitivity experiments, J Appl Meteorol Clim, 45, 63-86.

Dai, X. P., et al. (2001), The Common Land Model (CLM): Techincal documentation and user's guide.

Dai, Y. J., et al. (2003), The Common Land Model, B Am Meteorol Soc, 84, 1013-+. 
Henderson-Sellers, A., and B. Henderson-Sellers (1995), Simulating the diurnal temperature range: Results from phase 1(a) of the project for intercomparison of landsurface parameterisation schemes (PILPS), Atmos Res, 37, 19.

Holt, T. R., et al. (2006), Effect of land-atmosphere interactions on the IHOP 24-25 May 2002 convection case, Mon Weather Rev, 134, 113-133.

Jackson, J. E., et al. (1999), Soil moisture mapping at regional scale using microwave radiometry: The Southern Great Plains Hydrology Experiment, Ieee T Geosci Remote, 37, 15.

Jones, J. E., and C. S. Woodward (2001), Newton-Krylov-multigrid solvers for large-scale, highly heterogeneous, variably saturated flow problems, Adv Water Resour, 24, 763-774.

Kollet, S. J., and R. M. Maxwell (2006), Integrated surface-groundwater flow modeling: A freesurface overland flow boundary condition in a parallel groundwater flow model, Adv Water Resour, 29, 945-958.

Liang, X., et al. (2003), A new parameterization for surface and groundwater interactions and its impact on water budgets with the variable infiltration capacity (VIC) land surface model, J Geophys Res-Atmos, 108, -.

Lohmann, D., et al. (1998), The Project for Intercomparison of Land-surface Parameterization Schemes (PILPS) phase 2(c) Red-Arkansas River basin experiment: 3. Spatial and temporal analysis of water fluxes, Global Planet Change, 19, 161-179.

Manabe, S., et al. (1970), Simulated Climatology of a General Circulation Model with a Hydrologic Cycle, Mon Weather Rev, 98, 175-\&. 
Maxwell, R. M., et al. (2007), Effects of groundwater storage and surface and subsurface lateral flow on the atmospheric boundary layer in a coupled groundwater, land-surface, and mesoscale atmospheric model, Adv Water Resour, (in review).

Maxwell, R. M., and N. L. Miller (2005), Development of a coupled land surface and groundwater model, J Hydrometeorol, 6, 233-247.

NRC, N. R. C. (2004), Groundwater fluxes across interfaces, The National Academic Press, Washington, D.C., 85.

Patton, E. G., et al. (2005), The influence of idealized heterogeneity on wet and dry planetary boundary layers coupled to the land surface, J Atmos Sci, 62, 2078-2097.

Pitman, A. J., et al. (1999), Key results and implications from phase 1(c) of the Project for Intercomparison of Land-Surface Parametrization Schemes, Clim Dynam, 15, 673-684.

Qu, W. Q., et al. (1998), Sensitivity of latent heat flux from PILPS land-surface schemes to perturbations of surface air temperature, J Atmos Sci, 55, 1909-1927.

Quinn, P., et al. (1995), The Introduction of Macroscale Hydrological Complexity into Land Surface-Atmosphere Transfer Models and the Effect on Planetary Boundary-Layer Development, J Hydrol, 166, 421-444.

Schaap, M. G., and F. J. Leij (1998), Database-related accuracy and uncertainty of pedotransfer functions, Soil Sci, 163, 765-779.

Schlosser, C. A., et al. (2000), Simulations of a boreal grassland hydrology at Valdai, Russia: PILPS phase 2(D), Mon Weather Rev, 128, 301-321.

Shao, Y. P., and A. HendersonSellers (1996), Modeling soil moisture: A project for intercomparison of land surface parameterization schemes phase 2(b), J Geophys ResAtmos, 101, 7227-7250. 
Sophocleous, M., and S. P. Perkins (2000), Methodology and application of combined watershed and ground-water models in Kansas, J Hydrol, 236, 185-201.

Sophocleous, M. A., et al. (1999), Integrated numerical modeling for basin-wide water management: The case of the Rattlesnake Creek basin in south-central Kansas, J Hydrol, 214, 179-196.

Toth, J. (1963), A Theoretical Analysis of Groundwater Flow in Small Drainage Basins, $J$ Geophys Res, 68, 4795-\&.

Twine, T. E., et al. (2000), Correcting eddy-covariance flux underestimates over a grassland, Agr Forest Meteorol, 103, 279-300.

Yeh, P. J. F., and E. A. B. Eltahir (2005), Representation of water table dynamics in a land surface scheme. Part I: Model development, J Climate, 18, 1861-1880.

York, J. P., et al. (2002), Putting aquifers into atmospheric simulation models: an example from the Mill Creek Watershed, northeastern Kansas, Adv Water Resour, 25, 221-238. 


\title{
The groundwater-land-surface-atmosphere connection: soil moisture effects on the atmospheric boundary layer in fully-coupled simulations
}

Reed M. Maxwell, Fotini Katopodes Chow*, and Stefan J. Kollet

Atmospheric, Earth, and Energy Department, Lawrence Livermore National Laboratory, Livermore, California

*Department of Civil and Environmental Engineering, University of California, Berkeley, California

Submitted to Advances in Water Resources.

February 2, 2007

\begin{abstract}
This study combines a variably-saturated groundwater flow model and a mesoscale atmospheric model to examine the effects of soil moisture heterogeneity on atmospheric boundary layer processes. This parallel, integrated model can represent spatial variations in land-surface forcing driven by three-dimensional (3D) atmospheric and subsurface components. The development of atmospheric flow is studied in a series of idealized test cases with different initial soil moisture distributions generated by an offline spin-up procedure or interpolated from a coarse-resolution dataset. These test cases are performed with both the fully-coupled model (which includes 3D groundwater flow and surface water routing) and the uncoupled atmospheric model. The effects of the different soil moisture initializations and lateral subsurface and surface water flow are seen in the differences in atmospheric evolution over a 36-hour period. The fully-coupled model maintains a realistic topographically-driven soil moisture distribution, while the uncoupled atmospheric model does not. Furthermore, the coupled model shows spatial and temporal
\end{abstract}


correlations between surface and lower atmospheric variables and water table depth. These correlations are particularly strong during times when the land surface temperatures trigger shifts in wind behavior, such as during early morning surface heating,

\section{Introduction}

The characteristics of the land surface determine sensible and latent heat exchange with the atmosphere, thus affecting the evolution of the atmospheric boundary layer. Mesoscale atmospheric models currently rely on parameterized land-surface model (LSM) to provide fluxes of heat, momentum, and moisture from the land surface to the atmosphere. Land-surface models have evolved from so-called leaky-bucket parameterizations (Manabe et al. 1965) to more sophisticated parameterizations (see e.g. the review by Betts et al. 1996). Commonly-used models have been summarized and evaluated in the literature associated with inter-comparison studies (the Project for Intercomparison of Land-Surface Parameterization Schemes, e.g. Henderson-Sellers and Henderson-Sellers 1995; Shao and Henderson-Sellers 1996; Chen et al 1997; Qu et al 1998; Lohmann et al 1998; Pitman et al 1999; Schlosser et al 2000; Luo et al. 2003). While improvements have been made by tuning land-surface model parameters for a variety of test cases, LSMs are all limited to vertical transport in the soil column. They are thus unable to capture topographically-driven lateral variations in soil moisture and limited in their ability to provide spatial variability in predicted land surface fluxes. Current mesoscale atmospheric models are therefore not provided with realistic boundary conditions at the surface because LSMs cannot represent surface and subsurface lateral transport due to topography or moisture gradients. This can lead to errors in model predictions during periods when thermal forcing dominates the diurnal development of the boundary layer (see e.g. Chow et al. 2006a). 
The focus of this work is to understand the influence of soil moisture variability on atmospheric boundary layer forcing. This requires the development of a three-dimensional, fullycoupled groundwater-atmospheric flow model, as described in this paper.

Soil moisture and ground surface temperature variability effects on the atmospheric boundary layer have been shown through several previous studies both in idealized and realistic cases. Ookouchi et al. (1984) and Banta and Gannon (1995) showed that changes in soil moisture affect thermally-forced winds on a sloped surface, because the soil wetness determines land surface thermal conductivity and hence surface heat fluxes. Patton et al (2005) used idealized striped wet-dry soil moisture patterns to show that the development of convective cells in the atmospheric boundary layer directly relate to the wet-dry soil patterns. The influence of the land surface on the boundary layer extends further than the development of convection cells, because these then influence the development of clouds and precipitation. Indeed, Chen and Avissar (1994) showed that a soil moisture discontinuity affects wind, cloud and precipitation dynamics in a two-dimensional idealized domain. Clark et al. (2004) used a three-dimensional model to demonstrate that rainfall locations and intensities are affected by the locations and size of a wet soil patch and that these interactions may persist on scales as small as $10-15 \mathrm{~km}$.

Real case studies also indicate the extent of the influence of soil moisture variability on the atmosphere. Taylor et al. (1997) used observational data to study land-atmosphere interactions in semiarid conditions. They provide evidence that boundary layer variability is linked to antecedent rainfall and suggest that soil moisture patterns play a role in rainfall locations. Such observational evidence has led to modeling studies which attempt to improve representation of soil moisture processes. The effect of improved soil moisture data and landsurface parameterizations in simulations of conditions during the Southern Great Plains 
experiment in July 1997 was examined by Desai et al. (2005), who showed mixed results on the extent of the influence of soil moisture changes on dry sunny days. Chow et al. (2006a) found that soil moisture initialization was a crucial factor in accurate simulations of thermally-forced valley wind systems in the Swiss Alps using the ARPS (Advanced Regional Prediction System) mesoscale model. An off-line hydrologic model was used to more accurately represent spatial variability of soil moisture in the valley, significantly improving prediction of wind transitions in the valley. Holt et al. (2006) investigated the effects on weather prediction of different initial soil moisture distributions and land surface parameterizations over the IHOP domain. They found that both the different soil moisture initializations and different land parameterizations significantly altered the forecasts.

As LSMs have traditionally ignored the deeper soil moisture processes and the saturated zone (i.e. groundwater), there has been recent interest in incorporating a groundwater component into LSMs to improve the representation of soil moisture at the land surface. Liang et al. (2003) and Yeh and Eltihir (2005) incorporated groundwater processes into a land surface model at larger scales and demonstrated feedbacks on the land surface. Maxwell and Miller (2005) coupled a variably saturated groundwater model to a land surface model and showed the importance of including an explicit representation of the water table on shallow soil moisture distribution.

There has also been work to examine the coupling between the deeper subsurface and the atmosphere. Quinn et al. (1995) coupled the simplified, single-column SLAB boundary layer model to the TOPMODEL land-surface model to investigate the role of groundwater on boundary layer development. They studied wet and dry conditions and identified cases where increased physical complexity of the subsurface is warranted. York et al. (2002) studied the 
effects of a single-column atmospheric model connected to a single layer groundwater model through a reservoir-type land surface scheme. They focused on a small watershed in Kansas and found an effect of water levels on surface evapotranspiration. These studies all point to the need for better understanding of physical processes that occur at the interfaces between the deeper subsurface and land surface, and between the land surface and the atmosphere. LSMs are the current numerical mechanism which represents the latter. While LSMs have grown in sophistication, until this current study lateral flow (subsurface and overland) has not been explicitly accounted for.

The full effects of lateral surface and sub-surface flow and, consequently, land-surface properties on the development of the atmospheric boundary layer remain unknown. Open questions remain regarding the effect to which land-surface heterogeneity is reflected in atmospheric heterogeneity, the time and spatial scales over which the effect of soil moisture variations persist in the atmosphere, and how best to represent these processes for numerical simulations of atmospheric flow and transport over a watershed, and eventually over a larger region.

This paper describes the development and application of a dynamically coupled, variablysaturated groundwater, overland-flow, mesoscale atmospheric model (see also Chow et al. 2006b). This model is used to study the effects of soil moisture heterogeneity and water table depth on boundary layer processes. In particular, we have coupled ParFlow, a three-dimensional, parallel, variably saturated groundwater flow model (Ashby and Falgout 1996; Jones and Woodward 2001), with the Advanced Regional Prediction System (ARPS) mesoscale atmospheric model (Xue et al. 2000, 2001, 2003). ParFlow includes an integrated overland flow component (Kollet and Maxwell, 2006), and thus provides ARPS with soil moisture information 
that includes the effects of ponding, runoff, and subsurface flow, including an explicitly-resolved water table. In turn, ARPS, through its land-surface model, provides ParFlow with precipitation and evapotranspiration rates, usually not available in groundwater studies. This leads to a fullycoupled model which can represent spatial variations in land-surface processes and feedbacks, driven by physical processes in the atmosphere and the subsurface.

Our test case is the Little Washita watershed in Oklahoma, which has been the subject of numerous studies and provides a unique source of shallow subsurface, surface, and atmospheric data for validation (e.g. Jackson et al. 1999; Vine et al. 2001; Guha et al. 2003). We use this domain to conduct a series of idealized simulations with quiescent initial winds and no lateral forcing to effectively isolate land-surface forcing from other influences on the development of the boundary layer. These simulations are performed with two different soil moisture initializations based on model spin-up and interpolation of regional datasets. While this paper focuses on idealized simulations, the Little Washita test case was chosen for future fully-coupled studies where synoptic forcing and grid nesting will be incorporated.

\section{Model components and coupling}

We begin with a description of the individual model components for the atmospheric boundary layer, the land surface, and the subsurface and then describe the fully-coupled model.

\section{a. Atmospheric model: ARPS}

ARPS was developed at the Center for Analysis and Prediction of Storms at the University of Oklahoma, and is formulated as a parallel, large-eddy simulation (LES) code that solves the three-dimensional, compressible, non-hydrostatic, spatially-filtered Navier-Stokes equations. ARPS was developed for storm-scale atmospheric simulations and has been extensively tested in 
idealized and field applications (Xue et al. 2000, 2001, 2003). ARPS uses fourth-order spatial differencing for the advection terms and second-order schemes for other forcing terms. Temporal discretization is performed using a mode-splitting technique to accommodate high-frequency acoustic waves. The large time steps use the leapfrog method; first-order forward-backward explicit time stepping is used for the small time steps, except for terms responsible for vertical acoustic propagation, which are treated semi-implicitly. For this study solid wall lateral boundary conditions and zero-wind initial conditions are used to isolate the effects of the land-surface on boundary layer development. Initial conditions are provided from NOAA North American Regional Reanalysis (NARR) data as described further below. Full physics parameterizations (e.g. radiation and moisture processes) and land-surface schemes are used as would be done for simulations with realistic synoptic forcing.

The standard (uncoupled) land-surface soil-vegetation model used by ARPS solves energy and moisture budget equations in shallow, two-layer soil columns, as described in detail in Xue et al. (2001) and Ren and Xue (2004). The total soil column extends $1 \mathrm{~m}$ below the land surface, and is divided into a $1 \mathrm{~cm}$ thick surface layer and a $99 \mathrm{~cm}$ thick deep soil layer. Energy and moisture budgets are computed using a force-restore model to allow for vertical transport in each column. One soil column is used for each horizontal grid cell but these columns do not communicate and hence do not allow for surface or subsurface lateral transport. A separate canopy layer is used to account for interception of precipitation and transpiration processes. Clapp and Hornberger (1978) pedotransfer functions are used to describe the variation of soil moisture with pressure. Excess precipitation when the soil is fully saturated is ignored and does not contribute to surface runoff. 
ARPS uses 13 soil types (including water and ice), and 14 vegetation classes (following the United States Department of Agriculture classifications). Land use, vegetation, and soil type data are obtained from United States Geological Survey (USGS) STATSGO 30 second global data. Elevation data obtained from the USGS are given at 3 arc second intervals and sampled at 1 $\mathrm{km}$ resolution. Initial soil temperature is set equal to the air temperature in the first adjacent grid cell at the surface. Initial soil moisture is obtained either from the NARR data set at $32 \mathrm{~km}$ resolution or from an offline spinup process explained in Section 4.2.

\section{b. 3D variably saturated groundwater model: ParFlow}

ParFlow is a parallel, variably saturated groundwater flow model, and is described in detail by Ashby and Falgout (1996) and Jones and Woodward (2001). In the mode employed here, it solves the Richards equation in three dimensions using a parallel, globalized Newton method. ParFlow has been modified to optionally include the Common Land Model (CLM) (Dai et al. 2003), as described in Maxwell and Miller (2005), as well as an integrated overland flow module (Kollet and Maxwell 2006), which solves the kinematic wave equation. Thus ParFlow has the unique capability to explicitly resolve streamflow without the use of parameterized river routing subroutines. For the groundwater flow solution, ParFlow employs an implicit backward Euler scheme in time, and a cell-centered finite-difference scheme in space. At the cell interfaces, the harmonic averages of the saturated hydraulic conductivities and a one-point upstream weighting of the relative permeabilities are used. For the overland flow component, ParFlow uses an upwind finite-volume scheme in space and an implicit backward Euler scheme in time. ParFlow requires specification of subsurface hydraulic properties, such as the saturated hydraulic conductivity $\mathrm{K}_{\text {sat, }}$, porosity, $\varphi$, and the van Genuchten parameters for the pressuresaturation relationships. 


\section{d. Coupling approach: PF. ARPS}

The fully-coupled simulations require the simultaneous solution of the $3 \mathrm{D}$ groundwater flow equations (provided by ParFlow) and the 3D atmospheric flow equations (provided by ARPS). The original ARPS land surface model constitutes the interface between ParFlow and ARPS to pass surface moisture fluxes between the two models. This approach is shown in Figure 1. The coupling has been performed by integrating ARPS as a subroutine into ParFlow and creating a numerical overlay of the two soil layers of the land surface model in ARPS with the two soil layers at the land surface in ParFlow. The general solution procedure begins with the explicit advancement of ARPS. An operator-splitting approach is employed allowing the ParFlow model to honor the ARPS internal timestep (1 second for this application), or to take larger timesteps, such as $1 \mathrm{~h}$. Using the operator-splitting approach, surface fluxes that are relevant to ParFlow, such as infiltration and evaporation rates are integrated within ARPS over the entire ParFlow timestep (e.g. 1 hour) and used to provide surface fluxes at the new time for implicit time advancement of ParFlow. For the simulations presented here both atmospheric and subsurface timesteps are set to $1 \mathrm{~s}$ (and both the large and small ARPS timesteps are set to $1 \mathrm{~s}$ ). The subsurface moisture field calculated by ParFlow is passed directly to the land-surface model within ARPS and is used by the land surface model in ARPS in the next time step. The landsurface model is advanced for each internal ARPS time step to provide all the surface fluxes, but the soil moisture values are now specified by ParFlow.

\section{Model domain and setup}

\subsection{Little Washita watershed domain and grid}


The Little Washita watershed is located in central Oklahoma and has been the focus of several studies (e.g. Jackson et al. 1999; LeVine et al. 2001; Guha et al. 2003), with the result that it is the source of an extensive observational dataset. Figure 2 shows a map of the watershed. The soil and vegetation cover, shown in Figure 3, is predominately grass with shrubs and trees interspersed, underlain by mostly loamy sand, sand, and smaller coverage of sand and silt loam. A resolution of $1 \mathrm{~km}$ is used to represent the watershed area using a grid of $45 \times 32$ in the horizontal. ARPS uses 50 grid points in the vertical, with $40 \mathrm{~m}$ spacing near the ground and stretched above to give an average spacing of $400 \mathrm{~m}$ over the $20 \mathrm{~km}$ domain height. ParFlow uses 390 grid points in the vertical with $0.5 \mathrm{~m}$ resolution for a subsurface depth of $195 \mathrm{~m}$. We focus on the time period from the Southern Great Plains 1999 experiment (SGP99; LeVine et al. 2001; Guha et al 2003) from 7 am CST on July 9, 1999 to 7 pm CST on July 10, 1999.

\subsection{Surface-subsurface input data}

The land surface constitutes the upper boundary of the groundwater flow model and is obtained from a processed digital elevation model. The maximum depth of the aquifer below the subsurface is approximately $195 \mathrm{~m}$, with a no-flow boundary condition at the bottom of the computational domain. This results in a variable numbers of grid points in the subsurface. The maximum depth value was chosen from borehole information and results from other studies in the region (e.g. Davis 1955) and facilitates modeling of deep groundwater flow. The large depth of the model domain also ensures that the lower boundary condition does not influence the results at the land surface. The hydraulic properties of the deeper subsurface are average values derived from approximately 200 borehole logs collected in the region. The regionally uniform porosity value of $\varphi=0.4[-]$ corresponds to the arithmetic average of the borehole data. The 
average value of $\mathrm{K}_{\mathrm{sat}}$ was set to be $10 \mathrm{~m}$ /day initially, but was adjusted during spin-up to better match the measured hydrographs along the Little Washita River. The adjusted value is $\mathrm{K}_{\mathrm{s}}=5$ $\mathrm{m} /$ day, which is about a factor of five larger than the arithmetic mean from the borehole information. This discrepancy can be explained by the quite limited and uncertain information obtained from the borehole logs and the smoothed topography at $1 \mathrm{~km}$ resolution, which results in generally smoother water table relief and thus smaller pressure gradients.

The top two 0.5-m thick layers in ParFlow extending to $1 \mathrm{~m}$ depth below the ground surface are considered topsoil. The soil information was derived from the soil cover categories used by ARPS (as shown in Figure 3) and matched to the van Genuchten parameters for each corresponding soil type using the data and analysis in Schaap and Leij (1998). Topographic slopes were derived from the digital elevation model after filling sinks (areas of local convergence in the topography) by locally smoothing the topography. In this study, the Manning's coefficient used in the overland flow module is applied uniformly in space, though it can also be distributed to reflect non-uniform surface roughness. The van Genuchten parameters specified in the deeper subsurface correspond to a sandy loam, which we consider representative for the watershed.

\section{Test Cases}

\subsection{Configuration of test cases}

Idealized simulations of the Little Washita watershed are used to study the sensitivity of the evolution of the atmospheric boundary layer to spatial variations in soil moisture and water table depth. While the actual watershed topography and soil and vegetation types are incorporated, we initialize the simulations with zero winds and use solid wall lateral boundary 
conditions to isolate the effects of the land surface forcing. Initial potential temperature and humidity are specified with sounding observation data from nearby Norman, OK at 7 am on July 9,1999 . Boundary layer development is driven by the diurnal variations in incoming solar radiation and the consequent land surface fluxes. Three different idealized cases with different soil moisture initializations are performed.

1. First, the stand-alone ARPS model is used with soil moisture interpolated from the NARR dataset; Case 1- referred to as ARPS(narr) for ARPS using NARR soil moisture initialization.

2. Second, the fully-coupled PF.ARPS model is run with the initial soil moisture derived from the offline spin-up procedure described below; Case 2- referred to as PF.ARPS.

3. Finally, to distinguish between the effects of soil moisture initialization and soil moisture evolution, the stand-alone ARPS model is run using the same initial soil moisture provided in Case 2 but without any dynamic coupling to ParFlow; Case 3- referred to as ARPS(os), for ARPS-Offline Soil moisture initialization.

Note that Cases 2 and 3 have identical initial soil moisture, Cases 1 and 3 are identical models, and that all cases have identical initial soil temperature distributions. The offline spinup used in Case 2 and 3 is explained in more detail in the following section.

\subsection{Offline spin-up}

An offline, model spin-up is used to generate realistic initial soil moisture distributions for use in test cases 2 and 3 described above. Spin-up is defined as the dynamic equilibrium of the mass and energy balance over a certain time period over which a time series of atmospheric data is used to repeatedly force the model. To generate the offline spin-up data for initialization, 
ParFlow is run coupled with the more advanced land surface model CLM (Dai et al, 2003) driven by atmospheric forcing provided by the NARR reanalysis dataset. The forcing data are for the 1998-1999 water year and include wind speed and direction, surface air temperature, incoming radiation, precipitation, pressure and humidity. This configuration is used for spin-up (rather than using ParFlow with the ARPS land surface model) to more accurately represent thermal, snow and biogeophysical processes in a more sophisticated way (Noilhan and Planton, 1989; Dai et al, 2003). Though no comprehensive calibration process is used, good comparisons with observed time series of streamflow, soil moisture and land energy balance were obtained after repeated application of this meteorological forcing from September 1998 to October 1999 (not shown, Kollet and Maxwell, 2007). As mentioned above, both the Case 2, the fully-coupled PF.ARPS, and Case 3, the uncoupled ARPS(os) simulations, are initialized by the soil moisture fields from July 9, 1999 provided by this spin-up processes. This offline model used for spin-up incorporates more and better process descriptions in contrast to other methods that might calibrate, or tune, land surface parameters, or assimilate land surface data.

\subsection{Test case comparisons}

Figure 4 shows the soil moisture fields from PF.ARPS, ARPS(os) and ARPS(narr) at 12 hour intervals over the simulation period. The PF.ARPS and ARPS(os) soil moisture fields show the distinct signature of the Little Washita River, with wetter conditions along the river corridor and drier conditions in the uplands. This is due to the convergence of deeper groundwater water flow at discharge zones that are the Little Washita River valley and its tributaries during the offline spin-up processes. Additional variability is a result of the influence of the distributed soil and vegetation cover (as shown in Figure 3), which is, however, less pronounced than the impact 
of groundwater dynamics. In contrast, the soil moisture field from the uncoupled ARPS(narr) run shows small spatial variability, due to the use of interpolated coarse-resolution soil moisture data from NARR. Because of the land-surface parameterization in ARPS, the soil moisture values at a given grid cell can only be affected by shallow soil properties at that $\mathrm{x}, \mathrm{y}$ location, the land cover, soil type, and the atmospheric conditions. Thus the patterns of variability in soil moisture in the ARPS(narr) simulation track closely the variations in soil type and to a lesser extent the variation in vegetation type, as seen by comparing Figure 3 and the last column in Figure 4 . The ARPS land surface model is not able to account for topographically-induced lateral groundwater flow and, thus, cannot develop spatial patterns like those from PF.ARPS; the soil moisture field in ARPS(narr) tends to dry out uniformly over the simulation period until isolated precipitation events develop after about 24 hours of simulation (discussed further below).

Even though the PF.ARPS and ARPS(os) models are initialized with the same soil moisture distribution (shown at time zero, in the top panels of Figure 4), the soil moisture in these models begins to show differences as early as 12 hours of simulation time (second panel). These differences are most notable in the upper river valley (west and center part of the domain), in the headwaters $(\mathrm{x}=0-15 \mathrm{~km}, \mathrm{y}=15-25 \mathrm{~km})$, and along the hilltops. This is due, as pointed out above, to the inability of the soil model in ARPS to account for groundwater storage, lateral flow and surface water routing. Over the first 12 hours of simulation time the PF.ARPS model maintains the wet conditions in the river valley by a combination of groundwater storage below the root zone (non-existent in ARPS) and lateral redistribution of water due to topographically driven subsurface flow. These effects are more pronounced later in the simulation $(12 \mathrm{~h}$ and $24 \mathrm{~h}$, bottom two panels in Figure 4) after rainfall occurs. With no processes to maintain topographic surface and subsurface flow, the rainfall (see Figure 8 later) begins to significantly change the 
initial soil moisture distribution, particularly in the ARPS(os), but also the ARPS(narr) case, unlike the PF.ARPS case, which routes rainfall over the surface and in the subsurface. This is seen by the distinct circular patterns of soil moisture for the ARPS(narr) and ARPS(os) simulations in the bottom panel of Figure 4, directly due to the areas of convective rainfall (shown in Figure 8, below).

Figures 5, 6 and 7 plot the soil temperature, latent heat flux and potential temperature (respectively) for the three models for a time series covering early morning on the second simulation day, $\mathrm{t}=24,26$ and $27 \mathrm{~h}$ ( $7 \mathrm{am}, 9 \mathrm{am}$ and $10 \mathrm{am}$ local time). This time series was chosen because it corresponds to early morning land heating which drives convection. Soil moisture has been shown to play an important role in thermally-forced flows (see e.g. Patton et al. 2005, Chow et al. 2006a). Figure 5 shows that the soil temperature for PF.ARPS and ARPS(os) is quite different than that of the ARPS(narr) case. The soil temperatures exhibit patterns similar to the soil moisture, showing temperature variations between the river valleys and hill tops. For $\mathrm{t}=26$ and $27 \mathrm{~h}$, cooler temperatures are predicted in the wetter river valleys and warmer temperatures on the drier hill tops. At time $t=24 \mathrm{~h}$, the opposite is true, with warmer temperatures in the river valleys and colder temperatures on the hill tops. The temperature plots show more influence of soil and vegetation cover than the soil moisture profiles. The ARPS(narr) case, again, only shows variation in temperature due to variations in soil and vegetation cover with some slight variations in incoming radiation due to local surface slope changes.

The soil temperatures for PF.ARPS and ARPS(os) in Figure 5 show some minor differences, despite the more significant differences in surface soil moisture shown in Figure 4. The soil temperature determined by the ARPS land surface model comes directly from the 
formulation of Noilhan and Planton (1989). In this formulation the surface soil temperature depends on soil moisture from the second, or deeper, soil layer (Noilhan and Planton, 1989; see their Eq. 10), not the upper soil moisture used in other formulations (see e.g. Dai et al, 2003). Soil and vegetation cover are also a factor (see Eq. 8 and Table 2 in Noilhan and Planton, 1989) but as these parameters are the same in all simulations and the deeper soil layer responds more slowly than the upper soil layer, the soil temperatures between PF.ARPS and ARPS(os) are quite similar. The limitations of this aspect of the Noilhan and Planton (1989) approach have been previously discussed by Pleim and Xiu (1995; see their Section 2a) and requires further investigation.

Figure 6 plots the latent heat flux for the three model runs, showing patterns of both soil and vegetation type and soil moisture. While most of the domain is grasslands over loamy sand, a line of open shrub and croplands over loam along the river valley, and an area of crop and shrublands over silt loam in the headwaters area of the watershed are particularly visible. Even though vegetation and soil cover play a large role, soil moisture is a significant moderator of latent heat as demonstrated by the different results from the three simulations. The latent heat flux for the ARPS(narr) simulation is significantly different than for PF.ARPS and ARPS(os). The PF.ARPS and ARPS(os) simulations also show local differences in energy fluxes up to $25 \%$. These differences correspond to both the aforementioned areas of different vegetation cover and soil moisture differences seen in Figure 4. The bare ground evaporation and vegetation transpiration formulations used to determine the latent heat flux in ARPS are described by Noilhan and Planton (1989) and Noilhan and Mahfouf (1996). Soil moisture moderates both processes. Both relationships assume that soil moisture values greater than field capacity (taken as a fraction of saturation which is a function of soil type) present no resistance to evaporation 
and transpiration, making the latent heat flux less sensitive in wetter regions. Below field capacity, bare soil evaporation depends upon a sinusoidal relationship to soil moisture, whereas plant transpiration depends linearly on soil moisture. Bare soil evaporation has been shown to be sensitive to the formulation used (e.g. Kondo et al. 1990; Mahfouf and Noilhan, 1991). The role of subsurface water in evapotranspiration will be discussed further below.

Figure 7 plots the potential temperature at the first grid point above the ground for the three simulations. Again, the largest differences are between the ARPS(narr) case and the two cases initialized with the soil moisture fields from the offline spin-up. While the ARPS(narr) case starts with a topographically-influenced potential temperature, this evolves to reflect only the variation in the soil and vegetation cover. The potential temperature for the ARPS(narr) simulation is generally higher than the ARPS(os) and PF.ARPS cases. The PF.ARPS and ARPS(os) cases are similar overall, but the PF.ARPS case shows cooler potential temperatures in a number of locations, reflecting the influence of variations in soil moisture distribution. These changes in the near-surface air temperature demonstrate the direct forcing of the land surface on the atmosphere and will drive different convective processes, as described below.

Figure 8 shows the hourly rainfall distribution for the three cases, PF.ARPS (left), ARPS(os) (center) and ARPS(narr) (right) for two times (33 and 34h) late in the simulation. With no lateral forcing, the rainfall is generated convectively in all three cases and its location and intensity show little agreement between the three cases. The differences in potential temperature shown in Figure 7 trigger convective motions that develop into variable rainfall patterns, demonstrating the sensitivity of the atmosphere to land-surface forcing under calm conditions. The rainfall patterns are particularly strongly reflected in the soil moisture distribution for ARPS(os) and ARPS(narr) at $36 \mathrm{hr}$ as shown previously in the last row of Figure 
4. The influence of soil moisture on rainfall was recently studied by Clark et al. (2004), who correlated increased surface soil moisture resulting from antecedent rainfall to specific patterns of rainfall from subsequent frontal storms. While the current study involves a more complicated system than the idealized study of Clark et al. (2004), there may be some similarities between the observed precipitation processes. Figure 8 suggests that rainfall patterns for the PF.ARPS case, with precipitation occurring along the margins of the wet river valleys, might well be influenced by preceding soil moisture patterns. Additional work is needed to examine the mechanisms of these land-atmosphere feedbacks on rainfall, which is beyond the scope of this study.

Summarizing the evolution of soil moisture for the different cases, Figure 9 plots time series of the spatially-averaged surface soil moisture for the three model simulations. PF.ARPS and ARPS(os) start with the same spatial soil moisture distribution, while the ARPS(narr) model is initialized with the drier upper soil layer from NARR data. The ARPS(os) upper soil moisture dries out quite rapidly and is almost in agreement with the ARPS(narr) simulation by 36 hours. The PF.ARPS soil moisture also dries out slightly over the simulation period, but maintains a much wetter upper soil moisture than the ARPS(os) simulation. This further underscores the additional processes present in the fully-coupled PF.ARPS model and how lateral flow and groundwater storage help to maintain a much wetter soil profile.

\subsection{PF.ARPS correlations and analysis}

The fully-coupled PF.ARPS simulations provide a unique opportunity to evaluate effects of deep subsurface processes on atmospheric boundary layer development. Because the land surface formulation in ARPS includes separate dependence on each shallow soil layers (surface and deep), land heat fluxes depend more strongly on the water table depth than on either the 
upper or lower soil moisture alone. As mentioned previously, land surface temperature, for example, depends only on the deeper soil moisture (a limitation noted by Pleim and Xiu, 1995) while bare soil evaporation is a function of upper soil moisture. In the coupled model, PF.ARPS, the soil moisture is modeled as a coherent system from land surface to bedrock, directly accounting for water table storage and lateral flow. This allows correlations between water table and land surface functions to be fully realized in the coupled model.

To investigate the effect of the groundwater component on land surface and atmospheric processes, scatter plots are generated between water table depth (as distance below the land surface) and various surface and subsurface variables. These are either taken at a point in time or averaged over the entire PF.ARPS simulation. Figure 10 plots four such comparisons, for a) surface soil temperature, b) potential temperature, c) boundary layer depth, and d) the vertical wind speed at the surface as a function of water table depth for simulation times $24 \mathrm{~h}$ (top), $26 \mathrm{~h}$ (middle) and $27 \mathrm{~h}$ (bottom) for all surface points in the domain. These plots represent the influence of water table depth on land-surface and atmospheric processes.

At $24 \mathrm{~h}$, there is a negative correlation in surface soil temperature to water table depth with two patterns present, one for water table depths less than one meter and the other for water table depths greater than one meter. The ground surface temperatures corresponding to water table depths of less than one meter are in general warmer than the ground surface temperatures corresponding to water table depths greater than one meter, though there is significant scatter in the relationship. There is a weak trend in increasing surface air (potential) temperature with increasing water table depth, though with significant scatter. There is also a weak correlation between boundary layer depth and water table depth, and we see a weak negative correlation between the vertical wind component at the bottom atmospheric cell, w, and water table depth. 
As the land surface temperature increases during sunrise (times 26 and 27h), we see a reversal in correlation between upper soil temperature and water table depth, with soil temperature increasing with increasing water table depth. The potential temperature correlation with water table depth strengthens over these times as well, with less scatter apparent at 27 hours than at 24 hours of simulation time. The entire boundary layer becomes deeper and exhibits a stronger correlation to water table depth. The vertical velocity component also changes its correlation to water table depth, shifting to a positive correlation at 27 hours of simulation time to increasing water table depth, with mostly downward velocities at very shallow and upward velocities at deeper water table depth values. This corresponds to the onset of convection with downward velocities in the cooler river valleys and upward velocities at the warmer hill tops. The timing of this shift in convective behavior can be important in some systems, particularly thermally-forced slope flows. Modeling such wind transitions has been shown to be sensitive to soil moisture distribution (see e.g. Chow et al 2006a, Daniels et al 2006).

Figure 11 shows latent heat flux, averaged in time over the simulation, as a function of water table depth for a range of soil types and vegetation cover. Time averages over the duration of the simulation indicate the influence of water table depth with the shorter-term variability in other processes removed (e.g. solar forcing), thus showing which land-surface and atmospheric parameters might be correlated with water table depth over longer timescales. We see a relationship between latent heat flux and water table depth for some soil and vegetation types. The correlations between water table depth and latent heat flux are strongest for loamy sand (top middle panel). There are greater latent heat fluxes from areas in the domain with shallower water table depths and lower latent heat fluxes from areas with deeper water table depths. This corresponds to lower latent heat fluxes from the drier hill tops and greater latent heat fluxes from 
the wetter river valleys. We also see a negative correlation of latent heat flux with water table depth for open shrublands over loam, for trees over silt loam, and for sand, though there are only two locations in the domain where sand corresponds to a water table depth of less than one meter. For silt loam covered by grass or by open shrublands there is a weak correlation of latent heat flux with water table depth. This is also true for loam covered by grasslands. These relationships reflect the fact that many parameters that influence heat flux (soil moisture retention parameters, saturated hydraulic conductivity, and vegetation parameters) are all a function of soil type and vegetation cover. Figure 11 illustrates that while correlations are present between latent heat flux and water table depth, they also vary with soil type and land cover. The variations that water table depth imparts on latent heat flux, are as large as those imparted by variations in soil type and land cover. This is demonstrated by the range of heat flux variation with water table depth, on the order of $100 \mathrm{~W} / \mathrm{m}^{2}$ for loamy sand, being as great as or greater than the difference in heat fluxes observed between grasslands and trees. This provides strong motivation to include not only soil vegetation type but also water table influences in landsurface models for use with mesoscale atmospheric models.

Figures 12 a shows the potential temperature, averaged in time over the simulation, as a function of water table depth, demonstrating a positive correlation between potential temperature and water table depth over all soil and land cover types, similar to that seen for times $\mathrm{t}=24,26$, and $27 \mathrm{~h}$ in Figure 10. Figure $12 \mathrm{~b}$ shows potential temperature as a function of water table depth for loamy sand (all vegetation types) and loam covered by open shrublands, the two categories with the strongest correlation between latent heat flux and water table depth shown in Figure 11. We see that these two soil and land cover types account for some of the scatter in Figure 12a. This figure suggests that potential temperature is not only correlated to water table depth at 
instances in time (e.g. Figure 10) but that longer-term correlations may persist. Additionally, though there appears to be an influence of soil and land cover type on potential temperature, this influence is smaller than the influence of water table depth, again pointing to the need to include the effect of water table depth in land-surface models.

\section{Summary and Conclusions}

This paper presents the methodology for a fully-coupled, parallel, groundwater, overland flow, land-surface, and atmospheric model. Our fully-coupled model incorporates threedimensional subsurface flow and surface water routing into a mesoscale atmospheric flow model to better represent spatial variations in soil moisture. Results from the coupled model are compared to those from an uncoupled atmospheric model using a realistic test case with idealized boundary conditions. These results indicate the potential to improve predictions of boundary layer processes by incorporating physical processes at the land surface and below. We have demonstrated the sensitivity of thermally-forced boundary layer development to surface moisture and temperature conditions and our ability to more realistically represent the spatial variability in surface forcing using our coupled modeling approach.

A realistic initial spatial distribution of soil moisture can be generated using an offline spinup procedure to incorporate subsurface and surface processes forced by atmospheric data over a water year. The results can be used to provide improved initial conditions to mesoscale meteorological models. Other researchers (e.g. Holt et al, 2006) have shown this in an assimilation framework, it is shown here with improved surface-subsurface processes.

The initial distribution of soil moisture has a strong effect on the development of the atmospheric boundary layer under calm conditions. If lateral flow is not accounted for, this soil 
moisture distribution can decay during a 36-hour period, a time period shorter than many weather forecast periods. Lateral surface and subsurface flow is important to maintain topographically-induced drainage and soil moisture patterns over short (hour) timescales, as shown by comparisons between PF.ARPS and ARPS(os) runs in Figures 4-9 and can affect potential temperature and wind direction and speed over these timescales.

The interplay between soil and land cover and surface and subsurface moisture transport is quite complex and appears to be highly dependent on the particular formulations used in the land surface parameterization and deserve further examination and validation.

Correlations exist between water table depth and ground surface temperature, potential temperature in the first atmospheric cell above the land surface, and transient boundary layer development. Correlations are particularly strong during warm/cold transitions when surface heating determines boundary layer growth.

The coupled model shows correlation between water table depth and latent heat flux and potential temperature averaged over the simulation time of $36 \mathrm{~h}$. This suggests that these correlations may also persist over longer timescales.

The correlations between water table depth and land surface and atmospheric processes shown in Figure 11 explain much of the sensitivities that other researchers have seen (e.g. Chow et al 2006a; Holt et al 2006). The absence of these correlations under varying conditions (at different times or depending upon land and soil cover) also explains cases in which other studies have seen less sensitivity of boundary layer processes to land surface conditions (e.g. Desai et al 2005). The correlations shown in this work between water table and surface and boundary layer processes are testable in the field using collocated measurements of subsurface and atmospheric properties and parameters, which are currently lacking. This work and follow-up work of this 
kind should guide field experiments and campaigns to understand whether these correlations are seen in nature which will lead to further understanding of interactions of the subsurface and the atmosphere.

The largest differences in the idealized sensitivity simulations were between the ARPS(narr) stand-alone and the PF.ARPS simulations, clearly showing the inadequacy of typical land surface models in representing spatial variability at the land surface due to topographic variations. The PF.ARPS and ARPS(os) results did not deviate greatly, but still showed different rainfall patterns. The ARPS(os) results indicate that ARPS could be used in stand-alone mode if initialized with offline spin-up data to provide realistic spatially distributed soil moisture; ARPS could then be run over a short simulation period such as 24 hours, allowing a more practical application scenario for forecast-like simulations where lateral subsurface transport may not be as important as the soil moisture initialization. For longer-term simulations, the fully $3 \mathrm{D}$ coupled subsurface and atmospheric model is needed to fully incorporate the feedbacks between the atmospheric boundary layer and the subsurface. Examples of simulations requiring full coupling include seasonal simulations for regional climate prediction. Fully-coupled runs may also be useful for flood forecasting and in other cases where surface water routing and immediate feedbacks to the atmosphere are critical (see e.g. Sturdevant-Rees et al 2001, Castillo et al. 2003).

The additional computational costs for PF.ARPS are 3-50\% greater than for ARPS alone (depending upon the size of the subsurface and the timestep operator splitting); given the potential improvements of the improved land-surface feedback, this cost is warranted. Furthermore, as our approach is fully parallel, the additional computational costs may be offset through the use of larger parallel systems. 
Our coupled modeling approach is general, allowing for physically-accurate representation of subsurface, land-surface, and atmospheric processes; no previous atmosphericland-surface model combination is able to capture all of these processes. Because the fullycoupled model, PF.ARPS, is initialized using an offline spin-up process with atmospheric forcing data, calibration or tuning requirements are minimized. This demonstration study was performed with idealized boundary conditions to isolate the effects of the land surface on the atmosphere. Future work will apply PF.ARPS to larger domains with synoptic lateral forcing where the effects of soil moisture on model comparisons to observation data may be studied. Higher-resolution simulations will also be pursued to investigate the effect of topography representation for surface water routing in the watershed. Additionally, PF.ARPS can be used to study the effect of land-surface processes on regional climate predictions on seasonal time scales. Incorporation of lateral moisture transport through subsurface flow may be of even greater importance on these larger space and time scales.

\section{Acknowledgements}

This work was conducted under the auspices of the U. S. Department of Energy by the University of California, Lawrence Livermore National Laboratory (LLNL) under contract W7405-Eng and was supported by the LLNL Laboratory Directed Research and Development Program at LLNL. We are grateful for the efforts of Q. Duan and P. Granvold in support of this project.

\section{References}


Ashby, S. F. and R. D. Falgout, 1996: A parallel multigrid preconditioned conjugate gradient algorithm for groundwater flow simulations. Nuclear Science and Engineering, 124, 145159.

Avissar, R. and R. Pielke, 1989: A parameterization of heterogeneous land-surface for atmospheric numerical models and its impact on regional meteorology. Monthly Weather Revview, 117, 2113-2136

Banta, R. M. and P. T. Gannon, 1995: Influence of soil moisture on simulations of katabatic flow. Theor. Appl. Climatol., 52, 85 - 94.

Betts, A., J. Ball, A. Belijaar, M. Miller, and P. Viterbo, 1996: The land surface-atmosphere interaction: A review based on observational and global modeling perspectives. Journal of Geophysical Research, 101, 7209-7225.

Castillo, V.M., Gomez-Plaza, A., and M. Martinez-Mena, 2003: The role of antecedent soil water content in the runoff response of semiarid catchments: a simulation approach. Journal of Hydrology, 284 (1-4), 114-130.

Chen, F. and R. Avissar, 1994: Impact of Land-Surface Moisture Variability on Local Shallow Convective Cumulus and Precipitation in Large-Scale Models, Journal of Applied Metereology, 33, 1382-1401.

Chen, T. and Coauthors, 1997: Cabauw experimental results from the project for intercomparison of land-surface parameterization schemes. Journal of Climate, 10, 11941215.

Chow, F. K., A. P. Weigel, R. L. Street, M. W. Rotach, and M. Xue, 2006a: High-resolution large-eddy simulations of flow in a steep Alpine valley. Part I: Methodology, verification, and sensitivity studies. Journal of Applied Meteorology and Climatology , 45, 63-86. 
Chow, F.K., Kollet, S.J., Maxwell, R.M., and Q. Duan. 2006b. Effects of soil moisture heterogeneity on boundary layer flow with coupled groundwater, land-surface, and mesoscale atmospheric modeling. Paper 5.6. 17th Symposium on Boundary Layers and Turbulence, American Meteorological Society, 6 pages.

Clapp, R.B. and G.M. Hornberger, 1978: Empirical equations for some hydraulic properties. Water Resources Research, 14, 601-604.

Clark, D.B., C.M. Taylor and A.J. Thorpe, 2004: Feedback between the Land Surface and Rainfall at Convective Length Scales. Journal of Hydrometeorology, 5, 625-639.

Dai, Y., X. Zeng, R. Dickinson, I. Baker, G. Bonan, M. Bosilovich, A. Denning, P. Dirmeyer, P. Houser, G. Niu, K. Oleson, C. Schlosser, and Z. Yang, 2003: The common land model. Bulletin of the American Meteorological Society , 84, 1013- 1023.

Davis, L. V., 1955: Geology and ground water resources of frady and nothern stephens counties, Oklahoma. Bulletin no. 73, Oklahoma Geological Survey.

Desai, A. R., K. J. Davis, C. J. Senff, S. Imail, E. Browell, D. R. Stauffer, and B. P. Reen, 2005: A case study on the effects of heterogeneous soil moisture on mesoscale boundary-layer structure in the Southern Great Plains, U.S.A. Part I: simple prognostic model. BoundaryLayer Meteorology , 119, doi:10.1007/s10546-005-9024-6.

Guha, A., J. M. Jacobs, T. J. Jackson, M. H. Cosh, E.-C. Hsu, and J. Judge, 2003: Soil moisture mapping using ESTAR under dry conditions from the Southern Great Plains experiment (SGP99). IEEE Transactions on Geoscience And Remote Sensing, 41, 2392-2397.

Henderson-Sellers, A. and B. Henderson-Sellers, 1995: Simulating the diurnal temperature range: Results from phase 1(a) of the project for intercomparison of landsurface parameterisation schemes (PILPS). Atmospheric Research, 37, 229-248. 
Holt, T.R., D. Niyogi, F. Chen, K. Manning, M. LaMone and A. Qureshi, 2006. Effect of landatmosphere interactions on the IHOP 24-25 May 2002 convection case. Monthly Weather Review, 134, 113-123.

Jackson, T. J., D. M. L. Vine, A. Y. Hsu, A. Oldak, P. Starks, C. T. Swift, J. D. Isham, and M. Haken, 1999: Soil moisture mapping at regional scales using microwave radiometry: The Southern Great Plains Hydrology Experiment. IEEE Transactions on Geoscience And Remote Sensing, 37, 2136-2151.

Jones, J. E. and C. S. Woodward, 2001: Integrated surface-groundwater flow modeling: a freesurface overland flow boundary condition in a parallel groundwater flow model. Advances in Water Resources, 24, 763-774.

Kollet, S.J. and R.M. Maxwell, 2007: Investigating the influence of water table dynamics on land surface processes using a fully-coupled, distributed watershed model. In preparation, to be submitted to Water Resources Research.

Kollet, S. J. and R. M. Maxwell, 2006: Integrated surface-groundwater flow modeling: a freesurface overland flow boundary condition in a parallel groundwater flow model. Advances in Water Resources, 29, 945-958.

Kondo, J., N. Saigusa and T. Sato, 1990: A parameterization of evaporation from bare soil surfaces, Journal of Applied Meteorology, 29, 385-389.

Liang, X., Z. Xie, and M. Huang, 2003: A new parameterization for surface and groundwater interactions and its impact on water budgets with the variable infiltration capacity (VIC) land surface model. Journal of Geophysical Research, 198, 1194-1215. 
Lohmann, D. and Coathors, 1998: The project for intercomparison of land-surface parameterization schemes PILPS phase 2(c) Red Arkansas River basin experiment: 3. spatial and temporal analysis of water fluxes. Global and Planetary Change, 19, 161-179.

Luo, L., , and Coauthors, 2003: Effects of frozen soil on soil temperature, spring infiltration, and runoff: Results from the PILPS 2(d) experiment at Valdai, Russia. Journal of Hydrometeorology , 4, 334-351.

Mahfouf, J.F. and J. Noilhan, 1991: Comparative study of various formulations of evaporation from bare soil using in situ data. Journal of Applied Meteorology, 30, 1354-1365.

Manabe, S., J. Smagorinksy, and R. Strickler, 1965: Simulated climatology of a general circulation model with a hydrologic cycle. Monthly Weather Review , 93, 769-798.

Maxwell, R. and N. Miller, 2005: Development of a coupled land surface and groundwater model. Journal of Hydrometeorology, 6, 233-247.

Noilhan, J. and S. Planton, 1989: A simple parameterization of land surface processes for meteorological models. Monthly Weather Review, 117, 536-549.

Noilhan, J. and J.-F. Mahfouf, 1996: The ISBA land surface parameterization scheme. Global and Planetary Change, 13, 145-159.

Ookouchi, Y., M. Segal, R. C. Kessler, and R. A. Pielke, 1984: Evaluation of soil moisture effects on the generation and modification of mesoscale circulations. Mon. Wea. Rev., 112, $2281-92$.

Patton, E.G., P.P. Sullivan and C-H Moeng, 2005. The influence of idealized heterogeneity on wet and dry planetary boundary layers coupled to the land surface, Journal of the Atmospheric Sciences, 62, 2078-2097. 
Pitman, A. and Coauthors, 1999: Key results and implications from phase 1(c) of the project for intercomparison of land-surface parameterization schemes. Climate Dynamics, 15, 673684.

Pleim, J.E. and A. Xiu, 1995: Development and testing of a surface flux and planetary boundary layer model for application in mesoscale models. Journal of Applied Meteorology, 34, 16-32.

Qu, W. and Coauthors, 1998: Sensitivity of latent heat flux from PILPS land-surface schemes to perturbations of surface air temperature. Journal of Atmospheric Sciences, 55, 1909_ 1927.

Ren, D. and M. Xue, 2004: A revised force-restore model for land surface modeling. Journal of Applied Meteorology, 43, 1768- 1782.

Schaap, M. G. and F. J. Leij, 1998: Database-related accuracy and uncertainty of pedotransfer functions. Soil Science, 163, 765-779.

Schlosser, C. and Coathors, 2000: Simulations of a boreal grassland hydrology at Valdai, Russia: PILPS phase 2(d). Monthly Weather Review , 128, 301-321.

Shao, Y. and A. Henderson-Sellers, 1996: Modeling soil moisture: A project for intercomparison of land surface parameterization schemes phase 2(b). Journal of Geophysical Research, 101, 7227-7250.

Sturdevant-Rees, P., Smith, J.A., Morrison J., and M. L. Baeck, 2001: Tropical storms and the flood hydrology of the central Appalachians. Water Resources Research, 37 (8), 21432168.

Taylor, C.M., F. Said and T. Lebel, 1997: Interactions between the Land Surface and Mesoscale Rainfall Variability during HAPEX-Sahel. Monthly Weather Review, 125, 2211-2227. 
Vine, D. M. L., T. J. Jackson, C. T. Swift, M. Haken, and S. W. Bidwell, 2001: ESTAR Measurements during the Southern Great Plains experiment (SGP99). IEEE Transactions on Geoscience And Remote Sensing, 39, 1680-1685.

Xue, M., K. K. Droegemeier, and V. Wong, 2000: The advanced regional prediction system (ARPS): A multi-scale non-hydrostatic atmospheric simulation and prediction model. Part I: Model dynamics and verification. Meteorology and Atmospheric Physics, 75, 161193.

Xue, M., K. K. Droegemeier, V. Wong, A. Shapiro, K. Brewster, F. Carr, D. Weber, Y. Liu, and D. Wang, 2001: The advanced regional prediction system (ARPS): A multi-scale nonhydrostatic atmospheric simulation and prediction tool. Part II: Model physics and applications. Meteorology And Atmospheric Physics, 76, 143-165.

Yeh, P.-F. and E. Eltahir, 2005: Representation of water table dynamics in a land-surface scheme. Part I: Model development. Journal of Climate, 18, 1861-1880.

York, J. P., M. Person, W. J. Gutowski, and T. C. Winter, 2002: Putting aquifers into atmospheric simulation models: an example from the Mill Creek watershed, northeastern Kansas. Advances in Water Resources, 25, 221-238. 


\section{Figures}

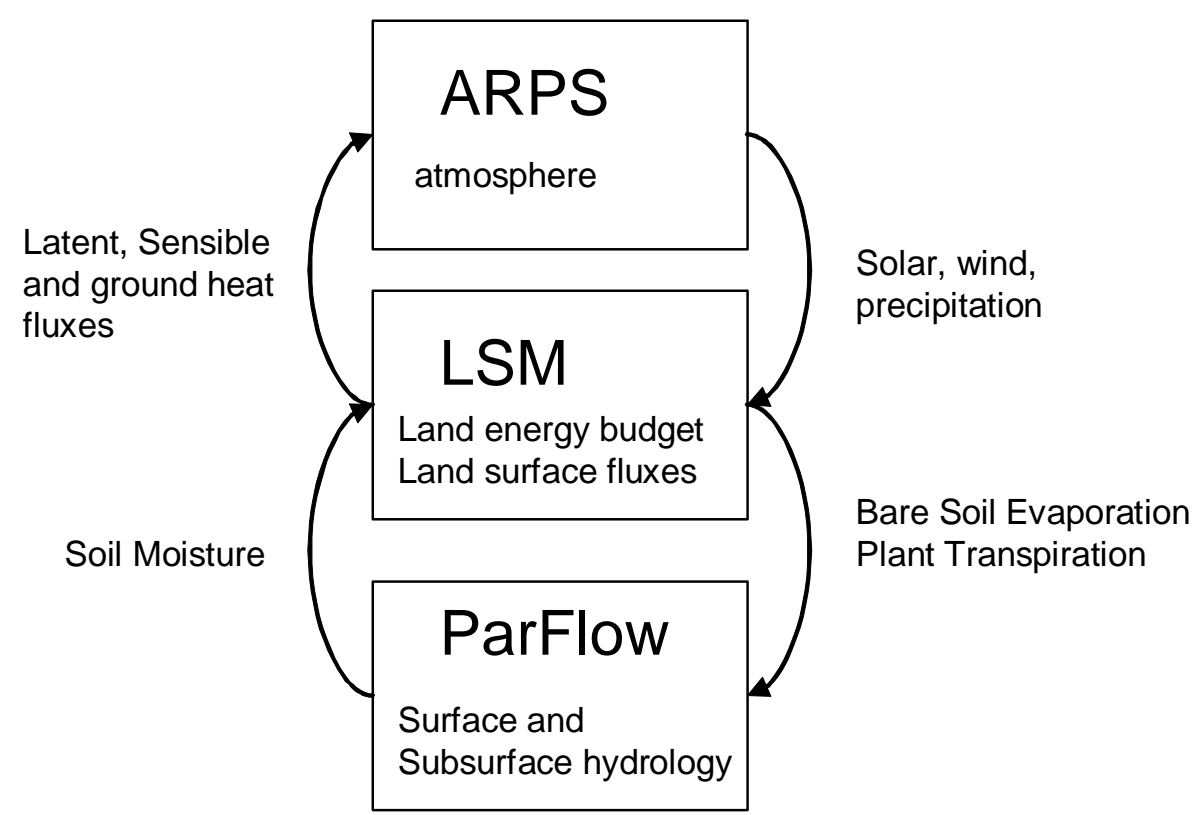

Figure 1. Simplified flowchart of coupled model process. 


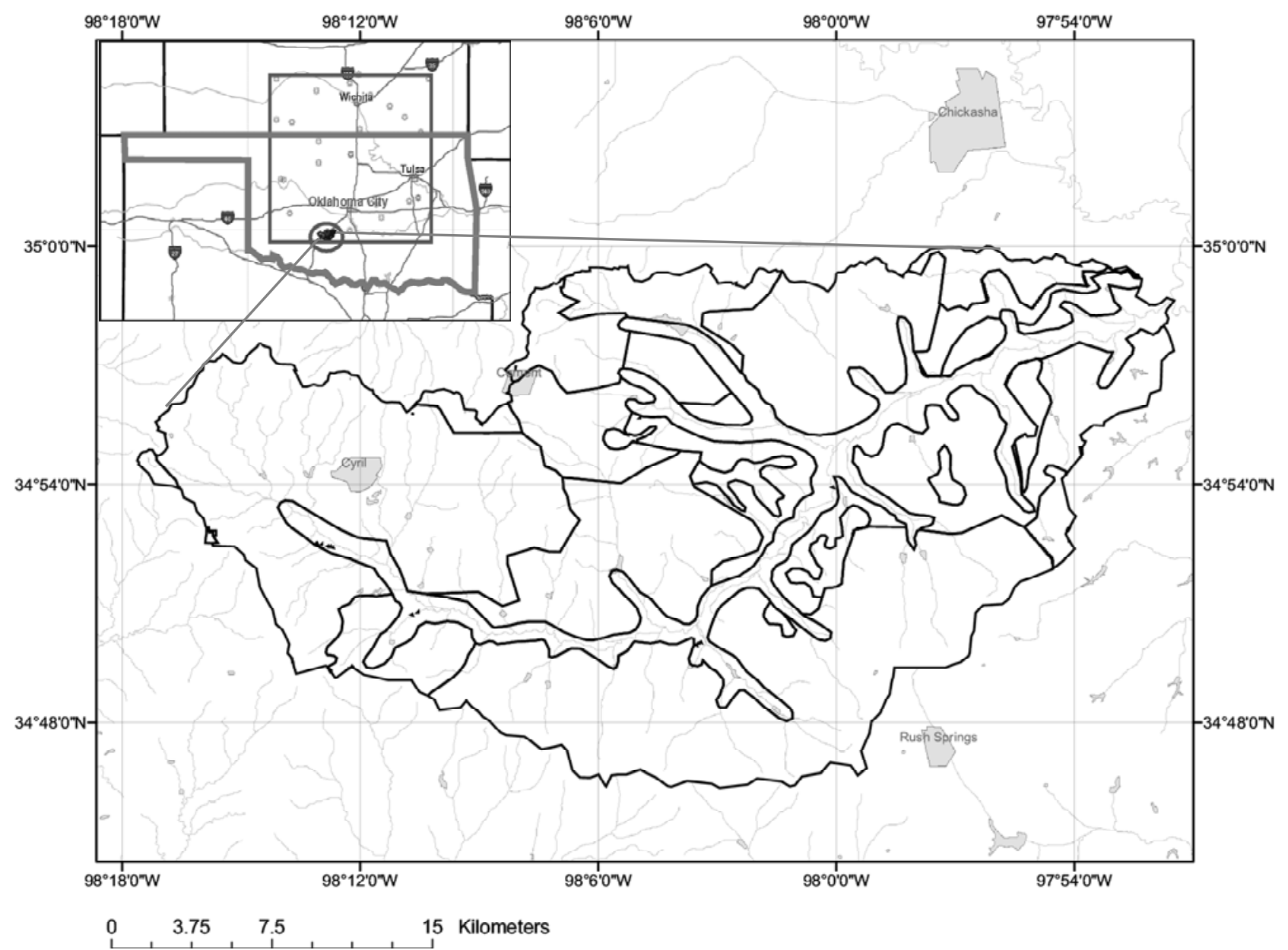

Figure 2. Location of the Little Washita watershed. The inset shows the location of the watershed in the state of Oklahoma. 

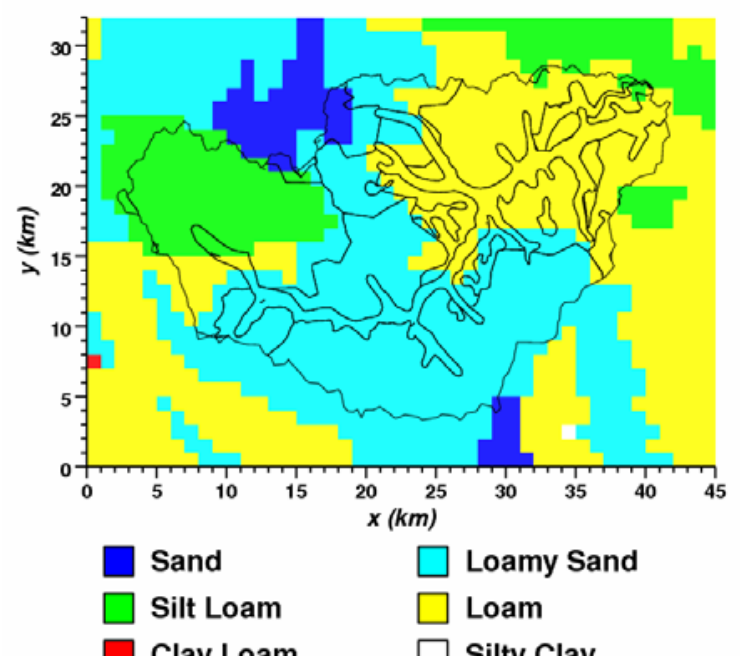

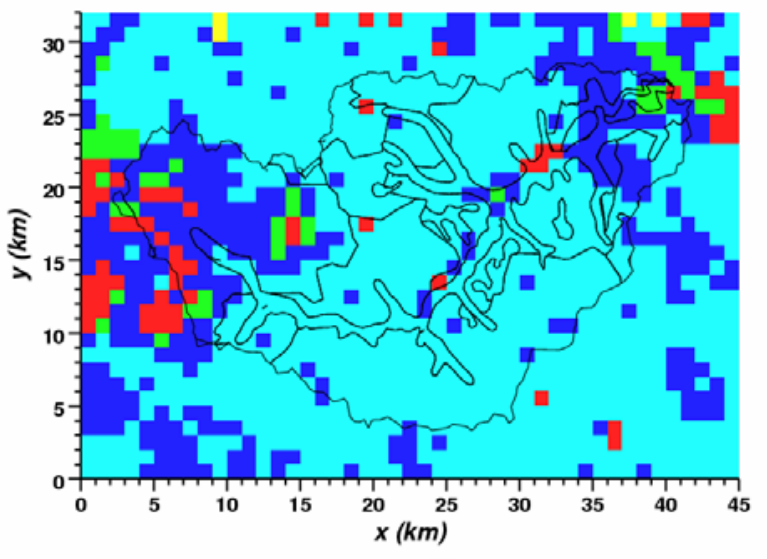

Open Shrublands $\square$ Grasslands $\square$ Deciduous Forest $\square$ Evergreen Broadleaf Croplands

A

B

Figure 3. Plot of a) soil type and b) vegetation type for the simulation. 


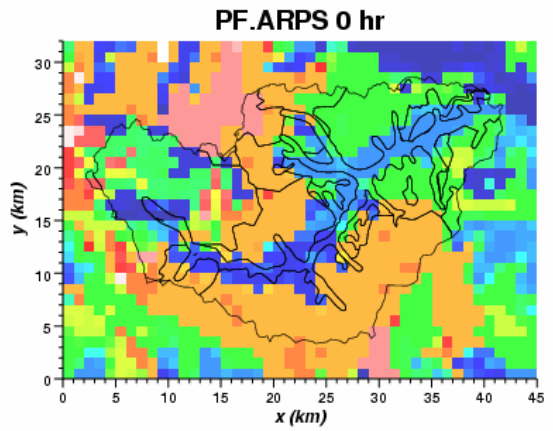

PF.ARPS $12 \mathrm{hr}$

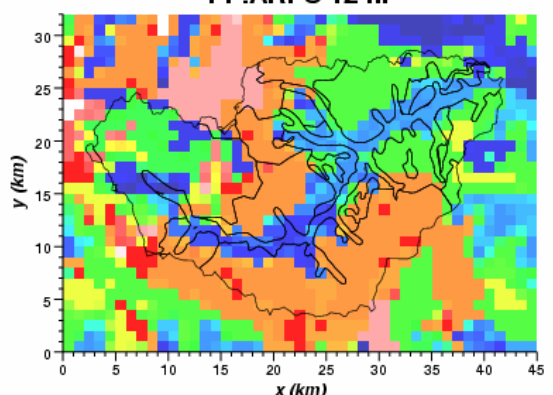

PF.ARPS $24 \mathrm{hr}$

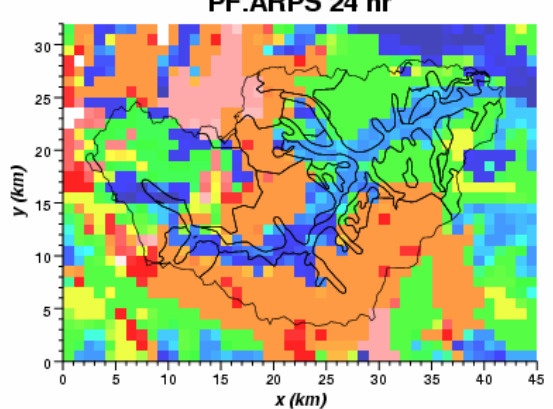

PF.ARPS $36 \mathrm{hr}$

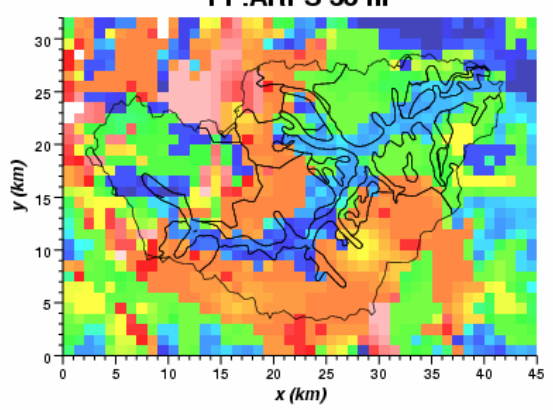

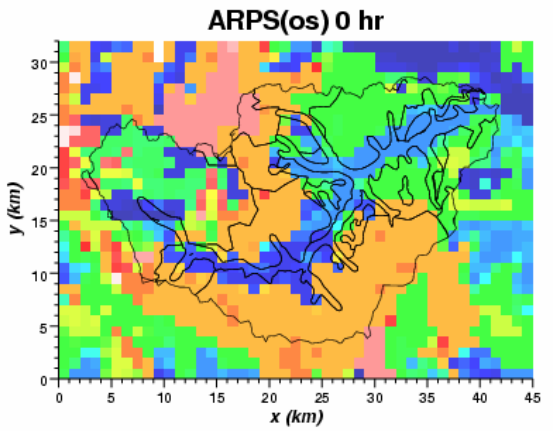

ARPS(os) $12 \mathrm{hr}$

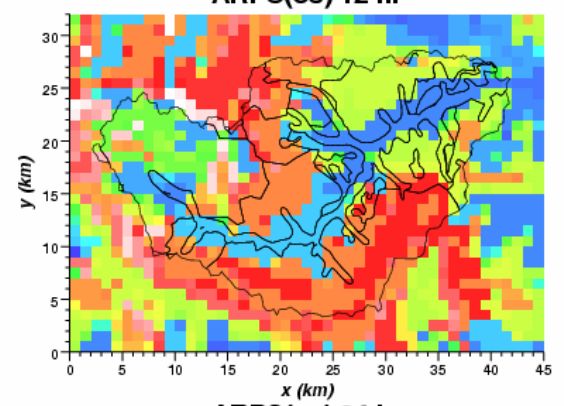

ARPS(os) $24 \mathrm{hr}$

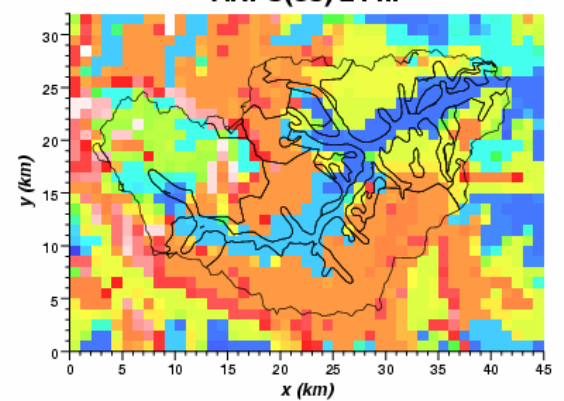

ARPS(os) $36 \mathrm{hr}$
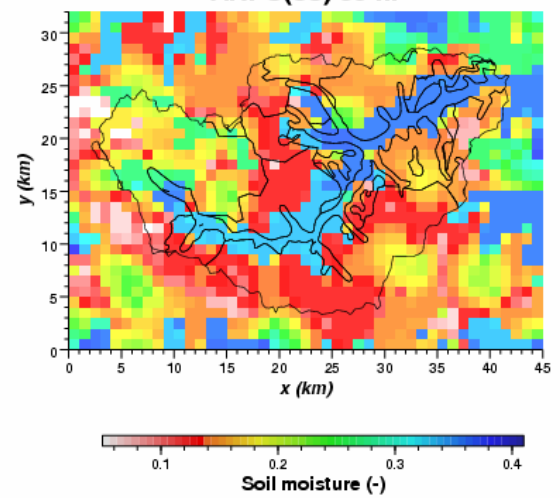

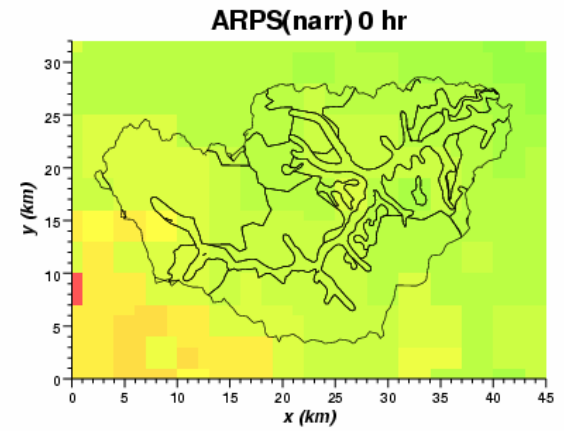

ARPS(narr) $12 \mathrm{hr}$

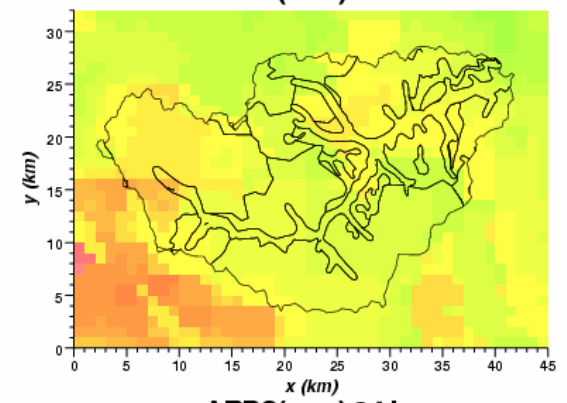

ARPS(narr) $24 \mathrm{hr}$

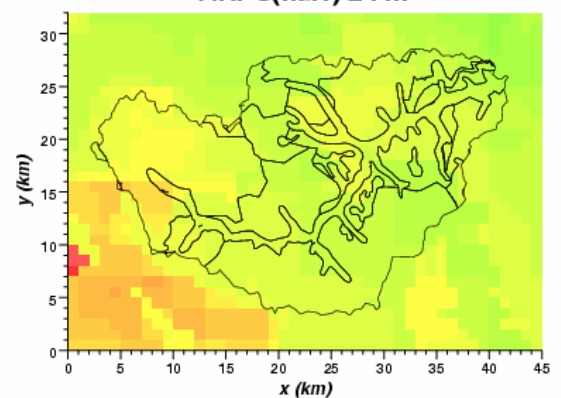

ARPS(narr) $36 \mathrm{hr}$

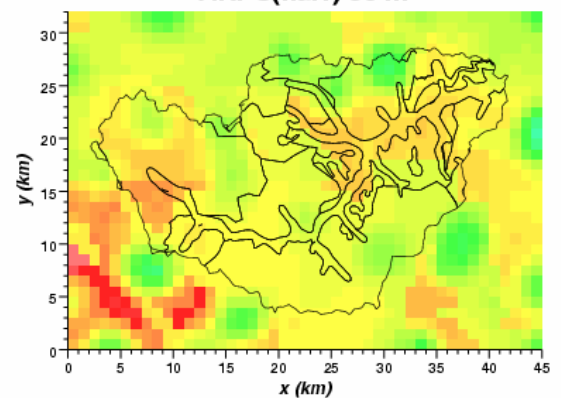

Figure 4. Plot of surface soil moisture for the PF.ARPS (left), ARPS(os) (middle) and ARPS(narr) (right) models at $12 \mathrm{~h}$ intervals from time zero to the end of the coupled simulation. 


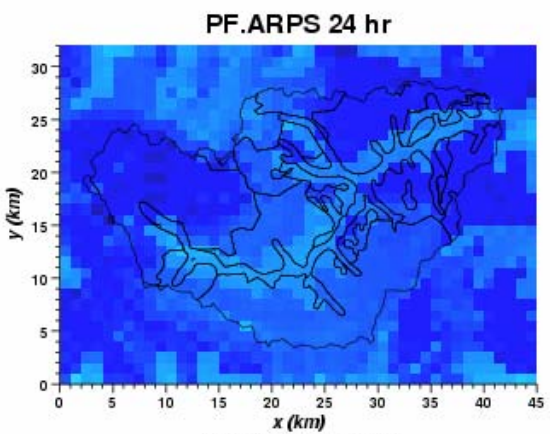

PF.ARPS $26 \mathrm{hr}$

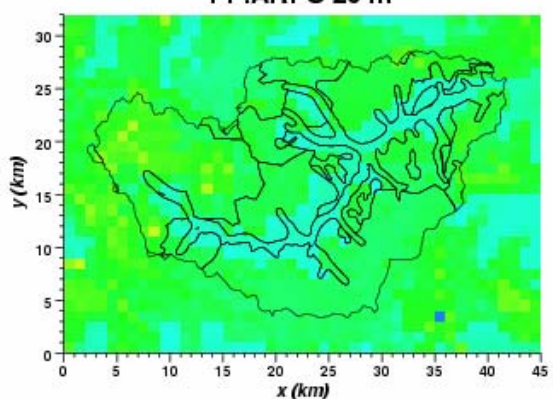

PF.ARPS $27 \mathrm{hr}$

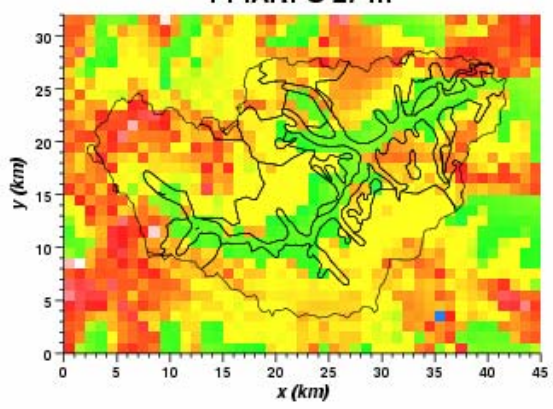

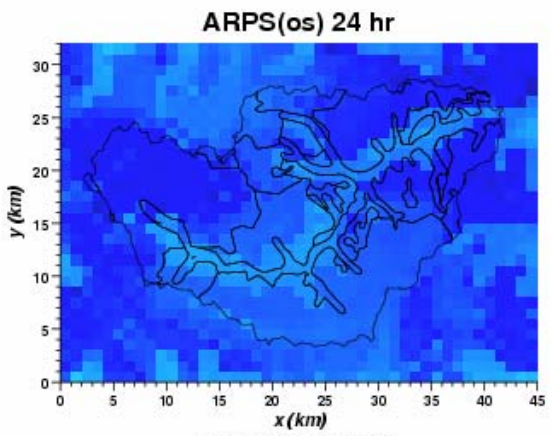

ARPS(os) $26 \mathrm{hr}$

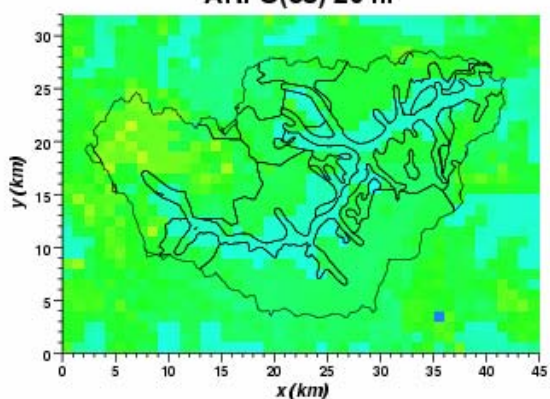

ARPS(os) $27 \mathrm{hr}$
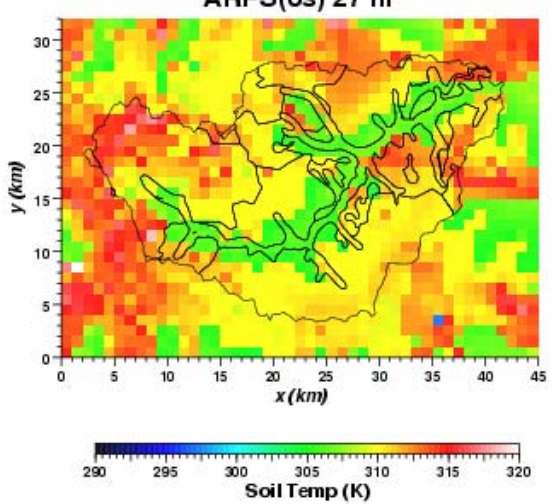

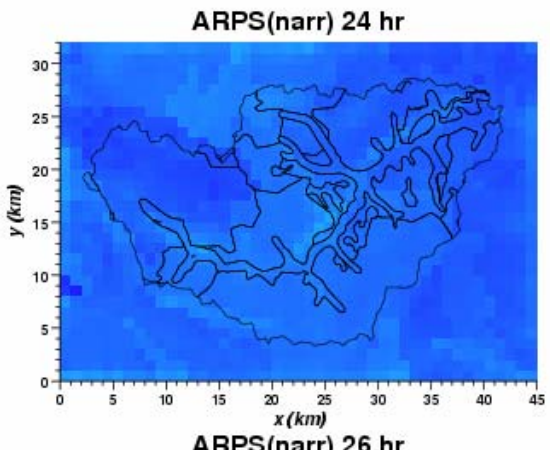

ARPS(narr) $26 \mathrm{hr}$

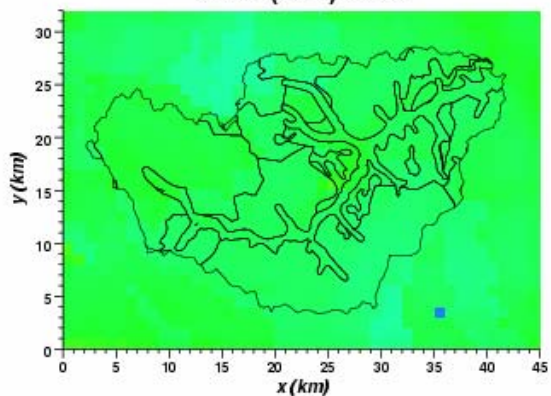

ARPS(narr) $27 \mathrm{hr}$

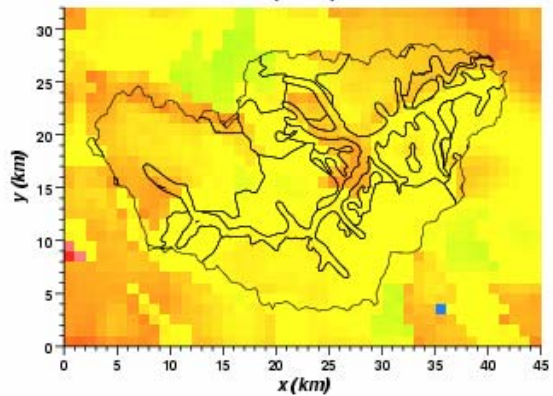

Figure 5. Plot of surface soil temperature for PF.ARPS (left), ARPS(os) (middle) and ARPS(narr) (right) at simulation times 24 (top), 26 (middle) and 27 (bottom) hours. 


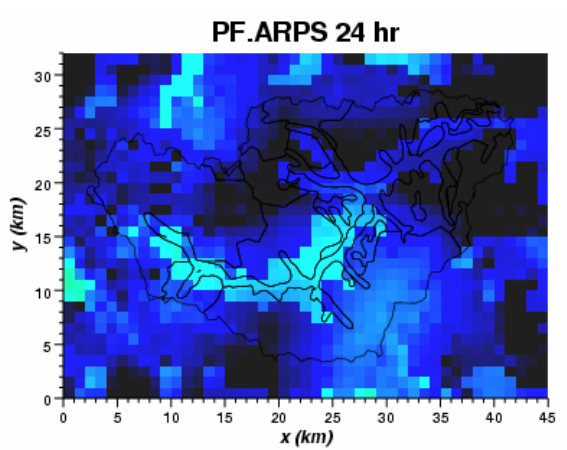

PF.ARPS $26 \mathrm{hr}$

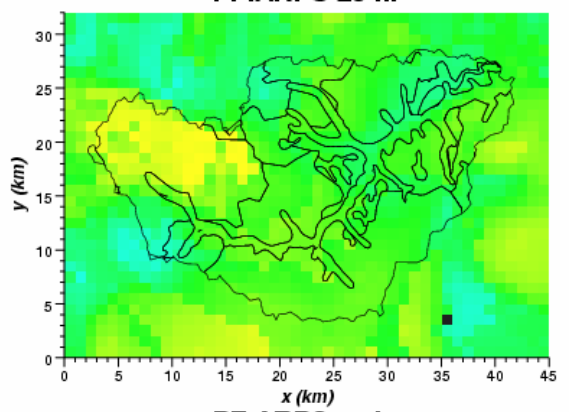

PF.ARPS $27 \mathrm{hr}$

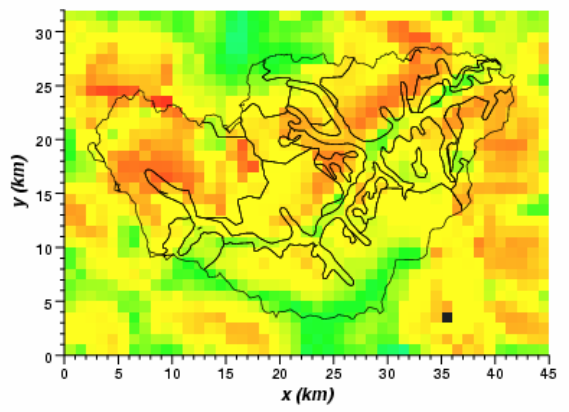

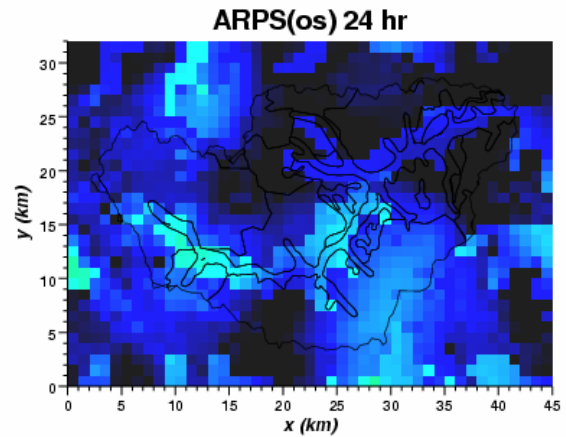

ARPS(os) 26 hr

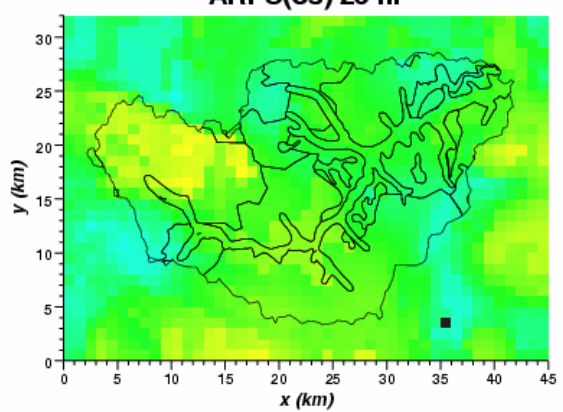

ARPS(os) $27 \mathrm{hr}$

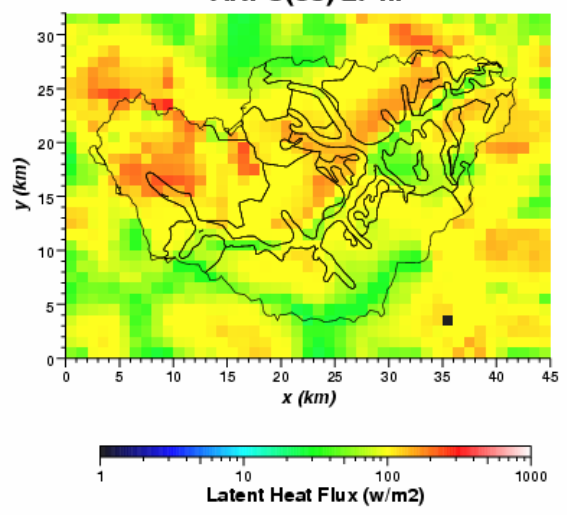

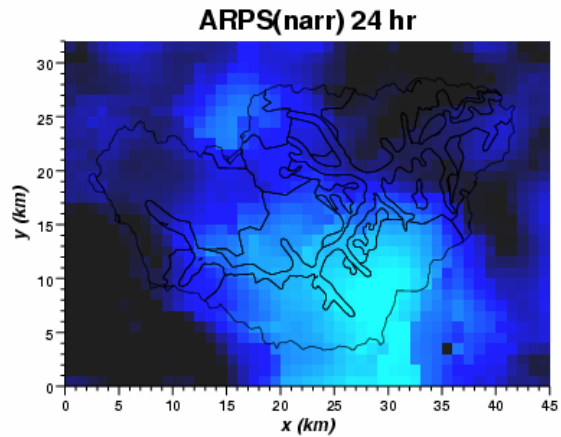

ARPS(narr) $26 \mathrm{hr}$

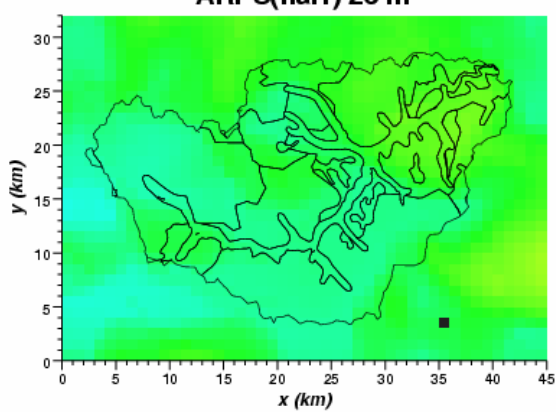

ARPS(narr) $27 \mathrm{hr}$

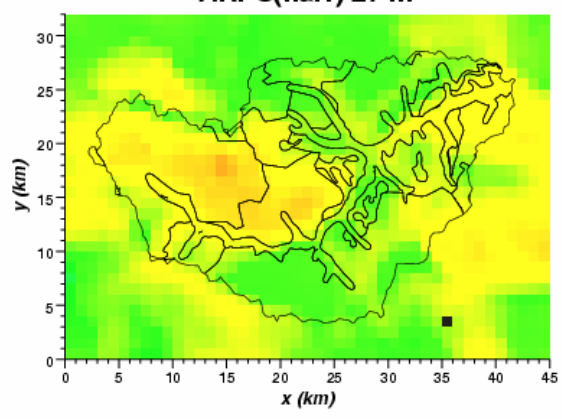

Figure 6. Plot of latent heat for PF.ARPS (left), ARPS(os) (middle) and ARPS(narr) (right) at simulation times 24 (top), 26 (middle) and 27 (bottom) hours. Note the log color scale for latent heat flux. 

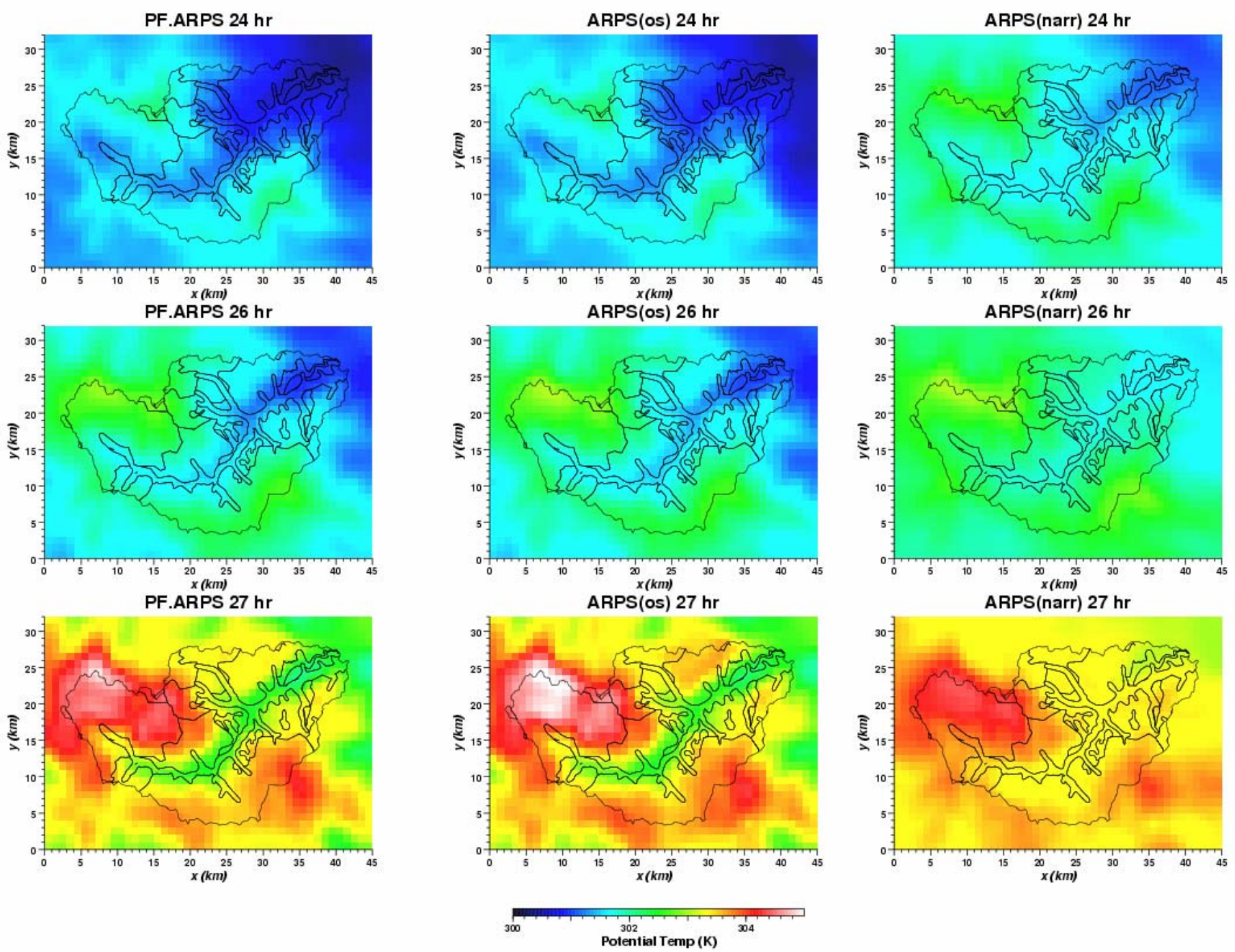

Figure 7. Plot of potential temperature for PF.ARPS (left), ARPS(os) (middle) and ARPS(narr) (right) at simulation times 24 (top), 26 (middle) and 27 (bottom) hours. 

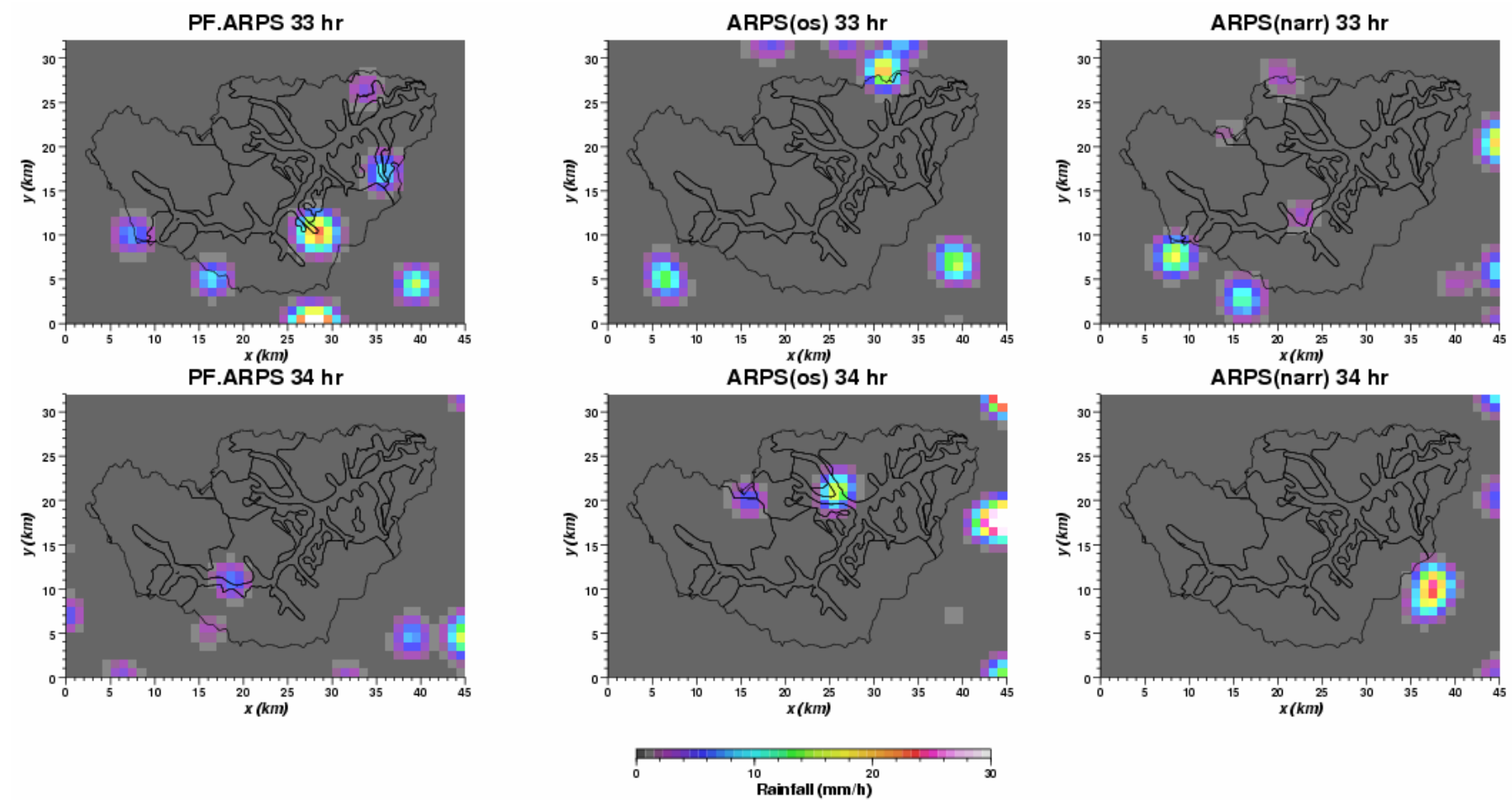

Figure 8. Plot of hourly rainfall for PF.ARPS (left), ARPS(os) (middle) and ARPS(narr) (right) at simulation times 33 (top) and 34 (bottom) hours. 


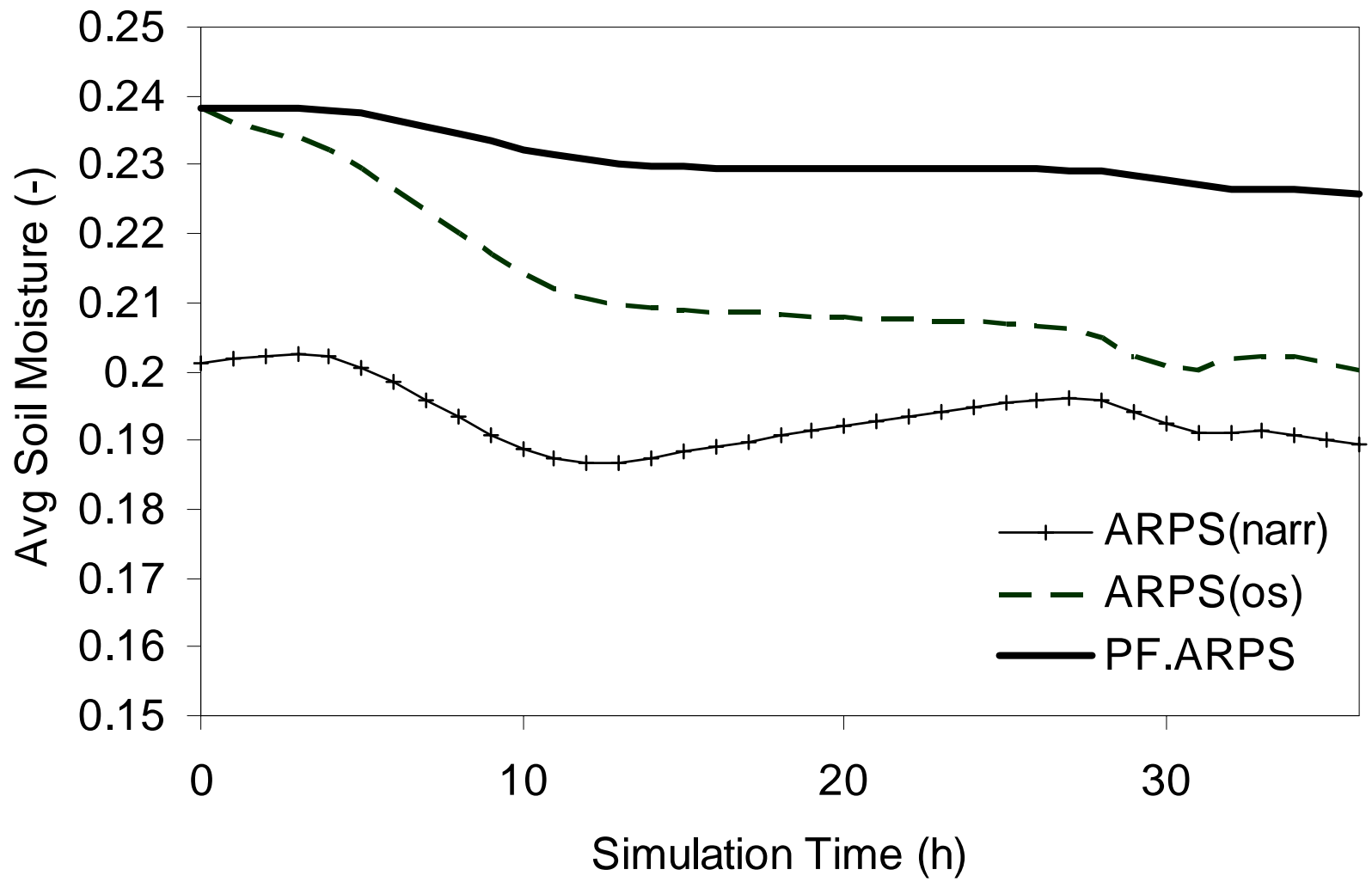

Figure 9. Plot of soil moisture (averaged over the domain) for the upper soil layer for the 36 hour simulation for three different test cases . 
A
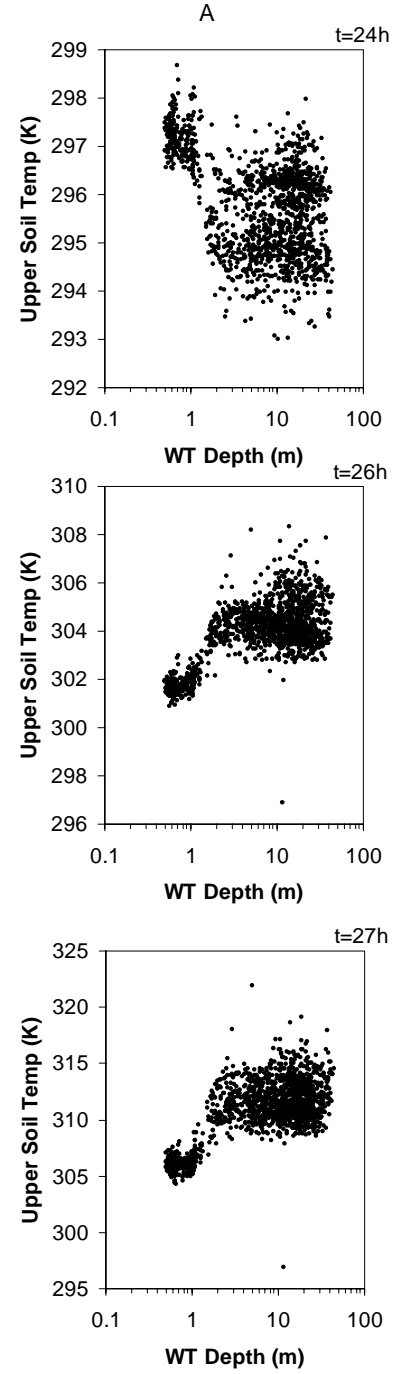

B
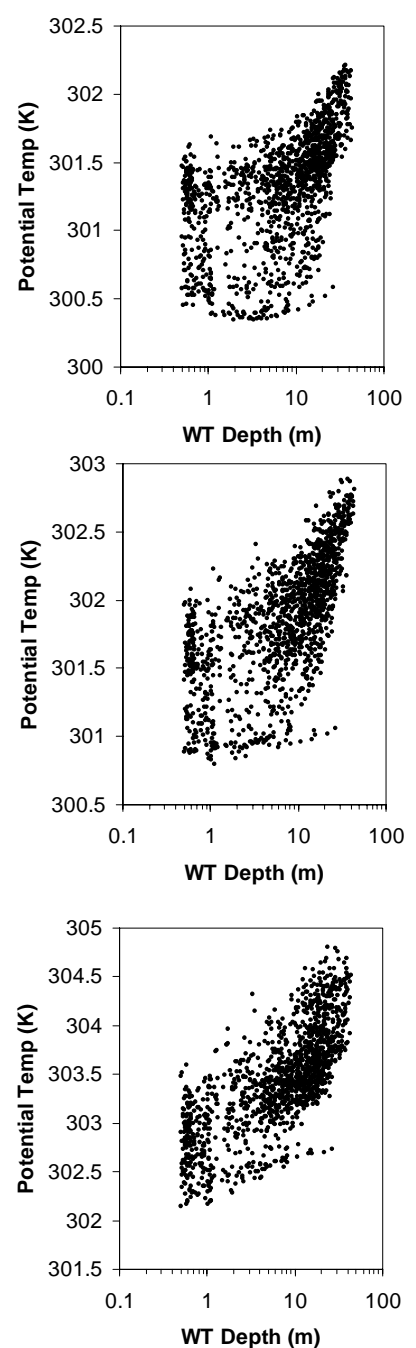

C
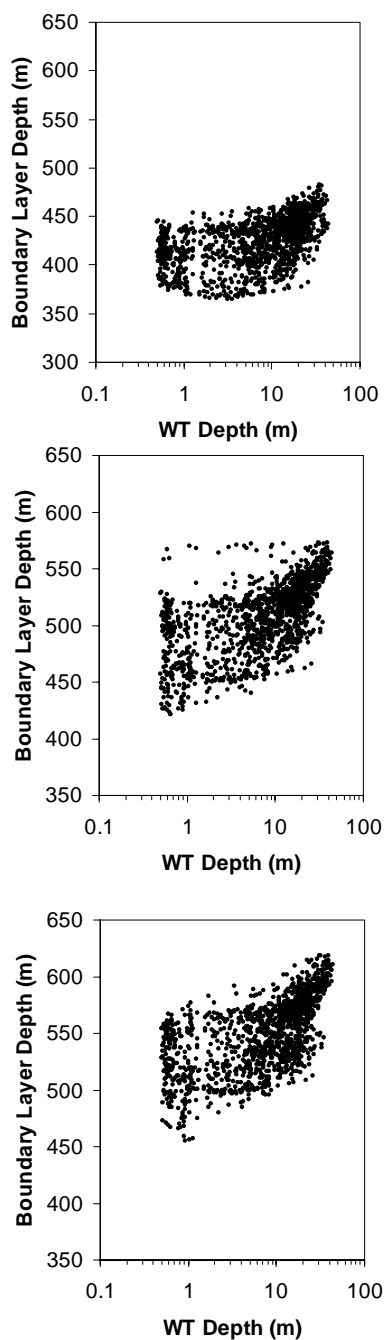

D
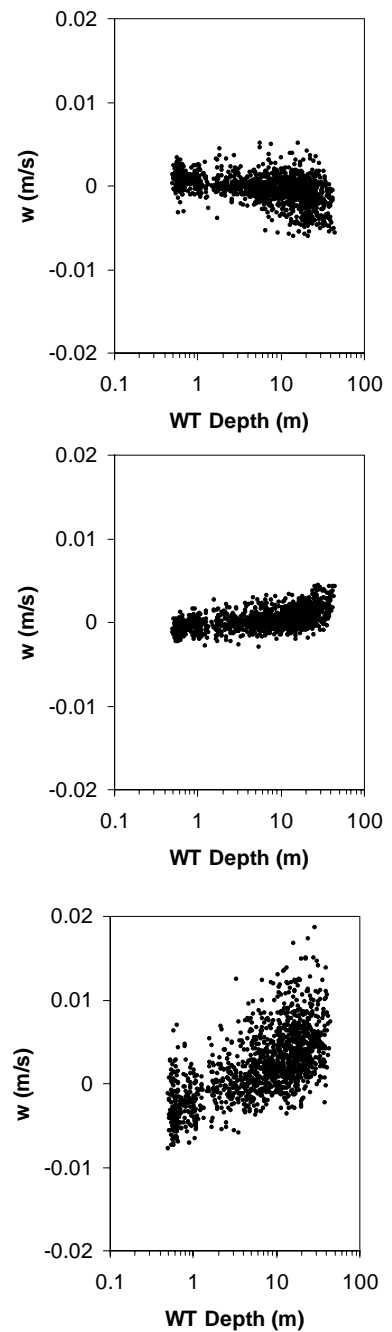

Figure 10. Semi logarithmic scatterplots of soil temperature (A), potential temperature (B), boundary layer depth (C) and vertical velocity (D) as a function of water table at simulation times 24 (top), 26 (middle) and 27 (bottom) hours. Note the different axis ranges in y for soil and potential temperature. 

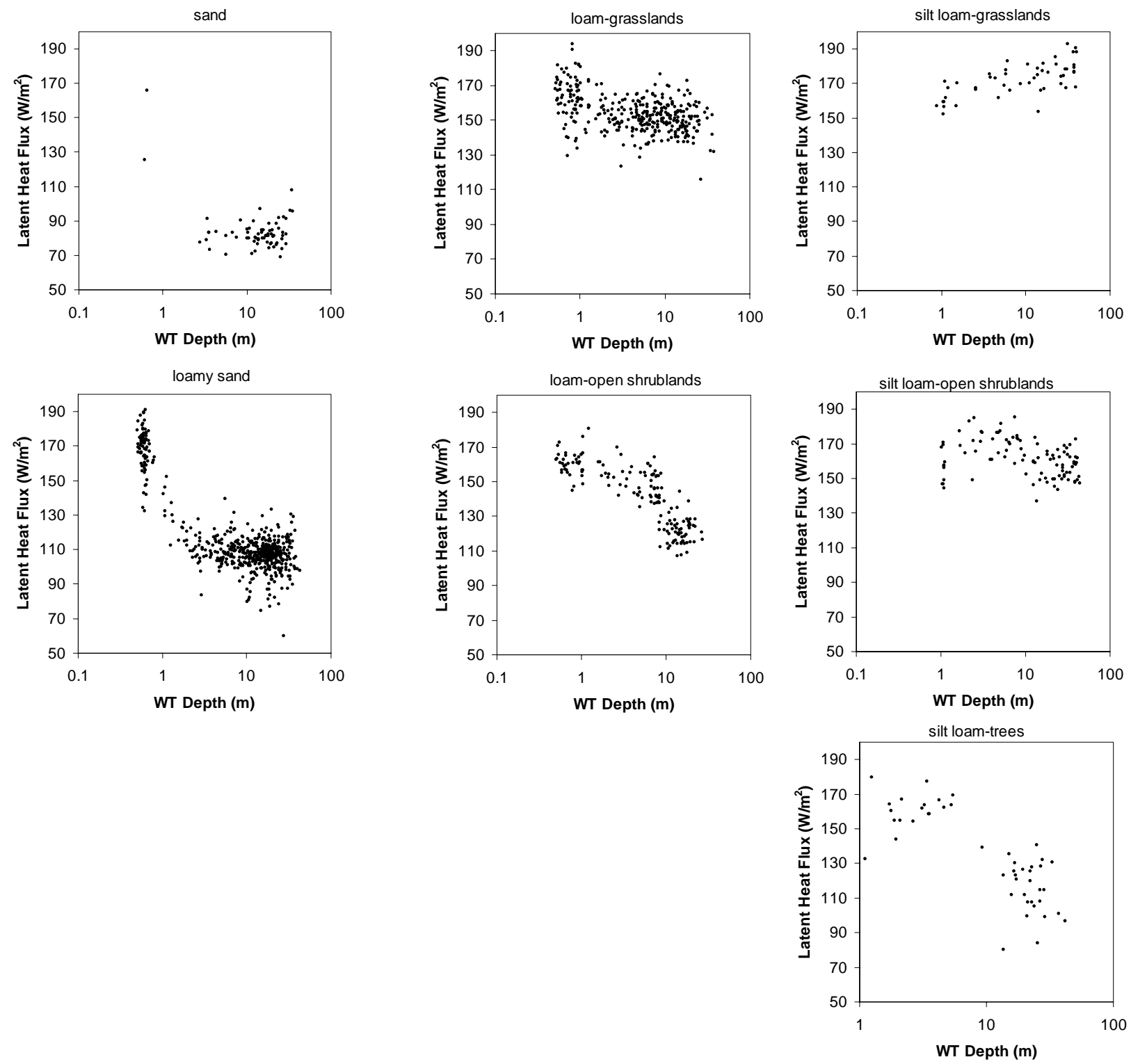

Figure 11. Semi logarithmic scatterplots of latent heat flux (averaged at each surface cell over the simulation time) as a function of water table (averaged over the simulation time) for a range of soil and vegetation types. 

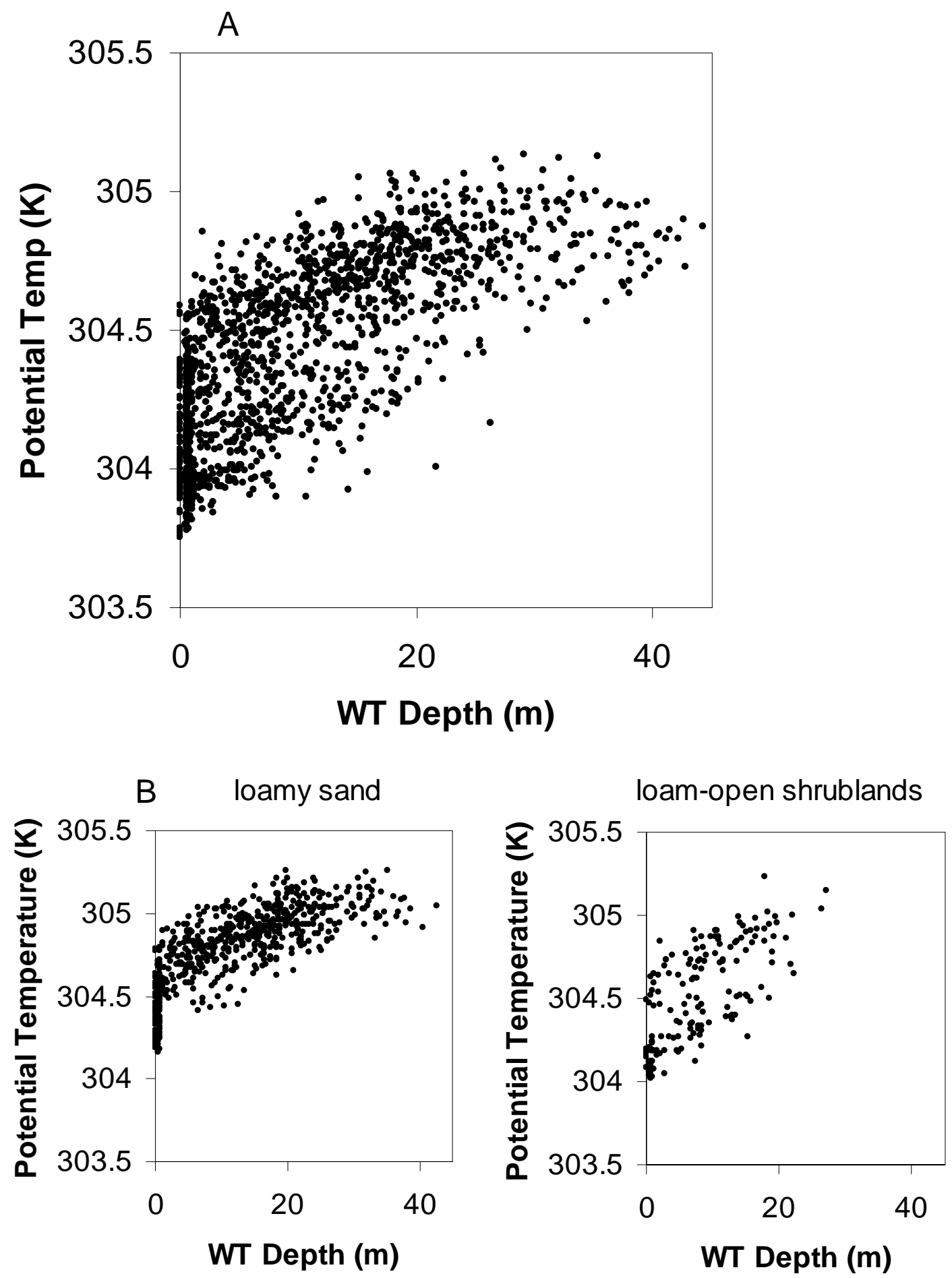

Figure 12a-b. Scatterplot of potential temperature (averaged at each lower atmospheric cell over the simulation time) as a function of water table (averaged over the simulation time), a) for all soil types and vegetation cover, b) for loamy sand (all vegetation types) and loam covered by open shrublands. 
ISBA soil model and the Advanced Regional Prediction System (ARPS)

Patrick Granvold and Fotini Katapodes Chow, Department of Civil and Environmental Engineering, University of California, Berkeley, California.

\subsection{Introduction}

This document examines the ISBA soil model as implemented in the Advanced Regional Prediction System (ARPS) by forcing a single cell domain with observational data. The outputs of the ISBA model are dependent on choice of timestep, though no stability limits exist similar to those governing atmospheric simulation. The model does not conserve water mass, due to artificial capping of soil moisture values and numerical error introduced by the soil model itself. Finally, the ARPS implementation of ISBA mixes formulations from two different sources, and the impact of this model choice is explored.

\subsection{Simulation Forcing}

The ARPS soil model was forced over a one cell domain ( $4 x 4 x 4$ ARPS domain, with 3 ghost points in each direction) with 100 hours of North American Regional Reanalysis (NARR) data. The forcing data corresponds to measurements from the Little Washita watershed in Oklahoma during the 1999 water year (September 1, 1998 - August 31, 1999). The data set includes: precipitation, surface specific humidity, surface temperature, lateral wind speeds $u$ and $v$ at $10 \mathrm{~m}$, surface pressure, and shortwave and longwave radiation. Figure 1 displays the first 100 hours of the data set. For runs with a timestep less than the NARR dataset (3600s), input data was linearly interpolated between hours.

Atmospheric simulation was disabled in the ARPS subroutine cordint by calling only the radiation and surface physics subroutines radfrc and sfcphys. Model output was taken directly from the soil model subroutine soilebm, called by sfcphys.
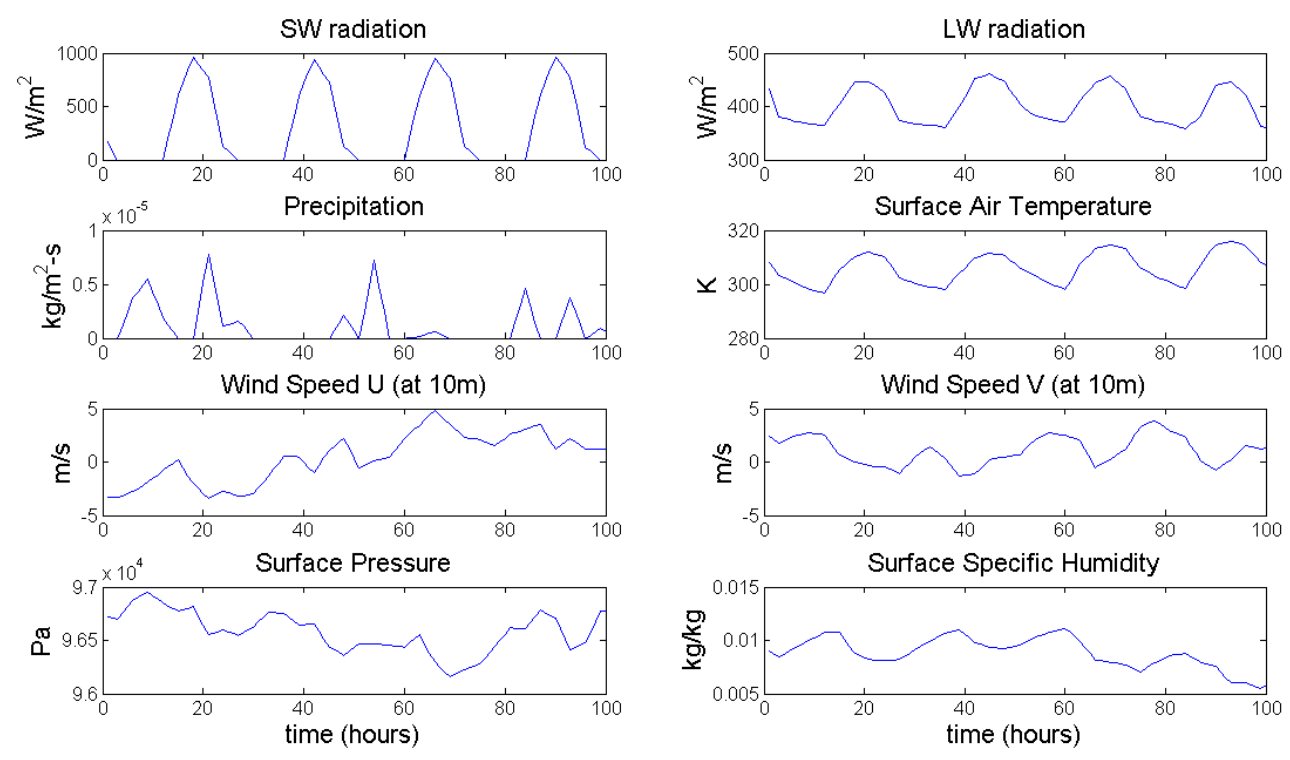

Figure 1: One hundred hours of radiative and meteorological NARR data (beginning midnight September 1,1998 ) used to force ARPS. 


\subsection{Simulation Timestep Dependence}

Figure 2 and Figure 3 show the dependence of soil moisture and temperature, respectively, on timesteps of 36s, 360s (6 minutes), and 3600s (1 hour). Setting dtbig at $36 \mathrm{~s}$ or 360 s results in nearly identical behavior. However, both moisture and temperature begin to diverge near the end of the simulation period; running longer periods might result in larger differences. The largest timestep, $d t b i g$ of 3600 s, results in oscillatory behavior during the daytime period, and different values than the other two timesteps. The soil model is not constrained by timestep stability limits, but larger timesteps result in markedly different behavior.

(a) Surface layer soil temperature (tsfc)

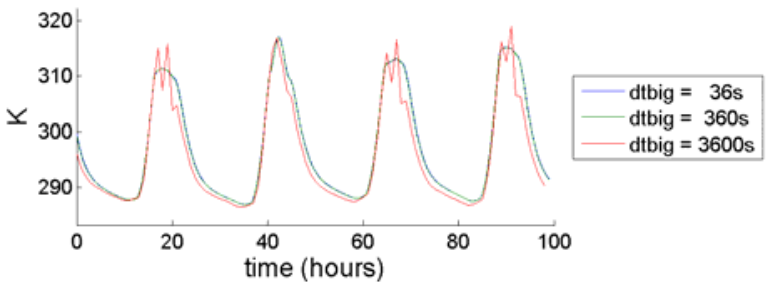

(b) Deep layer soil temperature (tdeep)

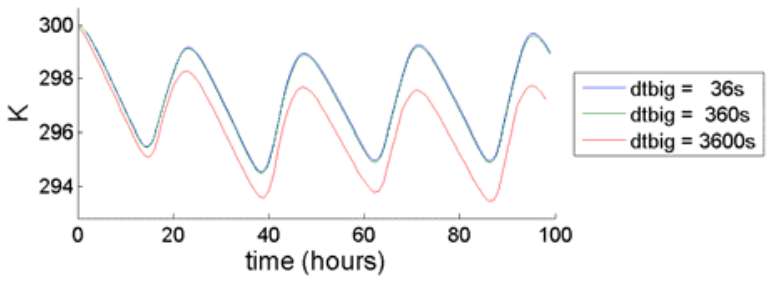

Figure 2: (a) Surface temperatures and (b) Deep soil temperatures for one hundred hours of simulation run at three differing timesteps. Temperatures vary in a diurnal pattern, with lower temperatures resulting from a larger timestep.

(a) Surface layer soil moisture (wetsfc)

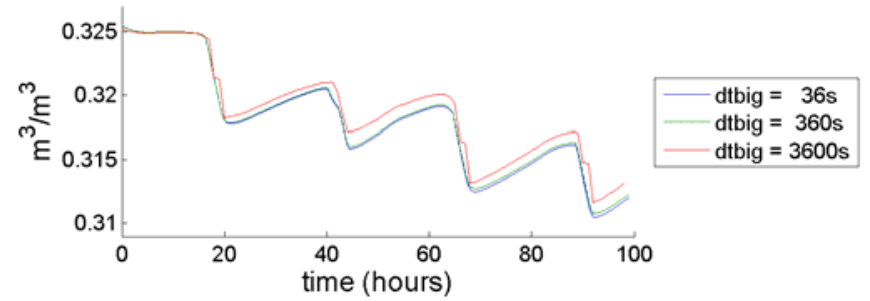

(b) Deep layer soil moisture (wetdp)

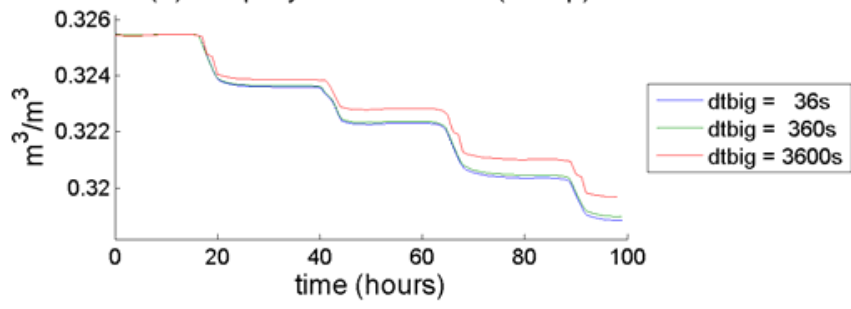

Figure 3: (a) Surface layer and (b) Deep soil moistures for one hundred hours of simulation at three different timesteps. The equivalent of approximately $5 \mathrm{~mm}$ of rainfall is lost during this period of minimal rainfall. Less water leaves the system with a larger timestep. 


\subsection{Water Balance}

The soil and canopy are two separate systems in the ISBA soil model, with no exchange (i.e. canopy drip). Figure 4 shows the storage and flux terms for the ISBA soil model with no vegetative cover (canopy). Since ISBA provides no lateral transport between cells, conservation of mass can be applied to each soil grid cell in the domain independently.

Total water in the soil is:

$$
\begin{aligned}
& q_{\mathrm{sfc}}=\text { wetsfc }^{*} z_{\mathrm{sfc}} \\
& q_{\text {deep }}=w_{\text {etdp }} * z_{\text {deep }}
\end{aligned}
$$

The precipitation to the ground is that portion of total precipitation striking bare ground:

$$
P_{\text {gnd }}=\operatorname{precip}^{*}(1-v e g)
$$

Water exiting (flux) due to transpiration $\left(E_{\text {tr }}\right)$ and direct ground evaporation $\left(E_{\mathrm{g}}\right)$ are:

$$
\begin{array}{lll}
E_{\mathrm{tr}} & =\text { evaprtr } \\
E_{\mathrm{g}} & =\text { evaprg }
\end{array}
$$

Then error $(\varepsilon)$ in the water balance over one time step, in $\mathrm{kg} / \mathrm{m}^{2}$-s, is given by:

$$
\varepsilon \quad=\quad\left(\Delta q_{\mathrm{sfc}}+\Delta q_{\mathrm{deep}}\right) * \rho_{w} / d t b i g+E_{\mathrm{tr}}+E_{\mathrm{g}}-P_{\mathrm{gnd}}
$$

In addition to using the evaporative fluxes given at the end of the time step, evapotranspiration and precipitation were averaged over the time step to obtain the mean values over each time step $n$. For any variable X:

$$
X_{\text {tr,aver }}(n) \quad=\quad 1 / 2(X(n)+X(n-1))
$$

Then error in the water balance using averaged fluxes $\left(\varepsilon_{\text {aver }}\right)$ over one time step, in $\mathrm{kg} / \mathrm{m}^{2}$ $\mathrm{s}$, is given by:

$$
\varepsilon_{\text {aver }}=\left(\Delta q_{\mathrm{sfc}}+\Delta q_{\text {deep }}\right) * \rho_{w} / d t b i g+E_{\text {tr,aver }}+E_{\text {g,aver }}-P_{\text {gnd,aver }}
$$

Figure 5 shows water balance error for the three time steps discussed in Section 3.0, for both reported and averaged water fluxes. Significant error occurs during the daytime periods, when evaporative fluxes peak. The magnitude of error decreases as the time step is reduced. There is no distinct difference in the magnitude of error when using reported or averaged fluxes; however, averaged fluxes slightly increase the error for dtbig at 3600s, and fluctuates more for smaller time steps.

The error shown in Figure 5 comes solely from the governing equations and the two-step force-restore model implementation. During high precipitation events, large amounts of water are lost when the water content is artificially "capped" to prevent supersaturated soil (see section 5.1 for example). The soil model has no runoff or pooling capability, though runoff is calculated separately for the canopy. 


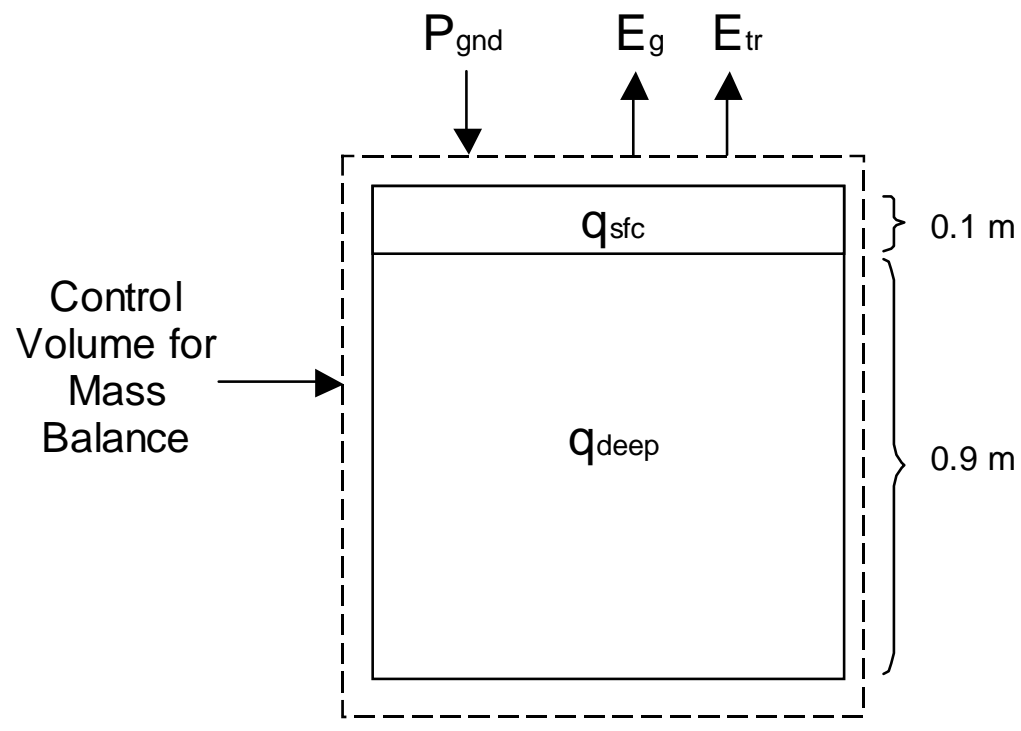

Figure 4: Schematic of two-layer ISBA soil model (without canopy). Control volume over which mass balance is taken is given by the dotted line. Soil moistures (qsfc and qdeep) are in units of $\mathrm{m}^{3} / \mathrm{m}^{3}$. Fluxes (precipitation $\mathrm{P}_{\text {gnd }}$, transpiration $\mathrm{E}_{\mathrm{tr}}$, ground evaporation $\mathrm{E}_{\mathrm{g}}$ ) are in units of $\mathrm{kg} / \mathrm{m}^{2}-\mathrm{s}$
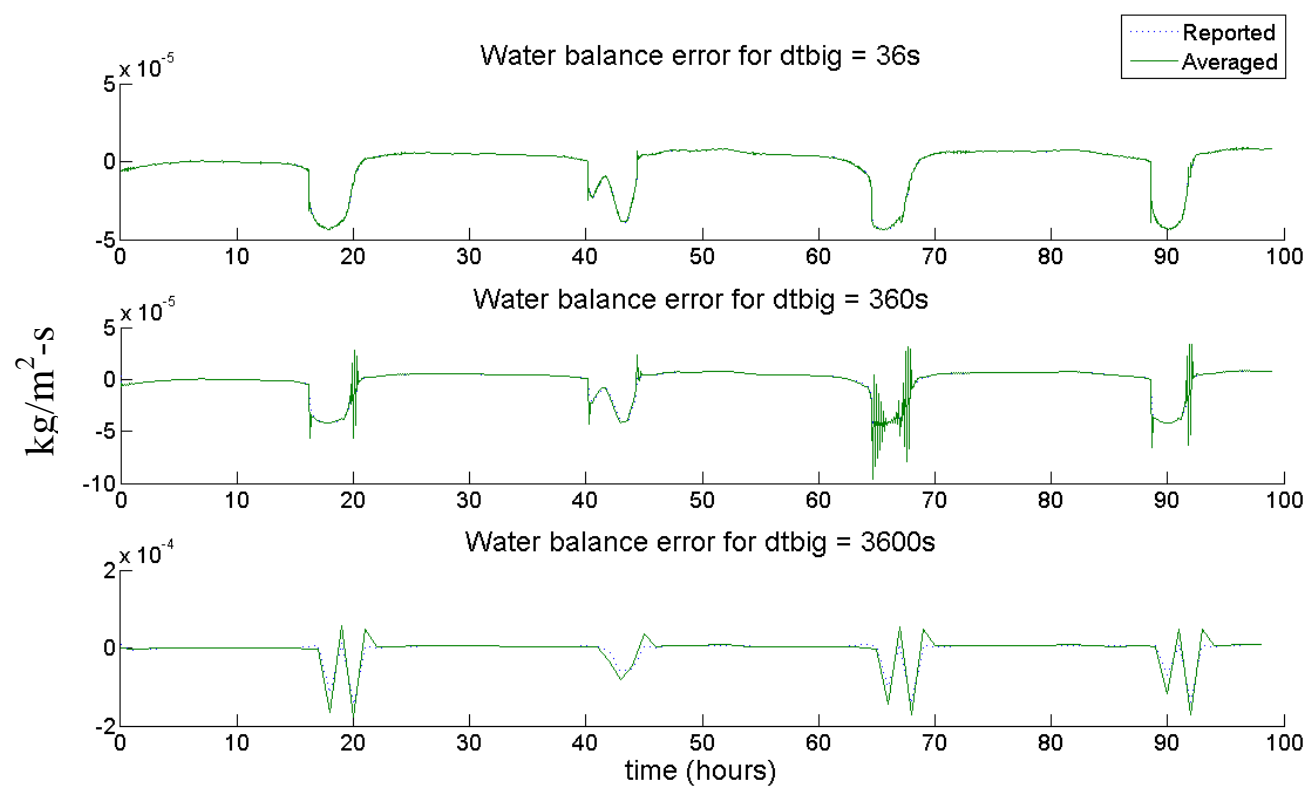

Figure 5: Water balance error (as flux) for three different time steps. Error shown comes from the parameterization used in the ISBA soil model. 


\subsection{Model Formulation and Sources}

The ISBA soil model is based on the proposed models of both Noilhan \& Planton (1989) and Pleim \& Xiu (1995). The two models use the same governing equations (ARPS documentation, section 6.10), but differ in parameterization of (1) land surface heat capacity $C_{T}$, (2) ground thermal coefficient $C_{G}$, and (3) soil moisture perturbation coefficient $C_{1}$. The equations used by the two formulations are shown in Table 1. Noilhan \& Planton use deep-layer soil moisture to calculate $C_{G}$ and $C_{1}$, while Pleim \& Xiu use surface-layer soil moisture. Noilhan \& Planton consider the diminishing effects of vegetated cover on the thermal coefficient $C_{T}$, while Pleim \& Xiu uniformly set $C_{T}$ to the calculated value for bare ground.

Table 1: Comparison of parameterizations between proposed models of Noilhan \& Planton (1989) and Pleim \& Xiu (1995). The implementation used in ARPS 5.2.4 is denoted by an asterisk (*).

\begin{tabular}{|c|c|c|}
\hline Coefficient & Noilhan \& Planton (1989) & Pleim \& Xiu (1995) \\
\hline$C_{G}$ & $C_{G}=C_{G, \text { sat }}\left(\frac{w_{\text {sat }}}{w_{g}}\right)^{b / 2 \log 10}$ & $C_{G}=C_{G, \text { sat }}\left(\frac{w_{\text {sat }}}{w_{2}}\right)^{b / 2 \log 10} *$ \\
\hline$C_{T}$ & $C_{T}=1 /\left(\frac{1-v e g}{C_{G}}+\frac{v e g}{C_{V}}\right) *$ & $C_{T}=C_{G}$ \\
\hline$C_{1}$ & $C_{1}=0.4 C_{1, \text { sat }}\left(\frac{w_{\text {sat }}}{w_{g}}\right)^{b / 2+1} *$ & $C_{1}=0.4 C_{1, \text { sat }}\left(\frac{w_{\text {sat }}}{w_{2}}\right)^{b / 2+1}$ \\
\hline
\end{tabular}

\subsection{Simulation Results}

For each parameter in Table 1, three figures are presented, comparing model output over a full year of simulation with the original ARPS 5.2.4 model, compared to model output with the parameter "switched", or using the alternate formulation. For each of the following model output items, timeseries from each run are overlaid and the differences between the two timeseries shown. :

- wetsfc

- wetdp

- $t s f c$

- tdeep

- cumulative evaporation

Figure 6 shows the results of switching $C_{G}$. Figure 7 shows the results of switching $C_{T}$. Figure 8 shows the results of switching $C_{1}$. Figure 9 shows the results of switching all parameters simultaneously. For all runs, precipitation is sufficient to saturate the soil for long periods, leading to constant water content (at wsat, here $0.465 \mathrm{~m}^{3} / \mathrm{m}^{3}$ ) and no difference resulting from choice of parameterization. 
(a) Surface layer soil moisture (wetsfc)

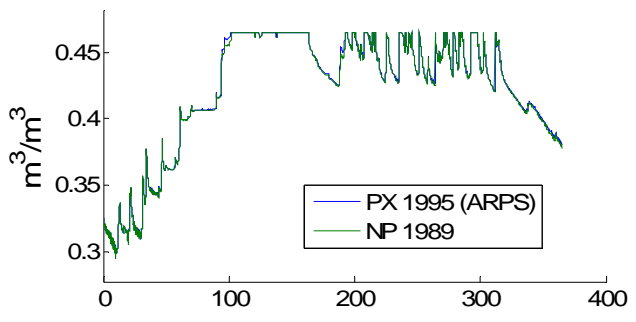

(c) Deep layer soil moisture (wetdp)

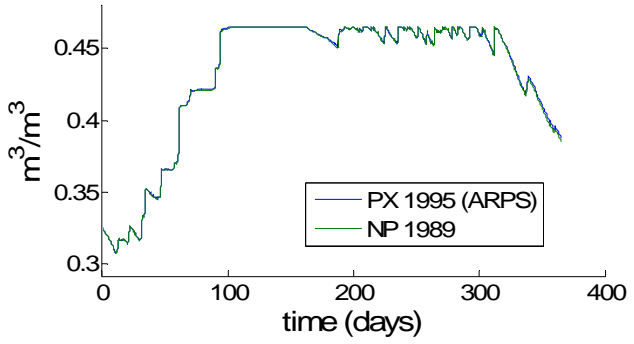

(e) Surface layer soil temperature (tsfc)

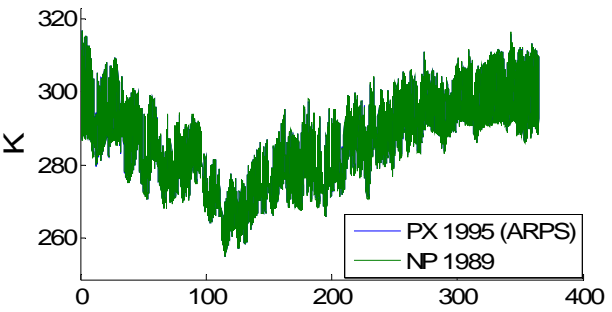

(g) Deep layer soil temperature (tdeep)
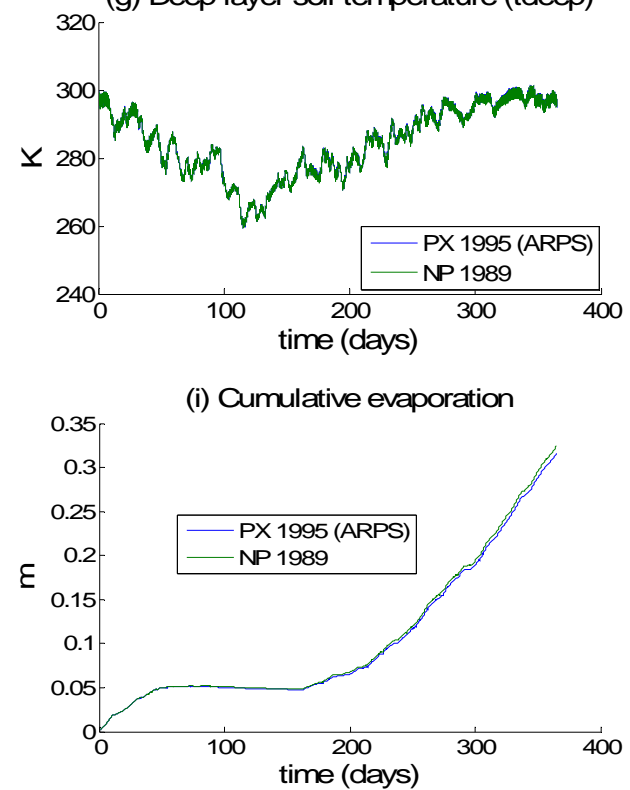
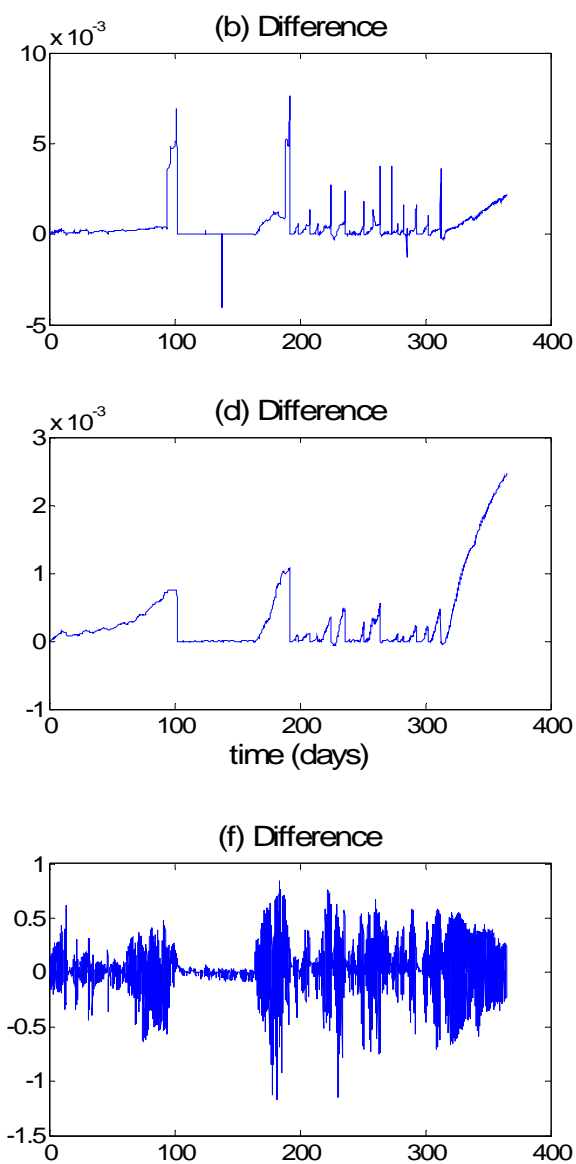

(h) Difference

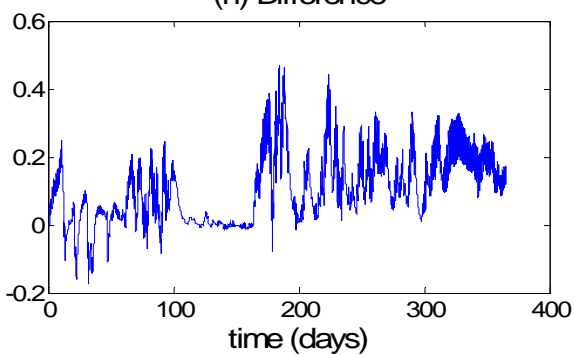

(j) Absolute difference

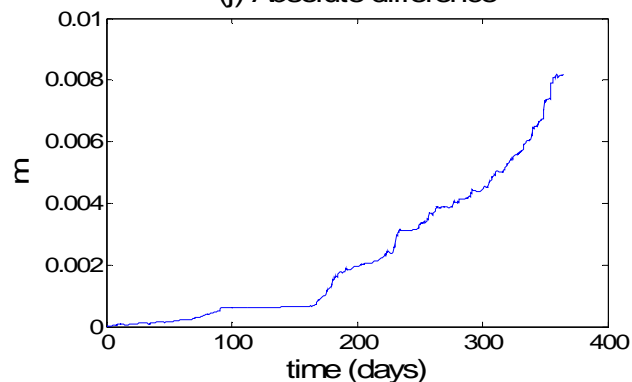

Figure 6: Switching $C_{G}$ : results of using wetsfc (Noilhan \& Planton 1989) or wetdp (Pleim \& Xiu 1995) to calculate ground thermal coefficient in ARPS 5.2.4 subroutine soilebm_frc. Left column is model output. Right column is difference in output between the two runs. ARPS 5.2.4 uses the Pleim \& Xiu formulation (wetdp). 
(a) Surface layer soil moisture (wetsfc)

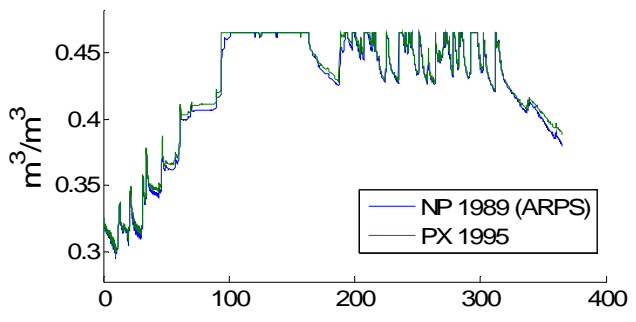

(c) Deep layer soil moisture (wetdp)

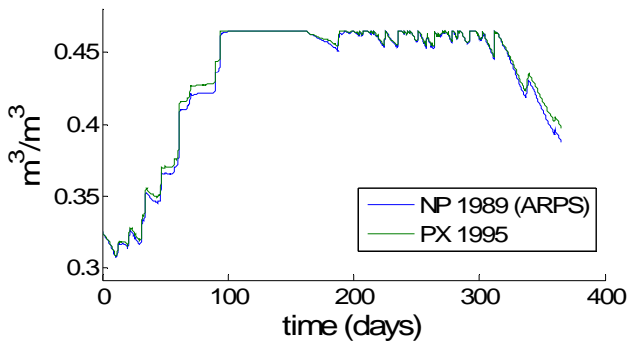

(e) Surface layer soil temperature (tsfc)

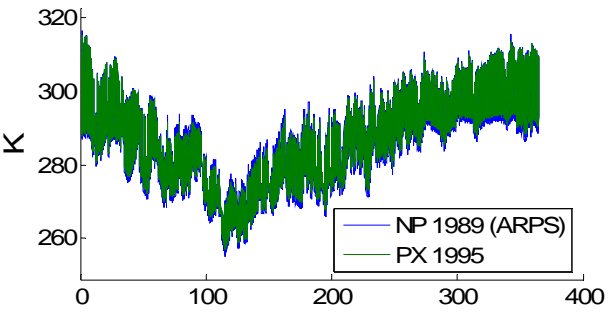

(g) Deep layer soil temperature (tdeep)

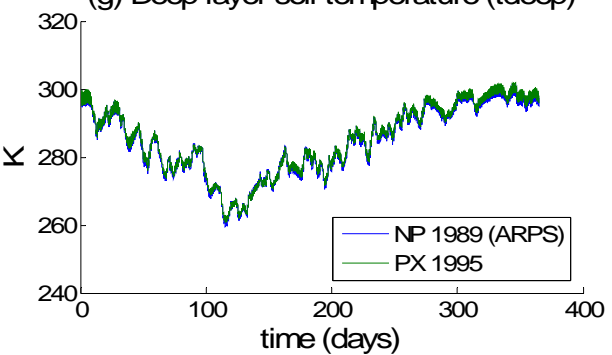

(i) Cumulative evaporation

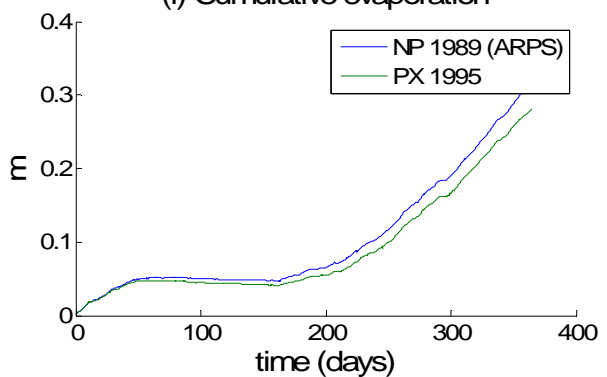

(b) Difference

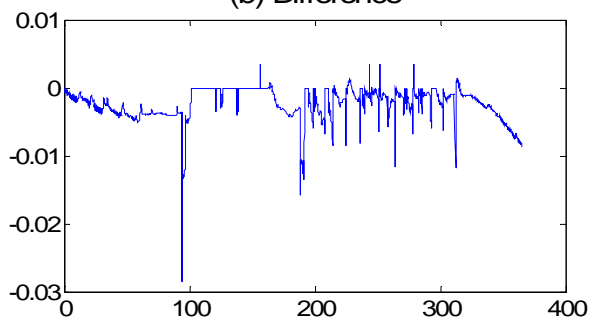

(d) Difference

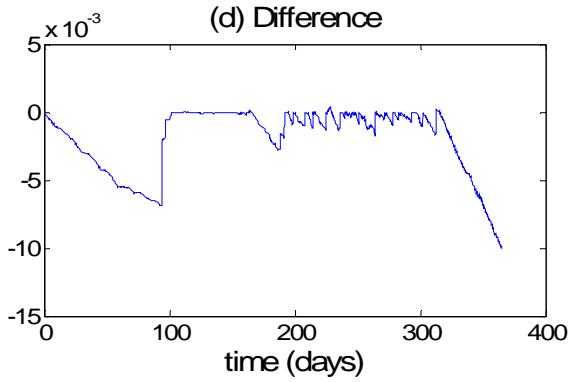

(f) Difference

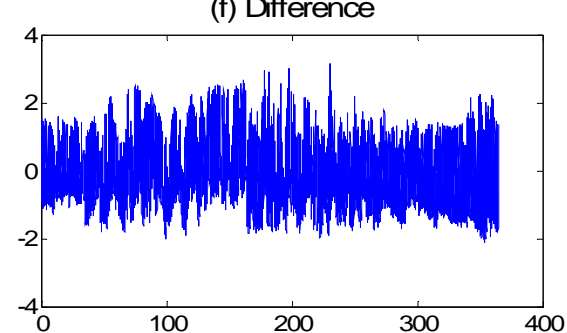

(h) Difference

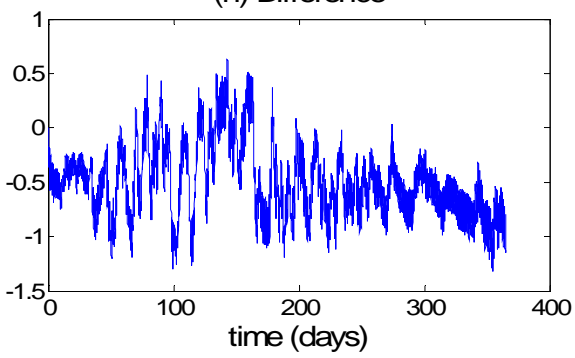

(j) Absolute difference

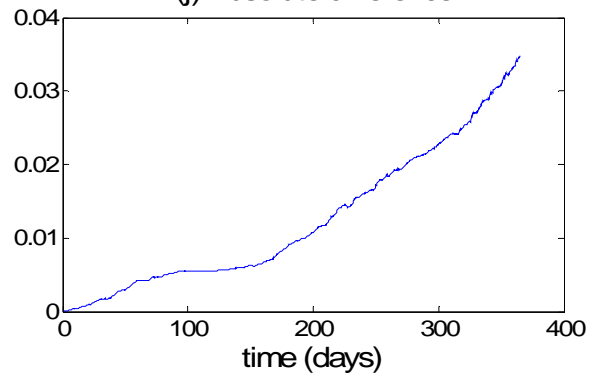

Figure 7: Results of accounting for vegetation fraction (Noilhan \& Planton 1989) or bare ground only (Pleim \& Xiu 1995) to calculate ground heat capacity $C_{T}$ in ARPS 5.2.4 subroutine soilebm_frc. Left column is model output. Right column is difference in output between the two runs. ARPS 5.2.4 uses the Noilhan \& Planton formulation (vegetation accounted for). 
(a) Surface layer soil moisture (wetsfc)

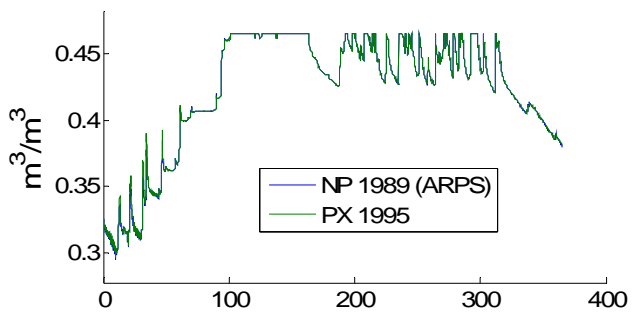

(c) Deep layer soil moisture (wetdp)

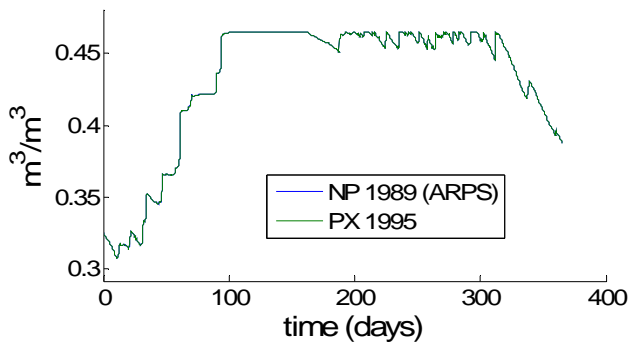

(e) Surface layer soil temperature (tsfc)

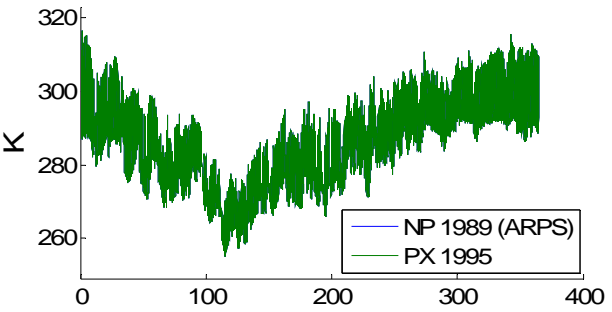

(g) Deep layer soil temperature (tdeep)

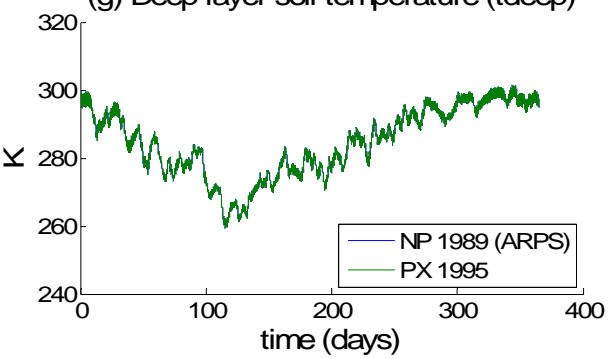

(i) Cumulative evaporation

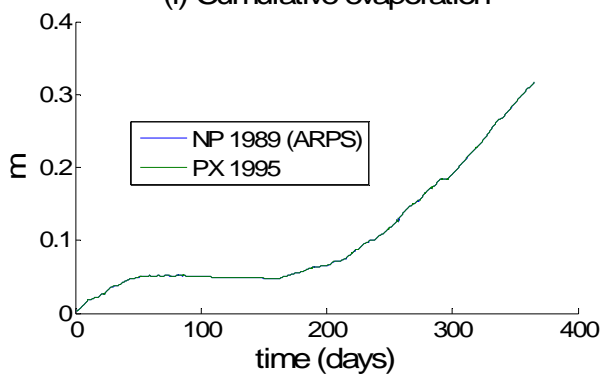

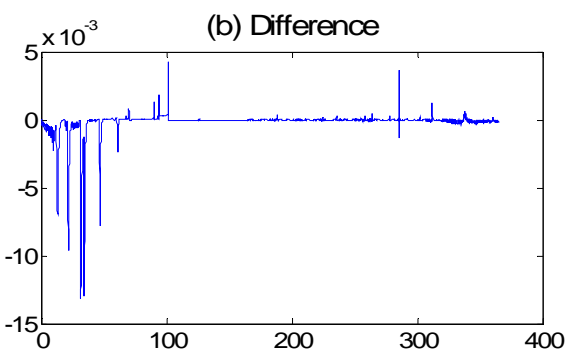

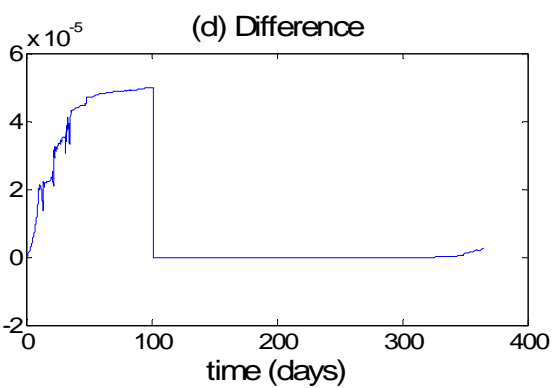

(f) Difference

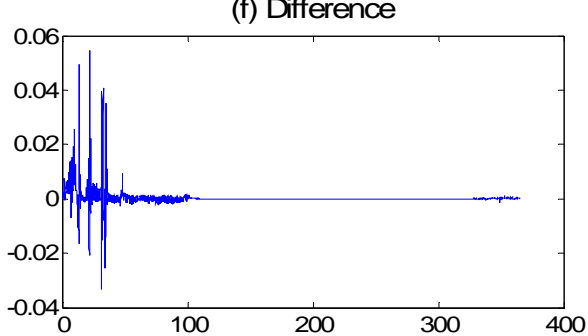

(h) Difference
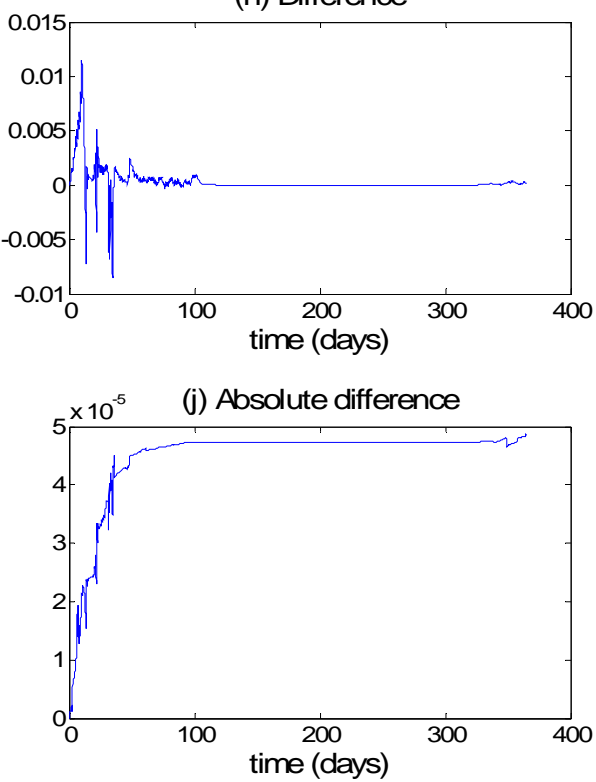

Figure 8: Results of using wetsfc (Noilhan \& Planton 1989) or wetdp (Pleim \& Xiu 1995) to calculate ground thermal coefficient $C_{T}$ in ARPS 5.2.4 subroutine soilebm_frc. Left column is model output. Right column is difference in output between the two runs. ARPS 5.2.4 uses the Noilhan \& Planton formulation (wetsfc). 
(a) Surface layer soil moisture (wetsfc)

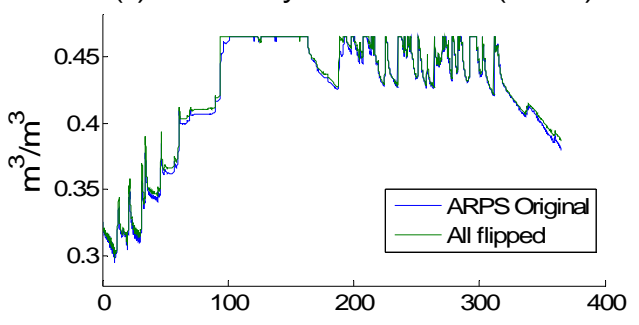

(c) Deep layer soil moisture (wetdp)

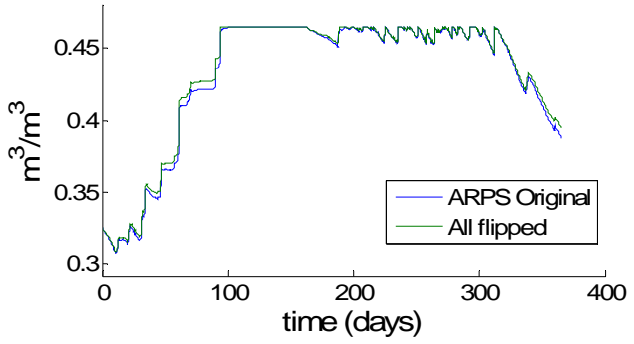

(e) Surface layer soil temperature (tsfc)

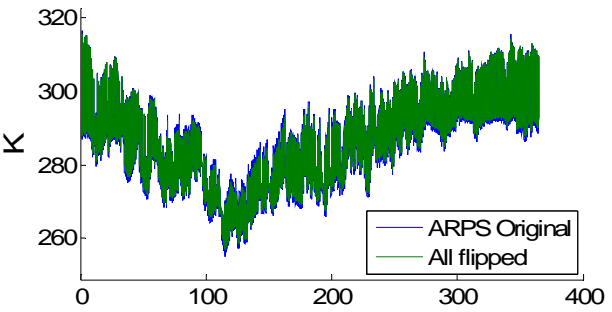

(g) Deep layer soil temperature (tdeep)

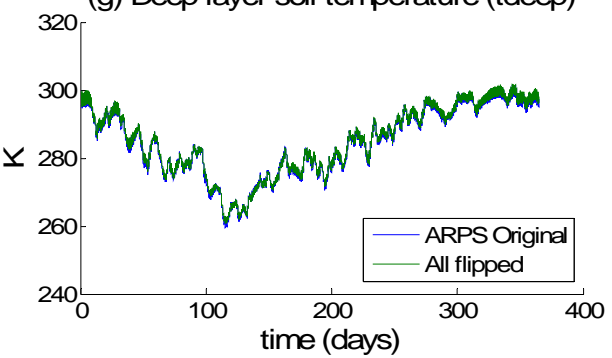

(i) Cumulative evaporation

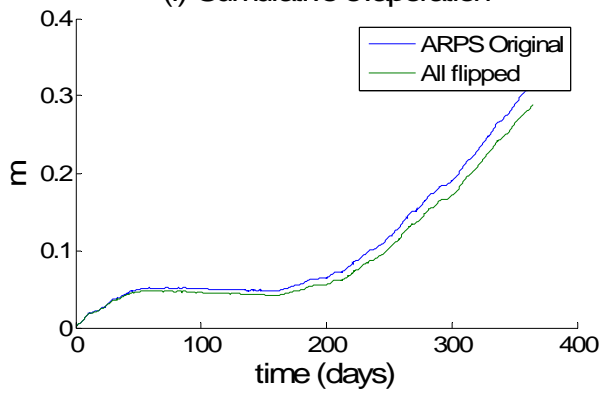

(b) Difference

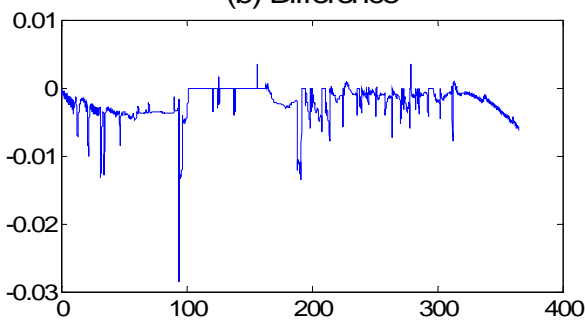

(d) Difference

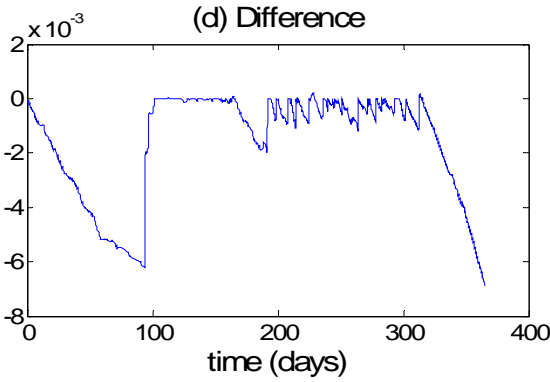

(f) Difference

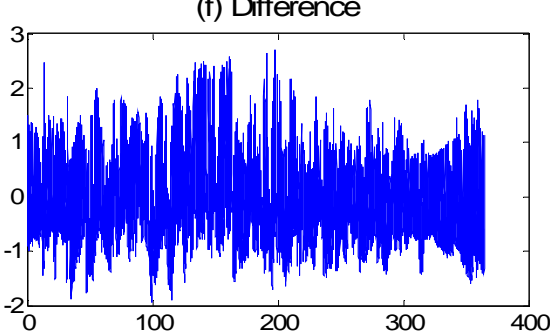

(h) Difference

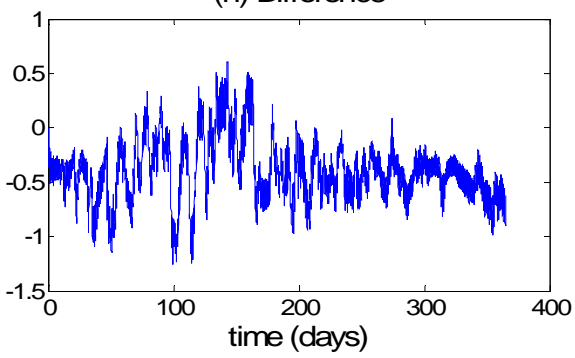

(j) Absolute difference

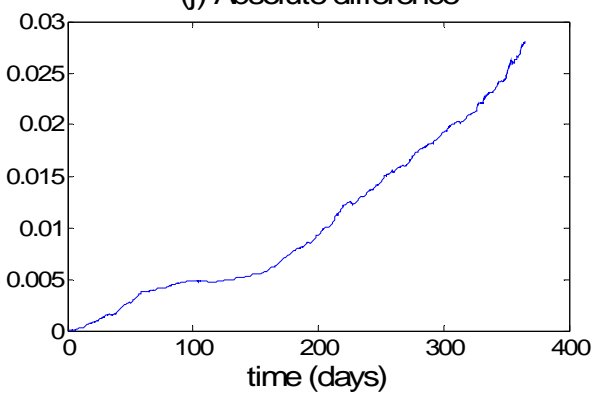

Figure 9: Results of switching all model choices $\left(C_{T}, C_{G}, C_{1}\right)$. ARPS uses Noilhan \& Planton formulation for $C_{T}$ (vegetated cover accounted for) and $C_{1}$ (from wetsfc) and Pleim \& Xiu for $C_{G}$ (from wetdp). 


\subsection{Discussion}

Table 2 shows the mean difference in model soil moisture and temperature for each set of results above. The mean temperature difference is taken over the entire year. The mean soil moisture difference is taken only when both runs are below saturation, since the identical saturation results are not attributable to convergence of the two runs.

Switching $C_{G}$ from the Pleim \& Xiu formulation (ARPS 5.2.4 implementation) to that of Noilhan \& Planton increases sensitivity of soil moisture and temperature, with the temperature using Noilhan \& Planton varying by up to $1 \mathrm{~K}$ further than when using Pleim \& Xiu. On average, both are raised slightly.

The most noticeable differences result from switching $C_{T}$ from Noilhan \& Planton to Pleim \& Xiu. Soil moisture drops on average by over $0.002 \mathrm{~m}^{3} / \mathrm{m}^{3}$, while soil temperatures in both levels drop on average by around $0.5 \mathrm{~K}$. The response of temperature over diurnal scales shows marked increases in daily maximums, of up to approximately $3 \mathrm{~K}$, and decreases at night

Switching $C_{1}$ has very little effect on model output. Switching all three flags give results similar to switching $C_{G}$, though reduced in magnitude by the effects of the other two flags.
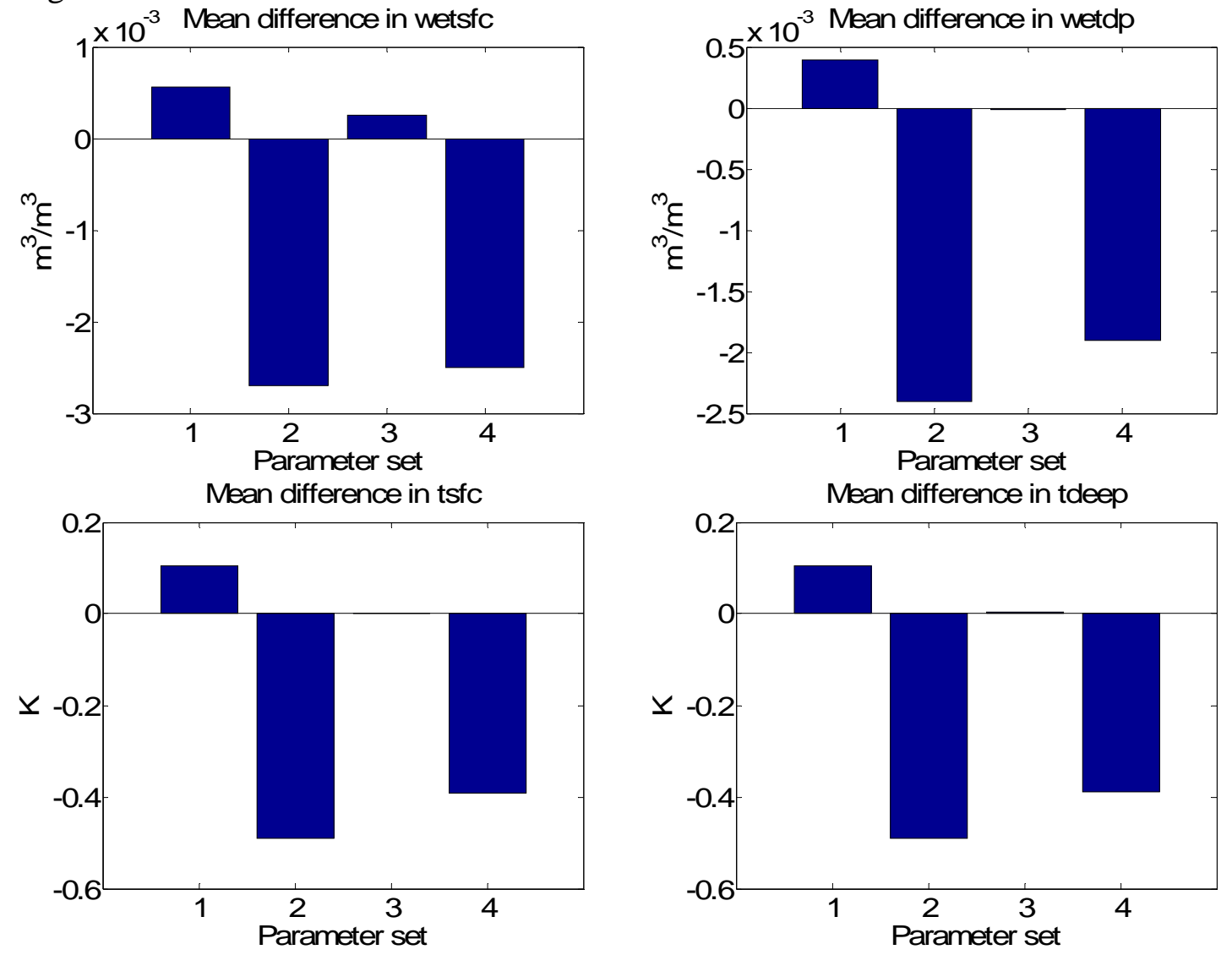

Figure 10: Comparison of mean differences between runs. Each bar gives the mean differences between the original ARPS 5.2.4 results and results where one or more parameters is switched. On the x-axis: (1) $C_{G}$ formulation is switched from Pleim \& Xiu to Noilhan \& Planton, (2) $C_{T}$ switched from Noilhan \& Planton to Pleim \& Xiu, (3) $C_{1}$ switched from Noilhan \& Planton to Pleim \& Xiu, and (4) all parameterizations are switched. 
Table 2: Data for comparison of runs. For the differences plotted in Figures 6-9, the mean difference, standard deviation from the mean difference, maximum and minimum differences, and the number of data points used (soil moisture values exclude periods where both models report saturation).

\begin{tabular}{c|ccccc} 
Effects of CG & $\begin{array}{c}\text { std. dev. } \\
\text { of } \\
\begin{array}{c}\text { Output } \\
\text { Variable }\end{array}\end{array}$ & $\begin{array}{c}\text { mean } \\
\text { difference }\end{array}$ & $\begin{array}{c}\text { maximum } \\
\text { difference }\end{array}$ & $\begin{array}{c}\text { minimum } \\
\text { difference }\end{array}$ & $\begin{array}{c}\text { data } \\
\text { difference } \\
\text { usints }\end{array}$ \\
\hline wetsfc & $5.67 \mathrm{E}-04$ & $9.70 \mathrm{E}-04$ & $7.00 \mathrm{E}-03$ & $-4.10 \mathrm{E}-03$ & 6708 \\
\hline wetdp & $3.98 \mathrm{E}-04$ & $5.76 \mathrm{E}-04$ & $2.50 \mathrm{E}-02$ & $-6.40 \mathrm{E}-05$ & 6708 \\
\hline tsfc & 0.1045 & 0.2171 & 0.8484 & -1.1725 & 8760 \\
\hline tdeep & 0.1041 & 0.0992 & 0.4720 & -0.1753 & 8760 \\
\hline
\end{tabular}

\section{Effects of CT}

\begin{tabular}{c|ccccc}
\hline $\begin{array}{c}\text { Output } \\
\text { Variable }\end{array}$ & $\begin{array}{c}\text { mean } \\
\text { difference }\end{array}$ & $\begin{array}{c}\text { std. dev. } \\
\text { of } \\
\text { difference }\end{array}$ & $\begin{array}{c}\text { maximum } \\
\text { difference }\end{array}$ & $\begin{array}{c}\text { minimum } \\
\text { difference }\end{array}$ & $\begin{array}{c}\text { data } \\
\text { points } \\
\text { used }\end{array}$ \\
\hline wetsfc & $-2.70 \mathrm{E}-03$ & $1.90 \mathrm{E}-03$ & $1.50 \mathrm{E}-03$ & $-2.52 \mathrm{E}-02$ & 6387 \\
\hline wetdp & $-2.40 \mathrm{E}-03$ & $2.50 \mathrm{E}-04$ & $3.51 \mathrm{E}-04$ & $-1.01 \mathrm{E}-02$ & 6387 \\
\hline tsfc & -0.4905 & 0.9182 & 3.1699 & -2.1356 & 8760 \\
\hline tdeep & -0.4891 & 0.3401 & 0.6281 & -1.3175 & 8760 \\
\hline
\end{tabular}

Effects of C1

\begin{tabular}{c|ccccc}
\hline $\begin{array}{c}\text { Output } \\
\text { Variable }\end{array}$ & $\begin{array}{c}\text { mean } \\
\text { difference }\end{array}$ & $\begin{array}{c}\text { std. dev. } \\
\text { of } \\
\text { difference }\end{array}$ & $\begin{array}{c}\text { maximum } \\
\text { difference }\end{array}$ & $\begin{array}{c}\text { minimum } \\
\text { difference }\end{array}$ & $\begin{array}{c}\text { data } \\
\text { points } \\
\text { used }\end{array}$ \\
\hline wetsfc & $-2.35 \mathrm{E}-04$ & $1.20 \mathrm{E}-03$ & $1.90 \mathrm{E}-03$ & $-1.32 \mathrm{E}-02$ & 6710 \\
\hline wetdp & $1.28 \mathrm{E}-05$ & $1.99 \mathrm{E}-05$ & $4.99 \mathrm{E}-05$ & $-2.98 \mathrm{E}-08$ & 6710 \\
\hline tsfc & 0.0000 & 0.0028 & 0.0546 & -0.3310 & 8760 \\
\hline tdeep & 0.0003 & 0.0012 & 0.0115 & -0.0085 & 8760 \\
\hline
\end{tabular}

Effects of flipping all variables

\begin{tabular}{c|ccccc}
\hline $\begin{array}{c}\text { Output } \\
\text { Variable }\end{array}$ & $\begin{array}{c}\text { mean } \\
\text { difference }\end{array}$ & $\begin{array}{c}\text { std. dev. } \\
\text { of } \\
\text { difference }\end{array}$ & $\begin{array}{c}\text { maximum } \\
\text { difference }\end{array}$ & $\begin{array}{c}\text { minimum } \\
\text { difference }\end{array}$ & $\begin{array}{c}\text { data } \\
\text { points } \\
\text { used }\end{array}$ \\
\hline wetsfc & $-2.50 \mathrm{E}-03$ & $1.80 \mathrm{E}-03$ & $1.70 \mathrm{E}-03$ & $-2.02 \mathrm{E}-02$ & 6390 \\
\hline wetdp & $-1.90 \mathrm{E}-03$ & $2.00 \mathrm{E}-03$ & $2.11 \mathrm{E}-04$ & $-6.90 \mathrm{E}-03$ & 6390 \\
\hline tsfc & -0.3909 & 0.7707 & 2.7059 & -1.9412 & 8760 \\
\hline tdeep & -0.3899 & 0.2859 & 0.6114 & -1.2623 & 8760 \\
\hline
\end{tabular}




\subsection{Two Dimensional Domain}

One year of simulation at $d$ tbig $=360$ s over a $45 \times 321 \mathrm{~km} \mathrm{x} 1 \mathrm{~km}$ grid of the Little Washita watershed in Oklahoma was performed using a flat domain (no terrain) and with an elevated domain (terrain). Both runs used the same set of surface characteristics: vegetation type, vegetated fraction, soil type, leaf area index (LAI), and surface roughness. Terrain characteristics consist only of elevation height, used to calculate surface angle at each grid cell.

Results for each 2D run are shown below. The effects of terrain on midnight and noon temperatures is shown in Figure 11-Figure 14. The effects of terrain on soil moistures is shown in Figure 15-Figure 18. 

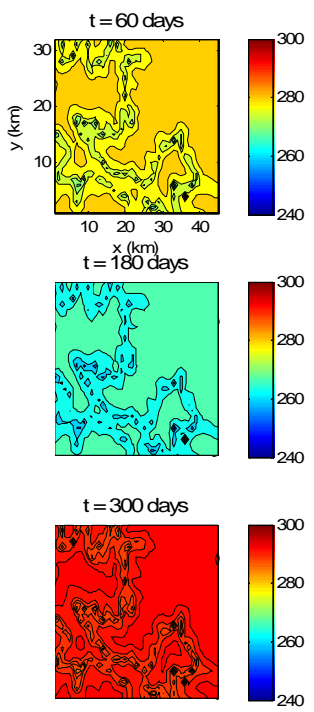
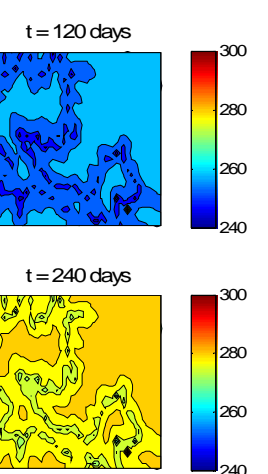

$t=360$ days

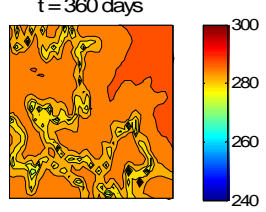

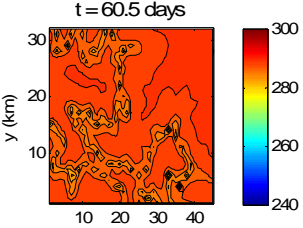

$\mathrm{t}=18{ }^{x}(\mathrm{~km})$ days

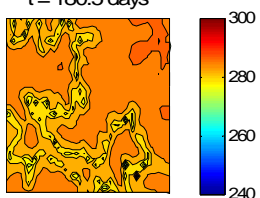

$t=300.5$ days

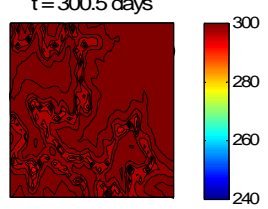

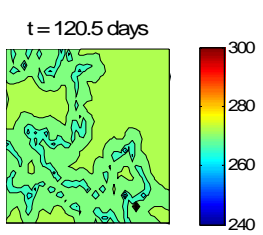

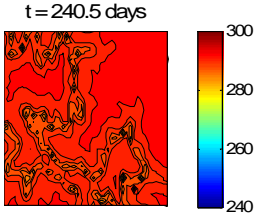

$t=360.5$ days

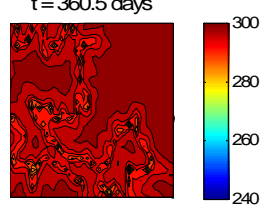

Figure 11: Contours of surface temperature (in K) each 60 days for ARPS 5.2.4 2D simulation with terrain effects. Temperatures reach nadir during winter (120 days), then peak in summer (300 days). The northeast region, which is flat and infrequently shaded by terrain, remains warmer than the rest of the domain. Left panel: midnight. Right panel: noon.

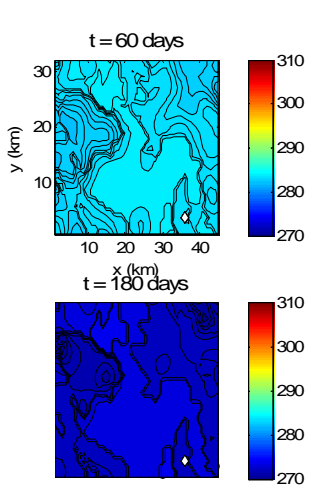

$\mathrm{t}=300$ days

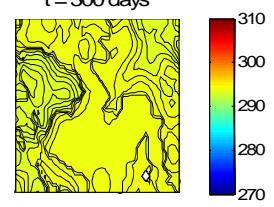

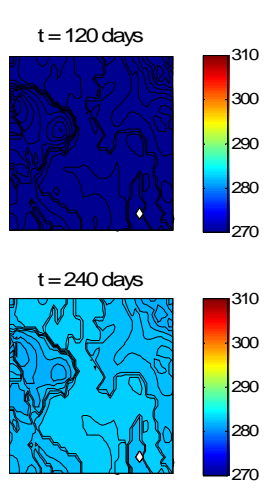

$\mathrm{t}=360$ days

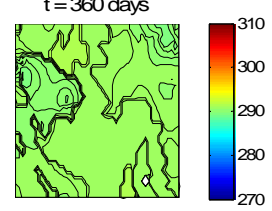

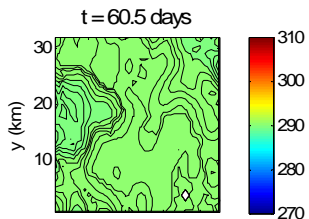

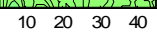

$\mathrm{t}=18 \mathrm{\gamma}^{\mathrm{k}} \mathrm{km}$ ) days

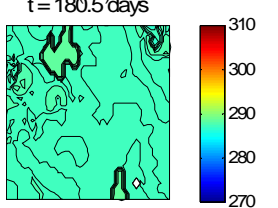

$t=300.5$ days

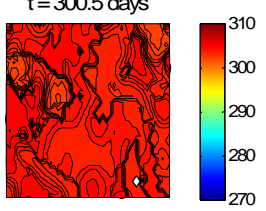

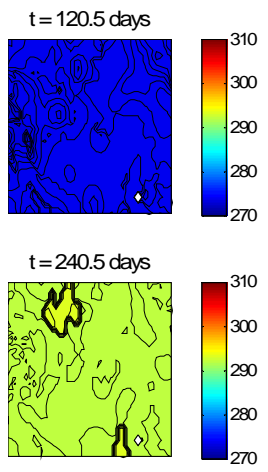

$t=360.5$ days

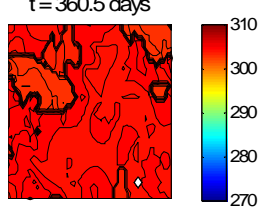

Figure 12: Contours of surface temperature (in K) each 60 days for ARPS 5.2.4 2D simulation without terrain effects. Temperatures are relatively uniform across the domain, compared to Figure 11; variations are driven by surface characteristics. Left panel: midnight. Right panel: noon. 

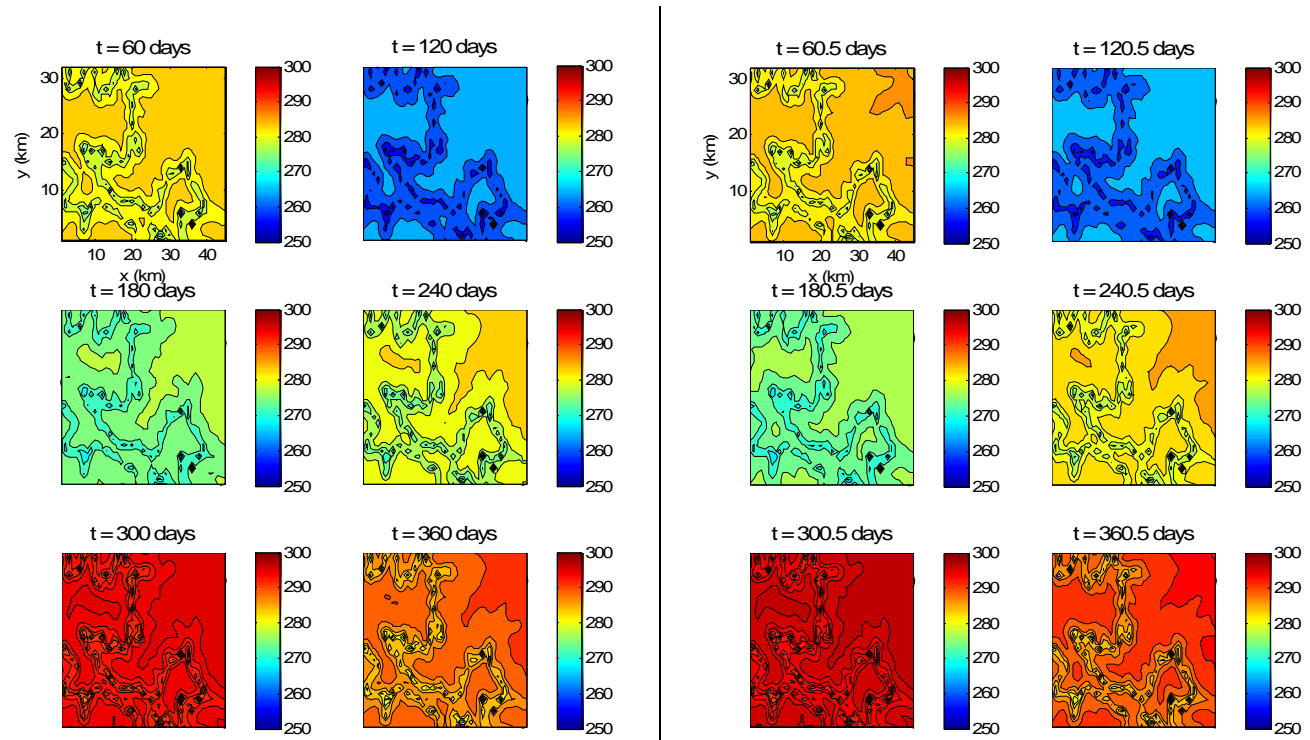

Figure 13: Contours of deep-layer temperature (in K) each 60 days for ARPS 5.2.4 2D simulation with terrain effects. Variation in magnitude is less than with surface temperatures (Figure 11), and values do not change significantly over short time periods. As with surface temperatures, the northeast region remains consistently warmer than the rest of the domain. Left panel: midnight. Right panel: noon.

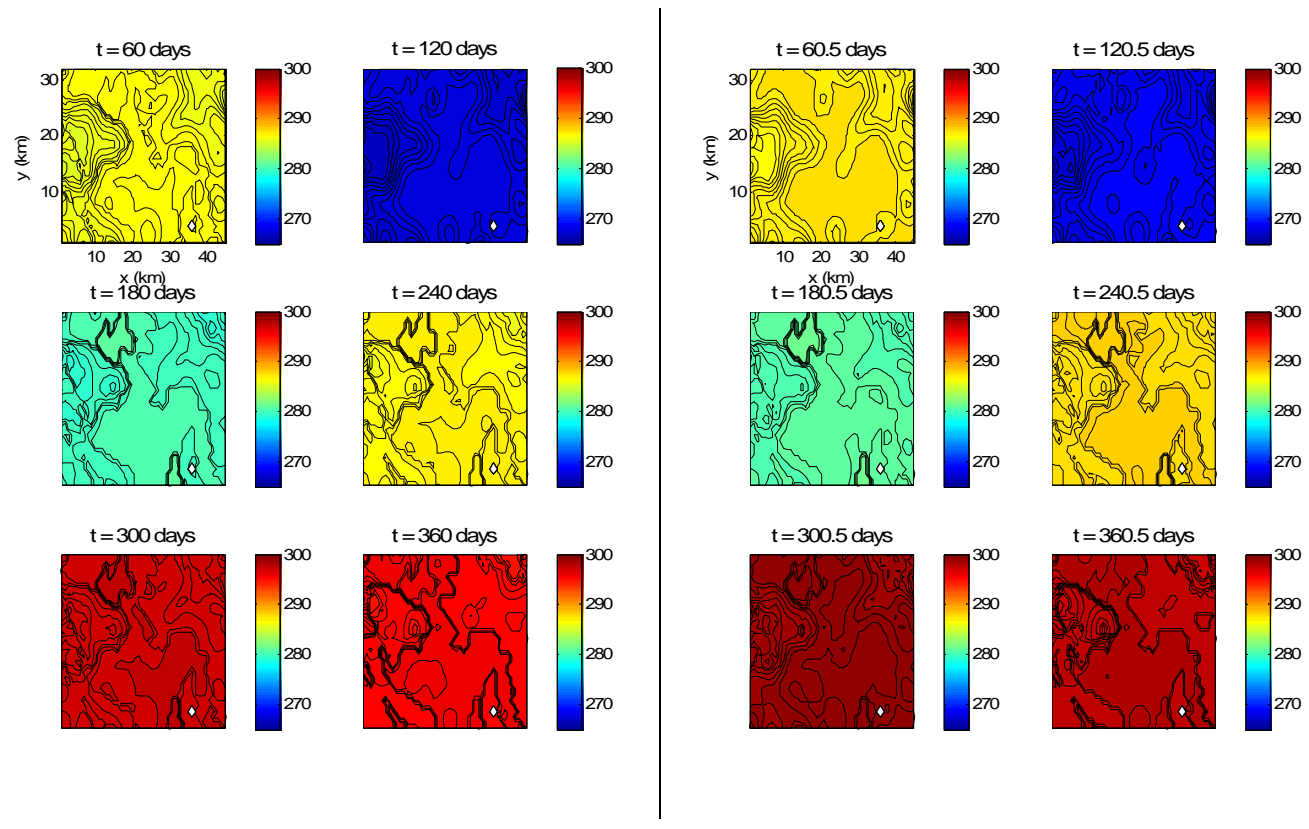

Figure 14: Contours of deep-layer temperature (in K) each 60 days for ARPS 5.2.4 2D simulation without terrain effects. Temperatures remain relatively uniform across the domain, varying slightly with surface properties. Again, temperatures are slightly higher at noon, but large changes in deep soil temperature occur over longer time periods. Left panel: midnight. Right panel: noon. 

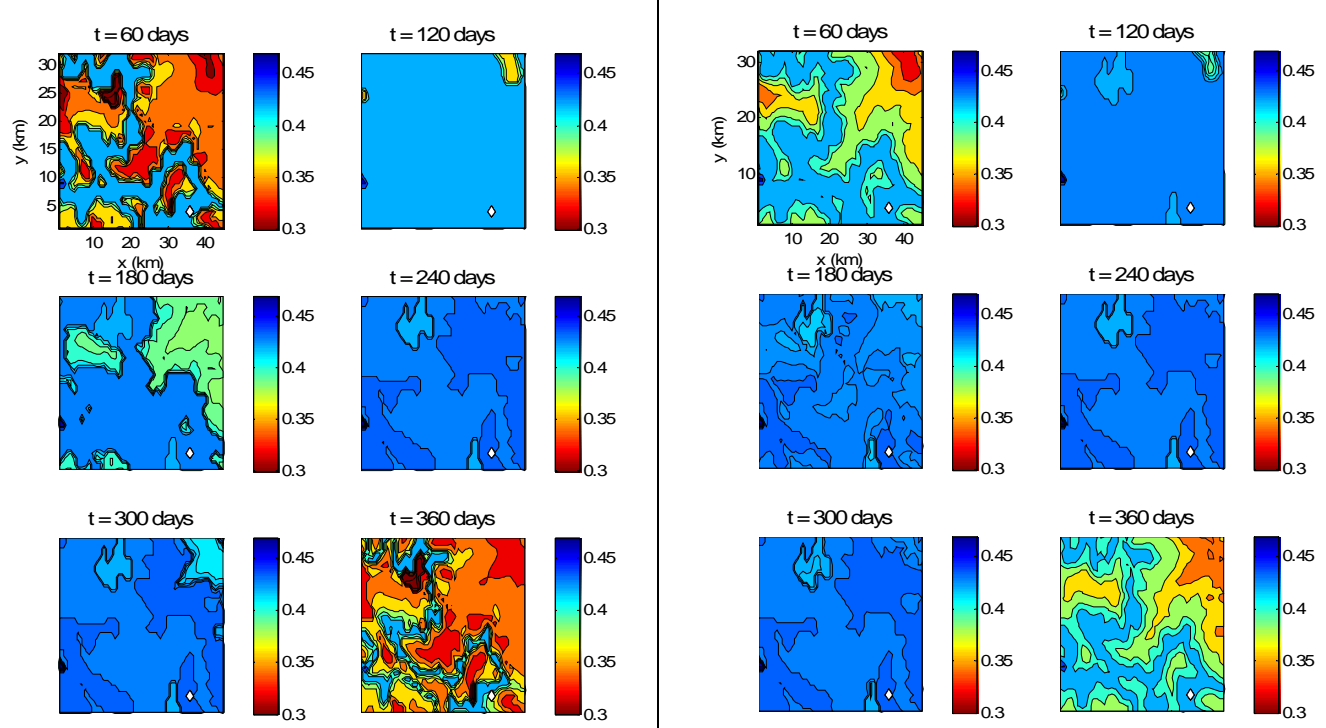

Figure 15: Surface (left) and deep (right) soil moistures each 60 days from ARPS 5.2.4 with terrain effects. In general, the northeast corner remains drier than the rest of the domain, due to higher rates of evaporation. Through the middle of the year, precipitation drives the system to saturation or nearsaturation values. Time of day?
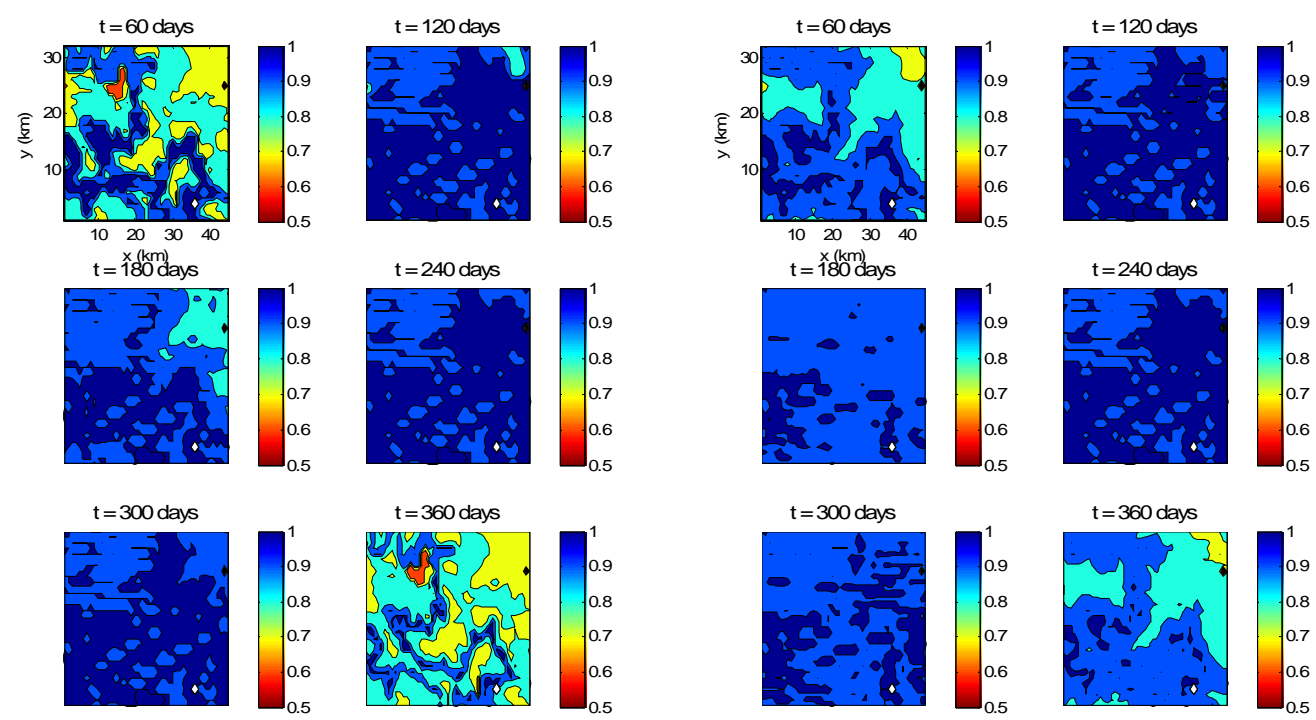

Figure 16: Fraction of saturation value for surface (left) and deep (right) soil moistures each 60 days from ARPS 5.2.4 with terrain effects. A value of 1 indicates fully saturated. During the middle of the year, the entire domain remains at or near saturation. 

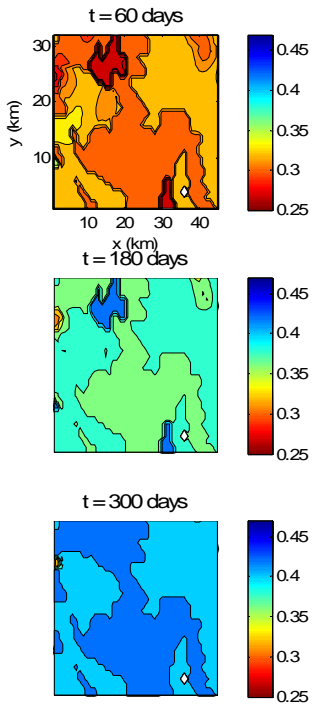

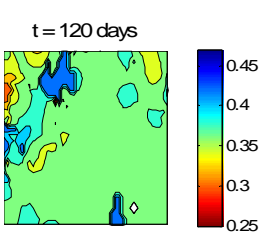

$t=240$ days

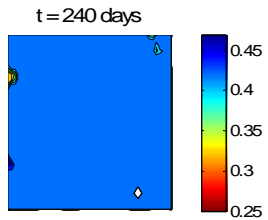

$\mathrm{t}=360$ days

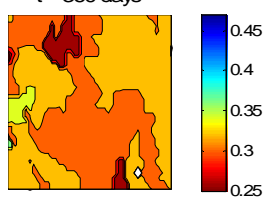

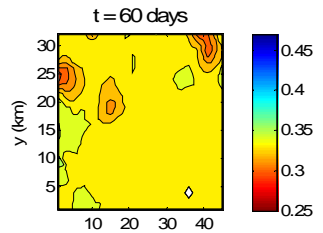

$\mathrm{t}=180$ days
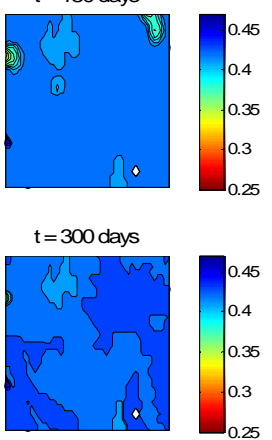

$\mathrm{t}=120$ days

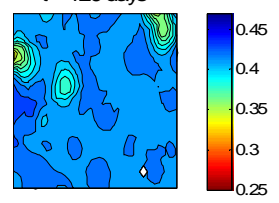

$t=240$ days
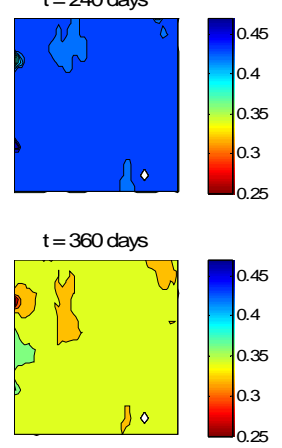

Figure 17: Surface (left) and deep (right) soil moistures each 60 days from ARPS 5.2.4 without terrain effects. Radiation input is equal across the domain, and evaporative effects are more strongly dependent on soil type. As with the run with terrain effects, precipitation continues to drives the system to saturation or near-saturation values during the middle of the year. Deep layer soil moisture is more uniform than surface soil moisture.
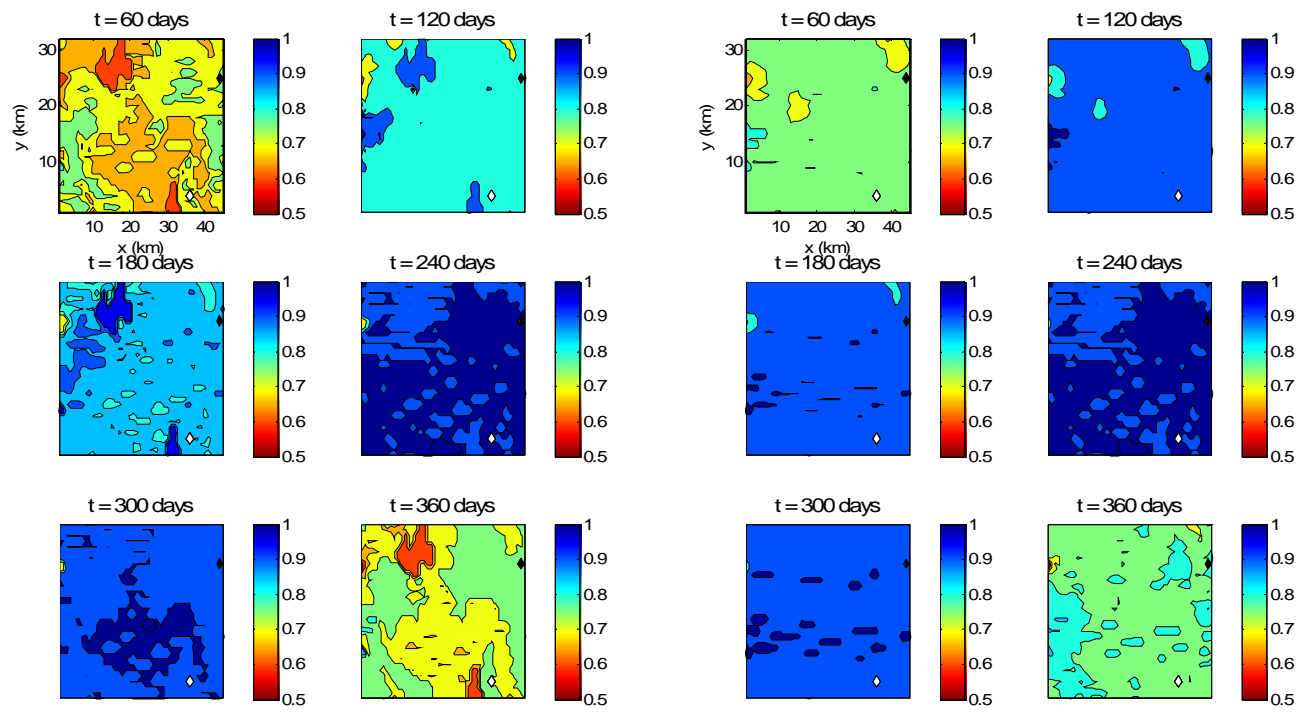

Figure 18: Fraction of saturation value for surface (left) and deep (right) soil moistures each 60 days from ARPS 5.2.4 without terrain effects. A value of 1 indicates fully saturated. During the middle of the year, the entire domain remains at or near saturation. 